Refinamento multinível em redes complexas baseado em similaridade de vizinhança

Alan Demetrius Baria Valejo 

SERVIÇO DE PÓS-GRADUAÇÃO DO ICMC-USP

Data de Depósito:

Assinatura:

\title{
Refinamento multinível em redes complexas baseado em similaridade de vizinhança
}

\author{
Alan Demetrius Baria Valejo \\ Orientador: Prof. Dr. Alneu de Andrade Lopes \\ Dissertação apresentada ao Instituto de Ciências \\ Matemáticas e de Computação - ICMC-USP, como \\ parte dos requisitos para obtenção do título de Mestre \\ em Ciências - Ciências de Computação e Matemática \\ Computacional. VERSÃO REVISADA
}


Ficha catalográfica elaborada pela Biblioteca Prof. Achille Bassi e Seção Técnica de Informática, ICMC/USP, com os dados fornecidos pelo(a) autor(a)

Valejo, Alan

V149r Refinamento multinível em redes complexas baseado em similaridade de vizinhança / Alan Valejo:

orientador Alneu Andrade Lopes. - - São Carlos, 2014. $75 \mathrm{p}$.

Dissertação (Mestrado - Programa de Pós-Graduação em Ciências de Computação e Matemática

Computacional) - - Instituto de Ciências Matemáticas e de Computação, Universidade de São Paulo, 2014.

1. Detecção de comunidades. 2. Particionamento Multinível. 3. Refinamento Multinível. 4. Redes Complexas. 5. Redes Sociais. I. Andrade Lopes, Alneu, orient. II. Título. 
"Foi o tempo que dedicastes à tua rosa que a fez tão importante". Antoine de Saint-Exupéry 



\section{Agradecimentos}

Dedico este trabalho primeiramente a Deus, pois, sem Ele, nada seria possível. Em especial, dedico este trabalho ao meu porto seguro, Fabiana Lopes Pedrosa, pelo incondicional apoio, bem como suas sábias palavras, encorajando-me a buscar mais um sonho. Além disso, agradeço por sua compreensão, paciência e incentivo em todos os momentos de minha ausência durante este trabalho. Também, seu carinho e dedicação foram de extrema importância nos últimos oito anos de minha vida.

Agradeço a minha família, pelo apoio, incentivo e compreensão em todos os momentos de minha vida. Principalmente, agradeço aos meus pais, Elzio e Aparecida, minha força e inspiração, pelo amor e carinho, bem como pela confiança em mim depositada.

Agradeço a todos os membros do corpo docente, em especial ao meu orientador Professor Dr. Alneu de Andrade Lopes, que além de se tornar um grande amigo, sempre teve paciência e atenção nos momentos em que necessitei de sua ajuda, principalmente nesta etapa final. Ainda, agradeço a confiança depositada em mim para a realização desta pesquisa.

A todos que, direta ou indiretamente, contribuíram para a realização deste trabalho. Em particular, aos colegas Jorge Carlos Valverde Rebaza, Luiz Borro e Geraldo Pereira Rocha Filho, que durante a minha estadia em São Carlos se tornaram grandes amigos, além de disponibilizarem os seus preciosos tempos em discussões agradáveis. Agradeço à CAPES pelo apoio financeiro. 



\section{Resumo}

Valejo, A. (2014). Refinamento multinível em redes complexas baseado em similaridade de vizinhança. 75 f. Dissertação (Mestrado), Instituto de Ciências Matemáticas e de Computação, Universidade de São Paulo, São Carlos.

No contexto de Redes Complexas, particularmente das redes sociais, grupos de objetos densamente conectados entre si, esparsamente conectados a outros grupos, são denominados de comunidades. Detecção dessas comunidades tornou-se um campo de crescente interesse científico e possui inúmeras aplicações práticas. Nesse contexto, surgiram várias pesquisas sobre estratégias multinível para particionar redes com elevada quantidade de vértices e arestas. O objetivo dessas estratégias é diminuir o custo do algoritmo de particionamento aplicando-o sobre uma versão reduzida da rede original. Uma possibilidade dessa estratégia, ainda pouco explorada, é utilizar heurísticas de refinamento local para melhorar a solução final. A maioria das abordagens de refinamento exploram propriedades gerais de redes complexas, tais como corte mínimo ou modularidade, porém, não exploram propriedades inerentes de domínios específicos. Por exemplo, redes sociais são caracterizadas por elevado coeficiente de agrupamento e assortatividade significativa, consequentemente, maximizar tais características pode conduzir a uma boa solução e uma estrutura de comunidades bem definida. Motivado por essa lacuna, neste trabalho é proposto um novo algoritmo de refinamento, denominado RSim, que explora características de alto grau de transitividade e assortatividade presente em algumas redes reais, em particular em redes sociais. Para isso, adotou-se medidas de similaridade híbridas entre pares de vértices, que utilizam os conceitos de vizinhança e informações de comunidades para interpretar a semelhança entre pares de vértices. Uma análise comparativa e sistemática demonstrou que o RSim supera os algoritmos de refinamento habituais em redes com alto coeficiente de agrupamento e assortatividade. Além disso, avaliou-se o RSim em uma aplicação real. Nesse cenário, o RSim supera todos os métodos avaliado quanto a eficiência e eficácia, considerando todos os conjuntos de dados selecionados.

Keywords: Detecção de comunidades, Particionamento Multinível, Refinamento Multinível, Redes Complexas, Redes Sociais. 



\section{Abstract}

Valejo, A. (2014). Multilevel refinement in complex networks based on neighborhood similarity. 75 f. Master's thesis, Institute of Mathematics and Computer Sciences, University of São Paulo, São Carlos.

In the context of complex networks, particularly social networks, groups of densely interconnected objects, sparsely linked to other groups are called communities. Detection of these communities has become a field of increasing scientific interest and has numerous practical applications. In this context, several studies have emerged on multilevel strategies for partitioning networks with high amount of vertices and edges. The goal of these strategies is to reduce the cost of partitioning algorithm by applying it on a reduced version of the original network. The possibility for this strategy, yet little explored, is to apply local refinement heuristics to improve the final solution. Most refinement approaches explore general properties of complex networks, such as minimum cut or modularity, however, do not exploit inherent properties of specific domains. For example, social networks are characterized by high clustering coefficient and significant assortativity, hence maximize such characteristics may lead to a good solution and a well-defined community structure. Motivated by this gap, in this thesis, we propose a new refinement algorithm, called RSim, which exploits characteristics of high degree of transitivity and assortativity present in some real networks, particularly social networks. For this, we adopted hybrid similarity measures between pairs of vertices, using the concepts of neighborhood and community information to interpret the similarity between pairs of vertices. A systematic and comparative analysis showed that the RSim statistically outperforms usual refinement algorithms in networks with high clustering coefficient and assortativity. In addition, we assessed the RSim in a real application. In this scenario, the RSim surpasses all evaluated methods in efficiency and effectiveness, considering all the selected data sets.

Palavras chaves: Graph Clustering, Multilevel Partitioning, Refinement, Complex Networks, Social Networks. 



\section{Sumário}

Agradecimentos $\quad$ i

Resumo iii

Abstract $\quad$ v

Lista de Figuras $\quad$ xi

Lista de Tabelas $\quad$ xiii

Lista de Acrônimos $\quad$ xv

Lista de Símbolos $\quad$ xvii

1 Introdução $\quad 1$

1.1 Problema e Motivação . . . . . . . . . . . . . . . . . . . . . . . . . 4

1.2 Hipótese . . . . . . . . . . . . . . . . . . . . . 5 5

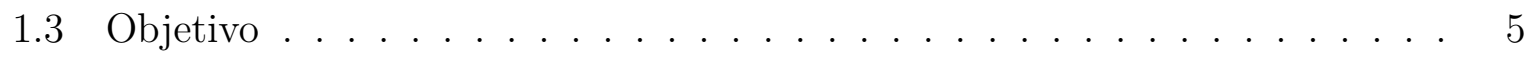

1.4 Metodologia . . . . . . . . . . . . . . . . . . 6

1.5 Contribuição do trabalho . . . . . . . . . . . . . . . . . . . . 7

1.6 Estrutura da dissertação . . . . . . . . . . . . . . . . . . . . . . 8

2 Redes Complexas 9

2.1 Definições Básicas . . . . . . . . . . . . . . . . . . . . . . . . 10

2.2 Propriedades e Medidas de Centralidade . . . . . . . . . . . . . . . . . 12

2.2.1 Caminhos mínimos . . . . . . . . . . . . . . . . . . . . . . . 12

2.2.2 Grau de intermediação . . . . . . . . . . . . . . . . . . . . . 12

2.2 .3 Conectividade . . . . . . . . . . . . . . . . . . 13

2.2.4 Densidade . . . . . . . . . . . . . . . . . . 13

2.2 .5 Clique . . . . . . . . . . . . . . . . . . 14

2.2.6 Coeficiente de Agrupamento . . . . . . . . . . . . . . . . . 14

2.2.7 Coeficiente de Assortatividade . . . . . . . . . . . . . . . . . . . 15

2.2.8 Grau de Heterogeneidade . . . . . . . . . . . . . . . . . . . 16 
2.3 Modelos de Redes . . . . . . . . . . . . . . . . . . . . . . . . . . 16

2.3.1 Redes Aleatórias . . . . . . . . . . . . . . . . . 16

2.3.2 Rede Mundo Pequeno . . . . . . . . . . . . . . . . . . 17

2.3 .3 Rede Livre de Escala . . . . . . . . . . . . . . . . . . . . . . . . . 18

3 Detecção de Comunidades e Refinamento Multinível 19

3.1 Exemplo introdutório . . . . . . . . . . . . . . . . . . . . . 20

3.2 Definições Básicas . . . . . . . . . . . . . . . . . . . . . . . . 21

3.3 Modularidade . . . . . . . . . . . . . . . . . . . . . . 22

3.4 Algoritmos de detecção de comunidades . . . . . . . . . . . . . . . . . . . 23

3.4.1 Algoritmos hierárquicos . . . . . . . . . . . . . . . . . . . 24

3.4.2 Algoritmos particionais ou planos . . . . . . . . . . . . . 26

3.4.3 Algoritmos espectrais . . . . . . . . . . . . . . . 27

3.5 Estratégia multinível de detecção de comunidades . . . . . . . . . . . . . . 29

3.5.1 Contração . . . . . . . . . . . . . . . . . . . . 30

3.5.2 Particionamento inicial . . . . . . . . . . . . . . . 32

3.5.3 Projeção . . . . . . . . . . . . . . . . . . . . . . 32

3.6 Refinamento multinível . . . . . . . . . . . . . . . . . . . . . 33

3.6.1 Kernighan-Lin . . . . . . . . . . . . . . . . . 34

3.6 .2 Fidducia Matheyses . . . . . . . . . . . . . . . . . . . 36

3.6.3 Otimização da Modularidade . . . . . . . . . . . . . . . . . 37

3.6.4 Outros algoritmos . . . . . . . . . . . . . . . . . 39

4 Refinamento multinível baseado em similaridade de vizinhança 41

4.1 Medidas de similaridade . . . . . . . . . . . . . . . . . . . . . 41

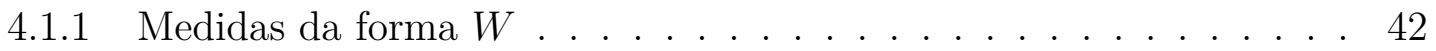

4.1 .2 Medida WIC . . . . . . . . . . . . . . . . . . 43

4.2 RSim . . . . . . . . . . . . . . . . . . . . . . 43

4.3 Extensão do RSim com base no coeficiente de agrupamento . . . . . . . . . 46

5 Avaliação Experimental $\quad 49$

5.1 Benchmark . . . . . . . . . . . . . . . . . . . . 49

5.1 .1 Conjuntos de dados . . . . . . . . . . . . . . . . . . . . . . . 49

5.1.2 Configuração do algoritmo multinível e fluxograma ...... . 51

5.1 .3 Medidas de desempenho . . . . . . . . . . . . . . . . 52

5.1.4 Resultados e análise . . . . . . . . . . . . . . . . . 54

5.2 Estudo de caso . . . . . . . . . . . . . . . . . . . . . . . 58

5.2 .1 Conjuntos de dados . . . . . . . . . . . . . . . . . . 59

5.2 .2 Método . . . . . . . . . . . . . . . . . . 6 60

5.2 .3 Medidas de desempenho . . . . . . . . . . . . . . . . . 62

5.2 .4 Resultados e análise . . . . . . . . . . . . . . . . 63 
5.3 Considerações finais . . . . . . . . . . . . . . . . . . . . 65

6 Conclusão e Trabalhos Futuros $\quad 67$

$\begin{array}{ll}\text { Referências Bibliográficas } & 69\end{array}$ 



\section{Lista de Figuras}

1.1 Estrutura de comunidades . . . . . . . . . . . . . . . . . . . . 1

1.2 Abordagem multinível de detecção de comunidades . . . . . . . . . . . . . . . . . . . . . . . .

1.3 Operações de refinamento local . . . . . . . . . . . . . . . . . . . . 3

2.1 Mapa do Brasil modelado a partir como um grafo . . . . . . . . . . . . . 9

2.2 Diferentes estrutura de dados representando uma rede . . . . . . . . . . . . 11

2.3 Exemplo de clique em uma rede simples . . . . . . . . . . . . . . . 14

2.4 Rede aleatória . . . . . . . . . . . . . . . . . . . . 16

2.5 Modelos de rede . . . . . . . . . . . . . . . . . . . . 17

2.6 Modelo de rede livre de escala . . . . . . . . . . . . . . . . . . . . 18

3.1 Rede de amizade Zachary Karate Clube . . . . . . . . . . . . . . . 20

$3.2 B i$-secção de uma rede . . . . . . . . . . . . . . . . . . . . . . 22

3.3 Dendograma ou árvore hierárquica . . . . . . . . . . . . . . . . . . . . . 24

3.4 Rede representada pela matriz Laplaciana . . . . . . . . . . . . . . . 27

3.5 Processo de contração de uma rede . . . . . . . . . . . . . . . . . . . 30

3.6 Diferentes estratégias de seleção de matching . . . . . . . . . . . . . . . . . 31

3.7 Processo de projeção multinível . . . . . . . . . . . . . . . . . . . . . 33

3.8 Estrutura de dados utilizada pelo FM . . . . . . . . . . . . . . . . . . 36

4.1 Diferença entre a medida $\Lambda_{v, u}$ tradicional e as medidas híbridas $\Lambda_{v, u}^{W}$ e $\Lambda_{v, u}^{I} . \quad 42$

4.2 Exemplo do processo de refinamento usando a variante RSim-CN . . . . . 45

4.3 Exemplo do processo de refinamento usando RSim . . . . . . . . . . . . . 46

4.4 Refinamento de um vértice mediantes diferentes estratégias . . . . . . . . . 46

4.5 Comparação entre os algoritmos de refinamento RSim-CN e Rcc . . . . . . 48

5.1 Fluxograma da metodologia experimental . . . . . . . . . . . . . . . . . 52

5.2 Gráfico ilustrativo da diferença estatística . . . . . . . . . . . . . . . 53

5.3 Gráfico ilustrativo de um histograma . . . . . . . . . . . . . . . . . 54

5.4 Diferença estatística considerando todos os algoritmos de refinamento . . . 56

5.5 Diferença estatística dos top-cinco algoritmos de refinamento . . . . . . . . 56

5.6 Diferença estatística dos algoritmos em dois cenários de interesse . . . . . . 57

5.7 Diferença estatística dos algoritmos em redes com baixa assortatividade . . 57 
5.8 Tempo de execução dos algoritmos de refinamento . . . . . . . . . . . . . . 58

5.9 Representação de citações ambíguas . . . . . . . . . . . . . . . . . . 60

5.10 Exemplo de gráfico de caixa. . . . . . . . . . . . . . . . . . . . 62

5.11 Diferença estatística dos algoritmos considerando duas medidas de qualidade 64

5.12 Distribuição estatística do desempenho dos algoritmos de refinamento . . . 65 


\section{Lista de Tabelas}

4.1 Medidas de similaridade local . . . . . . . . . . . . . . . . . . . . 43

4.2 Exemplo de refinamento usando três variantes do RSim . . . . . . . . . . 45

5.1 Propriedades estruturais básicas de doze redes . . . . . . . . . . . . 51

5.2 Eficácia quantificada através da Modularidade . . . . . . . . . . . . . . . 54

5.3 Configuração dos algoritmos avaliados . . . . . . . . . . . . . . . . . 61

5.4 Eficácia e eficiência dos algoritmos de refinamento considerando o problema de citação ambíguas na rede DBLP. . . . . . . . . . . . . . . . . . . . 63 



\section{Lista de Acrônimos}

AA Medida Adamic-Adar

AA-W Medida Adamic-Adar intra-comunidade

AL Rede Airline

AP Rede Astrophysics

BT Algoritmo Edge Betweenness

CN Medida Vizinhos Comuns

CN-W Medida Vizinhos Comuns intra-comunidade

DB Rede DBLP

FG Algoritmo Fastgreedy

HD Medida Hub Deprimido

HD-W Medida Hub Deprimido intra-comunidade

HEM Algoritmo de seleção de matching Heavy-edge Matching

HP Medida Hub Promovido

HP-W Medida Hub Promovido intra-comunidade

HT Rede High-energy theory

I Conjunto dos vizinhos comuns inter-comunidade

ID Rede Industry

IM Rede IMDB

Jac Medida Jaccard

Jac-W Medida Jaccard intra-comunidade

KK Algoritmo de refinamento baseado no corte mínimo

LEM Algoritmo de seleção de matching Light Edge Matching

LHN Medida Leicht-Holme-Newman

LHN-W Medida Leicht-Holme-Newman intra-comunidade

MHEM Algoritmo de seleção de matching Modified Heavy-edge Matching

MLP Detecção de comunidades multinível

NS Rede NetScience

PB Rede Political Blogs

PPI Interação Proteína-Proteína

PW Rede Power

RA Medida de Alocação de Recursos 
RA-W Medida de Alocação de Recursos intra-comunidade

Rcc Algoritmo de refinamento baseado no coeficiente de agrupamento

RFG Algoritmo de refinamento baseado na variação da Modularidade

RM Algoritmo de seleção de matching Random Matching

RSim Algoritmo de refinamento baseado em similaridade de vizinhança

RT Rede Router

Sal Medida Solton

Sal-W Medida Solton intra-comunidade

SN Rede Social

Sor Medida Sorensen

Sor-W Medida Sorensen intra-comunidade

W Conjunto dos vizinhos comuns intra-comunidade

WIC Medida inter e intra-comunidade

YT Rede Yeast

ZK Rede Zachary Karate 


\section{Lista de Símbolos}

\begin{tabular}{|c|c|}
\hline$e_{v, u}$ & Aresta (link) ligando os vértices $v$ e $u$ \\
\hline$\lambda$ & Autovalor da matriz Laplaciana $L$ \\
\hline$\vec{\gamma}$ & Autovetor associado a um autovalor \\
\hline$d_{v, u}$ & Caminho mínimo ou geodésico entre os vértice $v$ e $u$ \\
\hline$c c_{v}$ & Coeficiente de agrupamento de um vértice $v$ \\
\hline$c c_{v}^{W}$ & Coeficiente de agrupamento intra-comunidade de um vértice $v$ \\
\hline$\langle C\rangle$ & Coeficiente de agrupamento médio de $G$ \\
\hline$r$ & Coeficiente de assortatividade global de $G$ \\
\hline$\overline{P_{i}}$ & Complemento da comunidade $P_{i} \in P$ \\
\hline$P_{i}$ & Comunidade $i$ \\
\hline$P(v)$ & Comunidade que contém o vértice $v$ \\
\hline E & Conjunto de $m$ arestas de $G$ \\
\hline$V$ & Conjunto de $n$ vértices de $G$ \\
\hline$W$ & Conjunto de pesos correspondente a cada aresta de $G$ \\
\hline$\Lambda_{v, u}^{I}$ & Conjunto de vizinhos comuns inter-comunidade dos vértice $v$ e $u$ \\
\hline$\Lambda_{v, u}^{W}$ & Conjunto de vizinhos comuns intra-comunidade dos vértice $v$ e $u$ \\
\hline$\Gamma(v)$ & Conjunto de vizinhos do vértice $v$ \\
\hline$\Gamma(v)^{I}$ & Conjunto de vizinhos inter-comunidade do vértice $v$ \\
\hline$\Gamma(v)^{W}$ & Conjunto de vizinhos intra-comunidade do vértice $v$ \\
\hline$\sigma_{q}$ & Desvio padrão da distribuição $q_{k}$ \\
\hline$q_{k}$ & Distribuição de graus de $G$ \\
\hline$d_{\max }$ & Diâmetro de $G$ \\
\hline spec & Espectro da matriz Laplaciana $L$ \\
\hline$k_{P_{i}}$ & Grau da comunidade $P_{i}$ \\
\hline$k_{G}$ & Grau da rede $G$ \\
\hline$H$ & Grau de heterogeneidade de $G$ \\
\hline$B_{v}$ & Grau de intermediação de um vértice $v$ \\
\hline$k_{v}$ & Grau do vértice $v$ \\
\hline$k_{v}^{e x t}$ & Grau externo do vértice $v$ \\
\hline$k_{v}^{i n t}$ & Grau interno do vértice $v$ \\
\hline$w_{v}$ & Importância ou peso do vértice $v$ \\
\hline
\end{tabular}


adj Lista de adjacência

$k_{\max } \quad$ Maior grau de $G$

$A \quad$ Matriz de adjacência

$B \quad$ Matriz de Modularidade

D Matriz Diagonal

L Matriz Laplaciana

$L_{G} \quad$ Matriz Laplaciana Normalizada Generalizada

$k_{\text {min }} \quad$ Menor grau de $G$

$Q(P) \quad$ Modularidade de um particionamento $P$

$\langle B\rangle \quad$ Média do grau de intermediação

$\langle k\rangle \quad$ Média dos graus dos vértices de $G$

$m \quad$ Número de arestas de $G$

$e_{v} \quad$ Número de arestas entre os vizinhos de $v$

$e_{v}^{I} \quad$ Número de arestas entre os vizinhos inter-comunidade de $v$

$e_{v}^{W} \quad$ Número de arestas entre os vizinhos intra-comunidade de $v$

$d_{i, j}^{v} \quad$ Número de caminhos mínimos entre $i$ e $j$ que incluem $v$

$n \quad$ Número de vértices de $G$

$P \quad$ Particionamento de $V$ em $c$-comunidades

$w_{v, u} \quad$ Peso da aresta entre o par de vértices $v$ e $u$

$P_{k} \quad$ Probabilidade de escolher aleatoriamente um vértice de grau $k$

$G \quad$ Rede formada por um conjunto de vértices e links

$\langle d\rangle \quad$ Tamanho linear de $G$

$\Delta Q_{v \rightarrow P_{j}}$ Variação de $Q$ ao mover $v$ da comunidade $P_{i}$ para $P_{j}$

$\Delta Q_{i, j} \quad$ Variação de $Q$ ao unir as comunidade $i$ e $j$

$V_{o l} \quad$ Volume da comunidade $P_{i}$ 


\section{Introdução}

$\mathcal{R}$

edes ou grafos são estruturas relacionais que representam sistemas do mundo real, tais como redes sociais, redes biológicas, redes de informação e redes de tecnologia (Newman, 2003b). Nessas estruturas, os objetos são representados por vértices, e as relações observadas entre as entidades são representadas por arestas. Entretanto, existem sistemas reais dinâmicos que podem ser modelados por redes de larga escala, padrões de conectividade e estrutura topológica não triviais denominadas redes complexas. Redes complexas difere-se da teoria tradicional de grafos por se preocupar mais com as características estatísticas e topológicas de redes de grande escala. O estudo das redes complexas tornou-se um campo de crescente interesse científico, o qual se reflete nas pesquisas para o entendimento da evolução de redes reais (Dorogovtsev \& Mendes, 2002) e das suas propriedades topológicas e funcionais (Newman, 2003b; Costa et al., 2007).

Uma propriedade importante presente em muitas redes ${ }^{1}$ reais é a concentração elevada de arestas dentro de grupos de vértices, formando estruturas modulares locais denominadas comunidades (também chamada de módulos, partições ou sub-redes). A Figura 1.1 ilustra um exemplo da divisão em comunidades formada por uma rede de amizade de um corpo docente em uma universidade do Reino Unido, com 81 vértices (indivíduos) e 817 arestas. Cada grupo representa uma filiação diferente. Este conjunto de dados é comumente utilizado como teste para algoritmos de detecção de comunidade (Nepusz et al., 2008).

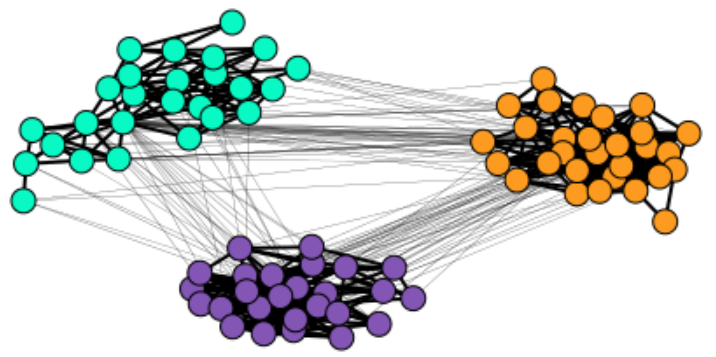

Figura 1.1: Estrutura de comunidades formada por uma rede de amizade de um corpo docente em uma universidade do Reino Unido. Cada grupo representa uma filiação.

\footnotetext{
${ }^{1}$ No presente trabalho, não mais nos referimos ao termo grafo, mas somente ao termo rede, utilizando-o como sinônimo de redes complexas.
} 
Por exemplo, na web, páginas relacionadas com um determinado tópico possuem, comparativamente, mais conexões entre si do que com páginas que abordam outros temas (Dourisboure et al., 2007). Em domínios biológicos, a estrutura de comunidades é observada em grupos de proteínas com a mesma função específica em diferentes organismos (Chen \& Yuan, 2006). Esse efeito também é encontrado em redes sociais, nas quais grupos de indivíduos estão reunidos por algum interesse comum (Moody \& White, 2003; Chen \& Redner, 2010; Mena-Chalco et al., 2014), ou em redes de colaboração que formam comunidades com base em temas de investigação similar (Chen \& Redner, 2010; Mena-Chalco et al., 2014).

É importante destacar que os vértices pertencentes à mesma comunidade compartilham características e/ou desempenham papéis semelhantes, consequentemente, a divisão em comunidades é útil para entender a estrutura da rede e seus processos dinâmicos, tais como fluxo ou propagação de informações (Fortunato, 2010). Sob este aspecto, detecção de comunidades tornou-se um campo de crescente interesse científico e possui inúmeras aplicações práticas. No contexto de aprendizado de máquina e mineração de dados, essa tarefa é denominada agrupamento ou particionamento, comumente referido como "aprendizado não supervisionado", no qual o objetivo é agrupar entidades semelhantes sem qualquer conhecimento prévio sobre os grupos.

Entretanto, detectar a melhor divisão em comunidades em uma rede é um problema da classe $\mathcal{N} \mathcal{P}$-completo, o que implica grande esforço computacional para determinar a solução ótima (Garey et al., 1976). Uma alternativa é utilizar heurísticas, que não garantem que a solução seja ótima, mas tendem a produzir boas soluções em um tempo computacional razoável. A desvantagem dessa abordagem é que diferentes algoritmos podem obter soluções distintas quando avaliados na mesma rede. Além disso, cada algoritmo possui um trade-off entre qualidade da solução e tempo de execução e, consequentemente, a escolha do algoritmo de detecção de comunidades adequado depende do contexto da aplicação (Fortunato, 2010).

O principal objetivo de um algoritmo de detecção de comunidades (ou algoritmo de particionamento) é a eficácia, ou seja, o algoritmo deve ser capaz de encontrar um particionamento de boa qualidade. Em segundo lugar, a eficiência é uma preocupação, isto é, encontrar o melhor particionamento possível em tempo hábil. Nesse contexto, recentemente, surgiram várias pesquisas sobre estratégias multinível (multilevel partitioning MLP) para particionar redes com elevada quantidade de vértices e arestas (Bichot, 2013). O objetivo dessa estratégia é diminuir o custo do algoritmo de particionamento aplicandoo sobre uma versão reduzida da rede original, viabilizando a avaliação de algoritmos com elevado custo computacional em redes de larga escala. O MLP reduz o tamanho da rede original mediante a contração de vértices e arestas, formando super-vértices. Em seguida, a rede reduzida é particionada usando algum algoritmo de detecção de comunidades. Por fim, a solução é projetada, sucessivamente, até a rede original. A Figura 1.2 ilustra com detalhes as fases do MLP. 


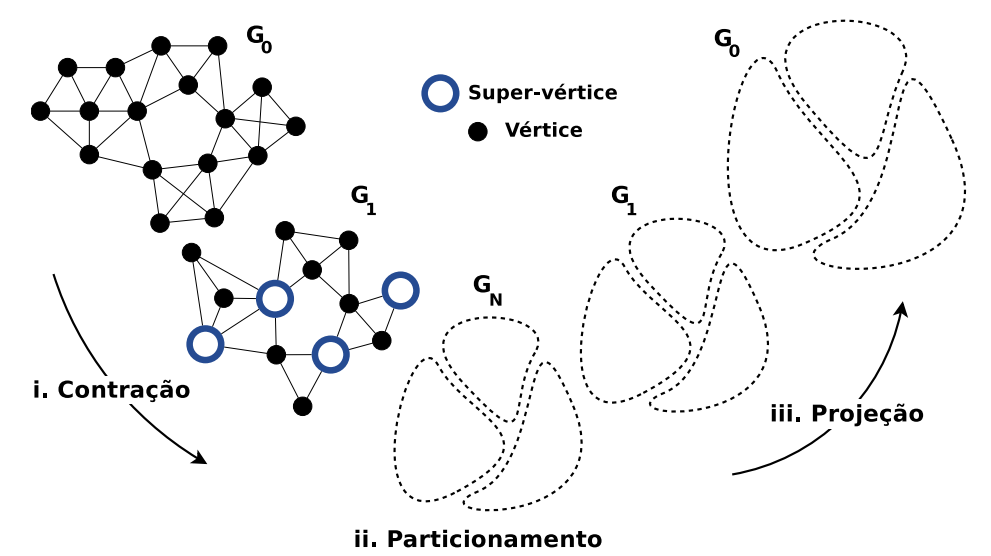

Figura 1.2: Abordagem multinível de detecção de comunidades.

Além disso, na fase de projeção, é possível considerar heurísticas de refinamento local a fim de melhorar a qualidade da solução, buscar ótimos locais e corrigir decisões ruins tomadas por algum algoritmo de detecção de comunidades guloso. Dado um particionamento inicial, o processo de refinamento é realizado, normalmente, movendo vértices entre comunidades adjacentes. As operações de refinamento, ilustradas na Figura 1.3, permitem: i. mover vértices entre comunidades; ii. unir comunidades; e iii. criar novas comunidades.

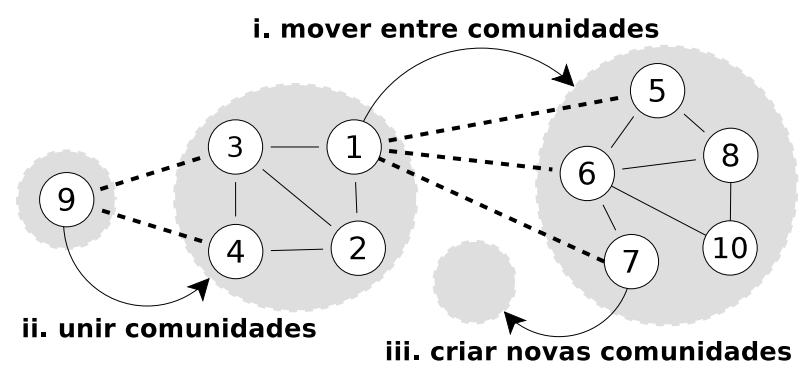

Figura 1.3: Operações de refinamento local. As linhas tracejadas representam ligações entre comunidades; as setas indicam as operações de refinamento.

Inicialmente, o método multinível foi criado apenas para acelerar os algoritmos existentes de particionamento (Bichot, 2013). Por outro lado, pesquisas empíricas demonstraram que essa estratégia também é eficaz em termos de qualidade de solução (Karypis \& Kumar, 1995a; Walshaw \& Cross, 2000; Newman, 2006b; Schuetz \& Caflisch, 2008; Ye et al., 2008; Almeida \& Lopes, 2009; Noack \& Rotta, 2009; Rotta \& Noack, 2011; LaSalle \& Karypis, 2013; Valejo et al., 2014b,c), no entanto, deve-se ressaltar que esse desempenho, em geral, depende diretamente de heurísticas de refinamento. Logo, o estudo dessa classe de algoritmos torna-se essencial quando a qualidade da solução é um fator de impacto na aplicação. 


\subsection{Problema e Motivação}

O principal objetivo de um algoritmo de refinamento é melhorar a qualidade do particionamento inicial, porém, a restrição é não prejudicar a escalabilidade do processo multinível. Segundo Hendrickson \& Leland (1995), um algoritmo de refinamento deve explorar conceitos e estruturas de dados que tornem o algoritmo rápido e eficaz para que sua inclusão no processo multinível seja considerada.

Com base nessa perspectiva, a maioria dos algoritmos de refinamento tendem a otimizar uma função objetivo, por exemplo, redução do corte e balanceamento das partições (Kernighan \& Lin, 1970; Fiduccia \& Mattheyses, 1982; Sanchis, 1989, 1993; Hendrickson \& Leland, 1995; Karypis \& Kumar, 1998b; Walshaw \& Cross, 2000; LaSalle \& Karypis, 2013) ou maximização da modularidade (Newman, 2006b; Schuetz \& Caflisch, 2008; Ye et al., 2008; Noack \& Rotta, 2009; Rotta \& Noack, 2011). Tais métodos utilizam as propriedades funcionais e estruturais gerais de redes complexas. Por exemplo, uma das definições aceitas para o particionamento ótimo de uma rede é aquele que reduz o número de arestas entre as comunidades. Nesse caso, maximizar a modularidade como critério de refinamento pode ser uma boa estratégia em um contexto geral. Porém, com pouco impacto no refinamento quando o algorítimo de particionamento já procurou otimizar essa medida.

Entretanto, algumas propriedades intrínsecas de tipos específicos de redes complexas não têm sido exploradas de forma eficiente no processo de refinamento. Existem diferentes tipos de redes, cada qual com características específicas. Por exemplo, avaliações empíricas (Newman, 2002, 2003a) mostraram que muitas redes sociais possuem assortatividade, isto é, tendência de conexão entre vértices semelhantes. Por outro lado, redes tecnológicas e biológicas, tipicamente, são não-assortativas, isto é, tendência de conexão entre vértices dissimilares.

No caso da Internet, vértices com alto grau de conectividade, no geral, representam provedores de telefonia e outras comunicações. Tais vértices, normalmente, possuem um grande número de conexões com os clientes que, por sua vez, possuem poucas ou apenas uma conexão. Em consequência, vértices de alto grau, de fato, se ligam aos de baixo grau. Já nas redes sociais, os indivíduos geralmente optam por associar-se com outros indivíduos que possuem características similares, como idade, raça, etnia, nacionalidade, localização, renda, escolaridade, religião, língua, dentre outras. Logo, a definição de um particionamento ótimo deve refletir o contexto da aplicação.

Essa diversidade de características presentes nos conjuntos de dados impossibilita que algoritmos de refinamento sejam eficientes em todos os casos (Valejo et al., 2014b). Assim, é relevante explorar as características inerentes ao contexto do problema no processo de refinamento, visto que, o objetivo é melhorar a qualidade de uma solução já existente. Por exemplo, no cenário de redes sociais, e com base na literatura apresentada nesse trabalho, não há qualquer estudo detalhado ou definição/formalização de estratégias de refinamento 
local baseadas na otimização das características que predominam nesse domínio.

\subsection{Hipótese}

Atualmente, um dos tipos mais estudados de redes complexas são as redes sociais (SN), nas quais os vértices representam indivíduos e as arestas representam alguma interação social (Newman, 2010), tais como amizade, família ou hobbie. Segundo Wasserman \& Faust (1994), a estrutura topológica de uma rede social é baseada na importância das relações entre os indivíduos que a compõem. Ainda, segundo Newman (2002), as redes sociais são caracterizadas por: i. elevado grau de transitividade, o que significa que há uma probabilidade elevada de duas pessoas se conhecerem se elas têm um ou mais conhecidos em comum; e ii. assortatividade significativa, isto é, tendência de conexões entre vértices semelhantes.

Em decorrência, a primeira hipótese levantada sugere que maximizar a transitividade e a assortatividade no processo de refinamento pode conduzir a uma boa solução, bem como uma estrutura de comunidades bem definida, quando aplicado em redes nas quais tais características são predominantes. Por definição, essa abordagem deve ser eficaz, principalmente, em redes sociais.

Tais características podem ser quantificadas mediante as relações entre os vizinhos ou vizinhança que vértices compartilham (Watts \& Strogatz, 1998; Newman, 2002; Newman et al., 2001; Newman, 2003a; Lü \& Zhou, 2011; Yin et al., 2010; Valverde-Rebaza \& Lopes, 2012, 2013). Nesse contexto, Valverde-Rebaza \& Lopes (2013) propuseram medidas de similaridade local híbridas entre pares de vértices, que utilizam os conceitos de vizinhança e informações da estrutura de comunidades para interpretar a semelhança entre pares de vértices, visto que, um algoritmo de refinamento possui duas características básicas: i. começar a partir de um particionamento existente; e ii. a otimização deve ser local; tornase possível utilizar tais medidas no processo de refinamento. Logo, a segunda hipótese julga possível explorar as características de transitividade e assortatividade no processo de refinamento otimizando as medidas de similaridade local híbridas.

Além disso, as medidas de similaridade local híbridas utilizam apenas informações locais entre pares de vértices, e, consequentemente, possuem baixo custo computacional (Lü \& Zhou, 2011; Valverde-Rebaza \& Lopes, 2013; Valejo et al., 2014b). Diante disso, a terceira hipótese deste trabalho é que a utilização de tais medidas no processo de refinamento não interfere na escalabilidade do processo multinível.

\subsection{Objetivo}

Este trabalho centra-se na heurística de refinamento multinível. Com base no problema abordado e hipóteses previamente definidas, é proposto um algoritmo, chamado: Algoritmo de refinamento baseado em similaridade de vizinhança (RSim), que explora as propriedades intrínsecas das redes sociais no processo de refinamento multinível. Para alcançar o objetivo principal de maneira satisfatória, alguns objetivos específicos foram 
estabelecidos:

Levantamento teórico: Realizar um levantamento teórico e uma análise dos métodos de refinamento multinível mais relevantes e populares, contribuindo para o entendimento dos fundamentos, aplicabilidade, limitações e tendências da área;

Desenvolvimento: Contribuir com o estado da arte de modo a propor formalmente heurísticas de refinamento multinível em redes complexas com base nos conceitos de assortatividade e transitividade;

Avaliação qualitativa e quantitativa: Avaliar o desempenho qualitativo e quantitativo com o intuito de validar a solução proposta neste trabalho. Escolher algoritmos clássicos da literatura para confrontar com a proposta. Aplicar os algoritmos desenvolvidos não somente utilizando conjuntos de dados benchmark, mas também em cenários reais em domínios de interesse para a comunidade que pesquisa na área de redes complexas e detecção de comunidades.

\subsection{Metodologia}

A fim de descrever e comparar sistematicamente a proposta deste trabalho com os algoritmos de refinamento existentes na literatura, foi realizado uma avaliação empírica em relação a eficácia (qualidade da solução) e eficiência (tempo de execução). As medições experimentais são baseadas em doze redes reais de diferentes domínios de aplicação, comumente utilizadas em benchmark, bem como em uma aplicação real.

Primeiro, considerando conjuntos de dados de benchmark, buscou-se determinar a capacidade de encontrar soluções factíveis próximas o suficiente de um referencial determinado em tempo hábil. Para isso, avaliou-se a proposta de forma comparativa e sistemática a partir da Modularidade. Os resultados obtidos foram submetidos a análise da diferença estatística significativa através de um teste post-hoc (Demšar, 2006). Tal análise foi realizada com base em um contexto geral, considerando todas as doze redes complexas, bem como uma análise em outros cenários de interesse. Tais experimentos indicaram que, em geral, o RSim tem desempenho comparável com os métodos descritos na literatura. No entanto, ao analisar apenas redes com assotatividade significativa e transitividade altas, o RSim supera os métodos de corte mínimo e maximização da Modularidade. Em seguida, os algoritmos foram submetidos a uma avaliação de eficiência com base no tempo de execução. Essa avaliação indica que, independentemente do tipo de rede analisada, o RSim é mais rápida do que os métodos avaliados.

Segundo, buscou-se avaliar o comportamento dos algoritmos em uma aplicação real a partir de um estudo de caso que aborda o problema de citações ambíguas em bibliotecas digitais. Nesse caso, foi utilizado as métricas de qualidade Modularidade e F-measure. Os resultados obtidos a partir dessas métricas foram submetidos a duas análises: i. análise da tendência central mediante um gráfico boxplot; e ii. análise da diferença estatística 
significativa através de um teste post-hoc (Demšar, 2006). Além disso, também analisouse o tempo de execução dos algoritmos. Nesse contexto, o RSim superou os métodos comparados tanto em eficácia quanto em eficiência.

\subsection{Contribuição do trabalho}

Este trabalho deu origem a uma implementação do algorítimo multinível RSim, bem como as seguintes publicações e colaborações.

- Valejo, A., Valverde-Rebaza, J., Drury, B., e Lopes, A. d. A. (2014). Multilevel refinement based on neighborhood similarity. In Proceedings of the 18th International Database Engineering 8 Applications Symposium, IDEAS '14, pp. 67-76, New York, NY, USA. ACM

- Valejo, A., Valverde-Rebaza, J. C., e Lopes, A. (2014). A multilevel approach for overlapping community detection. In Proceedings of the Brazillian Conference on Intelligent Systems, BRACIS 2014

- Valejo, A., Drury, B., Valverde-Rebaza, J. C., e Lopes, A. (2014). Identification of related brazilian portuguese verb groups using overlapping community detection. In PROPOR, Lecture Notes in Computer Science. Springer

- Drury, B., Valejo, A., Cardoso, P. F., Valverde-Rebaza, J. C., Pereira, F., e Lopes, A. (2014). An open source tool for crowd-sourcing the manual annotation of texts. In PROPOR, Lecture Notes in Computer Science. Springer

Além das publicações citadas, outras contribuições também foram alcançadas. No Capítulo 3, é realizado uma revisão das estratégias multinível de refinamento local. Acredita-se que este estudo pode ajudar as pesquisas futuras, fornecendo uma visão geral da área, os principais métodos disponíveis, as lacunas de pesquisa e perspectivas na área.

Outra contribuição deste trabalho, apresentada no Capítulo 4, é o desenvolvimento de um novo algoritmo de refinamento, chamado RSim, usando medidas de similaridade híbridas entre pares de vértices. O RSim alcançou importante performance em redes com alto coeficiente de agrupamento e assortatividade, características relevantes em redes sociais. Além disso, também é apresentado uma reformulação do coeficiente de agrupamento considerando informações topológicas da estrutura de comunidades. Essa reformulação originou uma extensão do RSim, denominada Rcc.

Ainda, no Capítulo 5, é realizado uma extensa comparação de algoritmos de refinamento multinível em inúmeras redes com características topológicas distintas e tamanhos diferentes. No mesmo capítulo, é demostrado, em uma aplicação real, a viabilidade da utilização da estratégia multinível, bem como a relevância da utilização de algoritmos de refinamento na tarefa de detecção de citações ambíguas em bibliotecas digitais. 


\subsection{Estrutura da dissertação}

O restante deste documento está organizado da seguinte maneira:

Capítulo 2: Nesse capítulo são apresentados os conceitos básicos de redes complexas, bem como sua formulação matemática, visando oferecer a base necessária para a compreensão deste trabalho.

Capítulo 3: Nesse capítulo são discutidos os conceitos e os principais algoritmos de detecção de comunidades. Uma maior ênfase é dada a caracterização das estratégias multinível, bem como uma revisão dos principais algoritmos de refinamento.

Capítulo 4: Nesse capítulo é feita a proposição de um algoritmo de refinamento multinível baseado em similaridade de vizinhança, o qual é a contribuição central deste trabalho.

Capítulo 5: Nesse capítulo são descritos os experimentos e os resultados que corroboram as hipóteses deste trabalho.

Capítulo 6: Nesse capítulo são apresentadas as considerações finais, expondo as conclusões e limitações desta pesquisa, bem como os trabalhos futuros que darão continuidade a essa pesquisa. 


\section{Redes Complexas}

rafos são ferramentas matemáticas fundamentais de abstração que permitem codificar as relações entre pares de objetos ou entidades. Em geral, as entidades são representadas por vértices e as relações representadas por arestas. Grafos são úteis na modelagem de problemas que representam sistemas reais e de interesse prático. Por exemplo, pode-se utilizar grafos para interpretar uma estrutura viária e usar algoritmos específicos para estabelecer rotas. Outro exemplo, é a representação da organização entre computadores em uma rede, em que se considera cada terminal como sendo um vértice e os cabos de comunicação como sendo arestas. Resumidamente, o grafo é um modelo matemático usado para representar sistemas, ou parte deles, bem como os relacionamentos entre eles, ou suas partes. A Figura 2.1 ilustra o mapa do Brasil modelado a partir de um grafo considerando estados e suas fronteiras. Uma contribuição teórica relevante sobre o tema pode ser encontrada no livro Graph theory, de Diestel (Diestel, 2010).

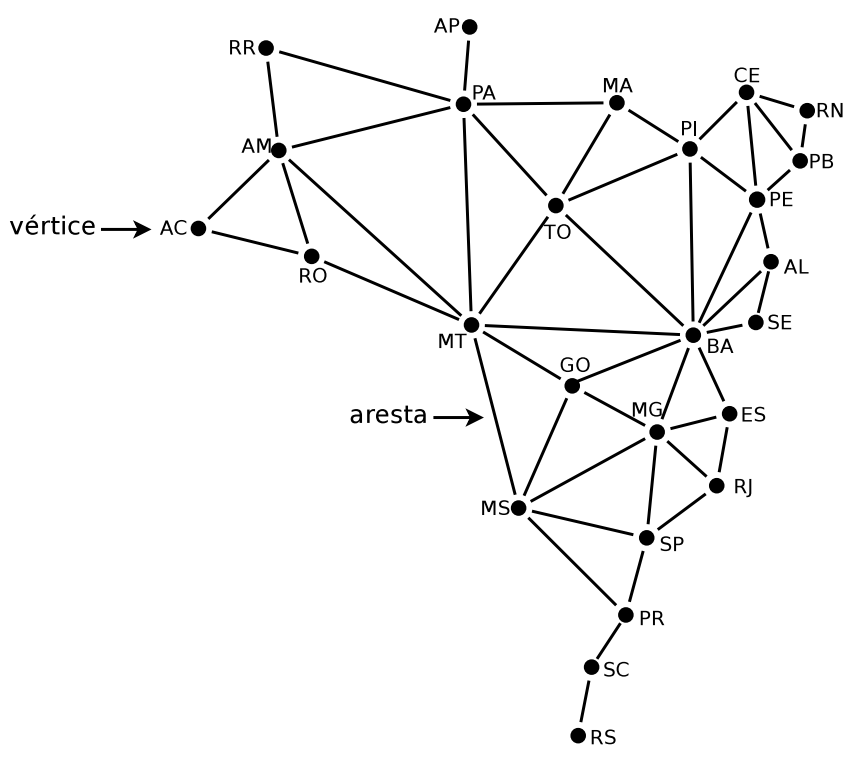

Figura 2.1: Mapa do Brasil modelado a partir de um grafo. Os vértices representam os estados; as arestas representam a relação de vizinhança entre estados (vizinhos $\equiv$ compartilham pelo menos uma fronteira).

Entanto, existem sistemas dinâmicos não-lineares (sistemas complexos) que possuem 
milhões de elementos e cuja complexidade está associada às propriedades que emergem do relacionamento entre seus elementos. Tais sistemas possuem estrutura topológica não trivial em que o padrão de conexão entre seus elementos não é puramente regular ou aleatório, em contraste, possui padrões de conectividade (espacial e temporal) únicos, presença de estrutura de comunidades, estrutura hierárquica e outras características estatísticas (Albert \& Barabási, 2002). Como exemplos, têm-se as redes de transmissão de doenças (epidemias), redes de distribuição (energia, água), redes sociais, redes de interação entre proteínas, sistemas nervosos e a World Wide Web.

Sistemas complexos necessitam de uma ferramenta robusta capaz de capturar várias características topológicas e o viés estatístico do sistema em questão. Logo, em geral, apenas a modelagem dos elementos que compõem um sistema complexo através de grafos é insuficiente para explicar seu comportamento e seus aspectos dinâmicos. Para esses casos, pode-se modelar o sistema usando redes complexas, que difere-se da teoria tradicional de grafos por se preocupar mais com as características estatísticas e topológicas de sistemas de grande escala com padrões não triviais de conexões.

Redes complexas, ou simplesmente redes, é um tema recente e multidisciplinar que envolve várias áreas do conhecimento, tais como física, matemática, biologia, engenharia e sociologia. A teoria que subsidia redes complexas se originou da união do formalismo matemático da Teoria dos Grafos com ferramentas estatísticas e conceitos de sistemas complexos. Ao contrário de grafos, redes complexas possuem propriedades úteis na análise dos mais diversos aspectos de um sistema, isto é, além da análise individual de vértices e arestas, redes complexas permitem analisar suas propriedades globais funcionais (funcionalidade) ou não-funcionais (confiabilidade, desempenho, segurança, proteção).

De acordo com Newman (2003b), as redes complexas podem ser divididas em quatro grandes grupos: redes sociais, redes de informação, redes biológicas e redes de tecnologia. As redes sociais são aquelas que determinam alguma característica de uma comunidade, por exemplo, uma rede de amizades de uma escola; redes de informação representam uma estrutura de conteúdo informativo, por exemplo, a web; redes biológicas são as que representam estruturas biológicas, por exemplo, uma rede de neurônios; e redes de tecnologia são redes que distribuem mercadorias ou recursos, por exemplo, uma rede ferroviária e a Internet.

\subsection{Definições Básicas}

Matematicamente, uma rede $G$ não direcionada pode ser interpretada pela relação $G=(V, E)$, em que $V$ é um conjunto de vértices e $E$ é o conjunto de arestas ou conexões. O número de vértices é definido por $n=|V|$ e o número de arestas por $m=|E|$, em que "I.|" indica a cardinalidade de um conjunto. Para redes densas $m \approx n^{2}$, por outro lado, em redes esparsas $m \approx n$. Uma rede não direcionada é chamada simples se cada par de vértices está ligado, no máximo, com uma aresta, isto é, não existem arestas paralelas.

Em alguns casos, quando se utiliza modelagem baseada em redes, é relevante considerar 
algumas propriedades relacionadas com as arestas e vértices. Uma situação que reflete a necessidade de armazenar informações particulares, é a modelagem de problemas que envolvem rotas e navegação em terrenos irregulares; nesse caso é importante armazenar dados referentes a tipo de terreno e distância entre pontos, que podem ser interpretados, por exemplo, usando a propriedade peso. A seguir, são definidas algumas propriedades de vértices e arestas.

Aresta. Uma aresta é definida pela relação $e_{v, u}=\{(v, u)=(u, v) \mid v, u \in V\}$. Cada aresta conecta no máximo dois vértices, particularmente é chamada de laço se conecta um vértice a ele mesmo. Dois vértices $v$ e $u$ são ditos extremidades da aresta $e_{v, u}$; em decorrência, a aresta $e_{v, u}$ é incidente nos vértices $v$ e $u$. Uma propriedade importante da aresta é o seu peso ou força de associação. Nesse caso, a rede é interpretado pela relação $G=(V, E, W)$, em que $W$ representa o conjunto de pesos das arestas na rede, logo, o peso da aresta entre o par de vértices $v$ e $u$ é representado por $w_{v, u}$. Em redes nas quais o peso não é relevante, considera-se todos $w_{v, u}=1$.

Vértice. A grandeza básica associada a um vértice $v \in V$ é o seu grau $k_{v}=\sum_{u \in V} w_{v, u}$, que indica o peso total de suas arestas, sendo $0 \leq k_{v} \geq n-1$. Se $e_{v, u}$ é uma aresta, é dito que os vértices $v$ e $u$ são vizinhos ou adjacentes. O conjunto de vizinhos do vértice $v$, também chamado de vizinhança de $v$, é definido pela relação $\Gamma(v)$ $=\left\{u \mid e_{v, u} \in E\right\}$. O maior grau da rede é denominado $k_{\max }=\max \left\{k_{v} \mid v \in V\right\} \mathrm{e}$ o menor grau da rede é denominado $k_{\min }=\min \left\{k_{v} \mid v \in V\right\}$. Além disso, o grau da rede é definido pela soma dos pesos de todas as arestas da rede, $k_{G}=\frac{1}{2} \sum_{v \in V} k_{v}$. A importância ou peso de um vértice $v$ é definido por $w_{v}$. Um vértice que não é vizinho de nenhum outro é chamado isolado.

Computacionalmente, a estrutura de uma rede com $n$ vértices pode ser representada por uma matriz de adjacência $A_{n \times n}=\left(a_{v, u}\right)$, na qual um elemento $a_{v, u}=w_{v, u}$ quando a aresta $e_{v, u}$ existe, e zero caso contrário. Por outro lado, também pode-se representar a estrutura de uma rede através de uma lista de adjacência, a qual consiste em um vetor adj de $n$ listas, uma para cada vértice de $V$, consequentemente, adj $[v]$ contém todos os vértices adjacentes a $v$. A Figura 2.2 ilustra uma rede simples e sua representação usando matriz de adjacência e lista.

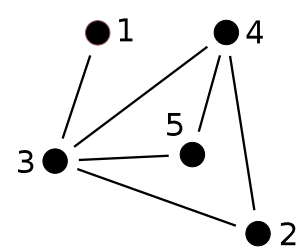

(a)

$$
A=\left[\begin{array}{lllll}
0 & 0 & 1 & 0 & 0 \\
0 & 0 & 1 & 1 & 0 \\
1 & 1 & 0 & 1 & 1 \\
0 & 1 & 1 & 0 & 1 \\
0 & 0 & 1 & 1 & 0
\end{array}\right]
$$

(b)

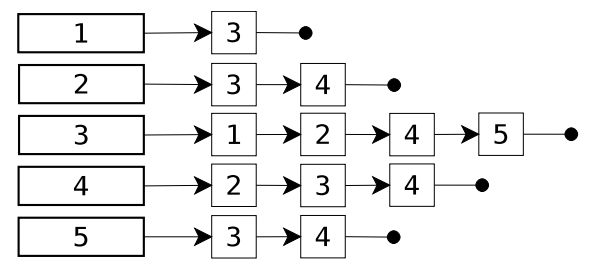

(c)

Figura 2.2: Modelagem da rede (a) por meio de uma matriz de adjacência (b) e lista de adjacência (c). 


\subsection{Propriedades e Medidas de Centralidade}

A estrutura topológica de uma rede possui inúmeras propriedades (informações globais e locais), que podem ser extraídas mediante medidas específicas e utilizadas em sua análise. A avaliação quantitativa dessas propriedades, tais como a conectividade, simetria, capacidade de transferência de sinais ou estrutura de comunidades pode revelar características qualitativas implícitas da rede avaliada. Por exemplo, informações de centralidade local de vértices permitem encontrar sub-redes e vértices influentes/importantes, bem como grupos de vértices com funções semelhantes. Com base em Newman et al. (2001); Newman (2002, 2003b,a, 2010) e Costa et al. (2007), a seguir, são apresentadas as principais medidas de centralidade.

\subsubsection{Caminhos mínimos}

Um caminho é um conjunto de arestas que ligam dois vértices quaisquer, dado por uma lista de vértices $V=\left\{v_{1}, v_{2} \ldots, v_{n}\right\}$, tal que para cada vértice existe uma aresta para o próximo vértice na sequência. Em redes pesadas, o caminho pode ter um custo ou valor calculado considerando os pesos associados a cada aresta.

O caminho mínimo ou caminho geodésico, denotado por $d_{v, u}$, entre dois vértices $v$ e $u$ é definido pelo número mínimo de arestas necessárias para atingir o vértice $u$ a partir de $v$. Em outras palavras, é o conjunto de arestas que ligam os dois vértices com o menor custo total. Quando cada um dos vértices pertencem a componentes distintos, define-se $d_{v, u}=\infty$. Além disso, $d_{i, j}^{v}$ representa o número de caminhos mínimos entre $i$ e $j$ que incluem $v$.

O maior valor de $d_{v, u}$ entre todos os pares de vértices define o diâmetro $\left(d_{\max }\right)$ da rede. O tamanho linear da rede ou média dos caminhos mínimos $\langle d\rangle$ é dado pela média sobre todos os caminhos mínimos entre todos os pares de vértices na rede (Equação 2.1).

$$
\langle d\rangle=\frac{1}{n(n-1)} \sum_{v_{j} \neq v_{i}} \frac{1}{d_{v_{i}, v_{j}}}
$$

\subsubsection{Grau de intermediação}

O grau de intermediação (betweenness), $B_{v}$, indica a importância de um vértice $v$ em termos de sua localização ou centralidade. Vértices com maior betweenness fazem parte de um número maior de caminhos mínimos e, portanto, são mais importantes para a estrutura da rede. Em outras palavras, essa medida mensura a importância de um vértice em termos do controle que esse exerce no fluxo de informação na rede. Por exemplo, em uma rede que representa aeroportos espalhados ao redor do mundo, aeroportos mais conectados, isto é, que possuem maior número de rotas ou escalas entre os demais aeroportos, são mais importantes.

O betweenness de um vértice $v$ é dado pela quantidade de caminhos mínimos entre 
todos os pares de vértices que passam por $v$, em relação a todos os caminhos mínimos entre todos os pares de vértices na rede (Equação 2.2). A média do grau de intermediação $\langle B\rangle$ para uma rede com $n$ vértices é dada pela Equação 2.3 .

$$
B_{v}=\sum_{i, j \in V, i \neq v, j \neq v} \frac{d_{i, j}^{v}}{d_{i, j}} \quad(2.2) \quad\langle B\rangle=\frac{1}{n} \sum_{v \in V} B_{v}
$$

\subsubsection{Conectividade}

Como já definido, o grau de um vértice $v$, representado por $k_{v}$, configura o número de arestas incidentes a ele, de modo que, $0 \leq k_{v} \geq n-1$. Essa medida indica quão um vértice está conectado com seus vizinhos. Em alguns casos, quanto maior o valor do grau, maior será a sua importância. Já o grau médio da rede é dado pela soma do grau de todos os vértices dividido pelo número total de vértices na rede (Equação 2.4).

$$
\langle k\rangle=\frac{1}{n} \sum_{v=1}^{n} k_{v}
$$

Além disso, pode-se calcular a distribuição da conectividade dos vértices na rede, de modo a definir a probabilidade de um vértice ter $k$ arestas. A distribuição de grau é a característica estatística básica de uma rede, sendo de grande importância na sua descrição e caracterização. Considere uma rede com $n$ vértices e $n_{k}$ como sendo o número de vértices com grau igual a $k$. A fração de vértices com grau $k$ é dado por $f_{k}=n_{k} / n$, a qual representa, de forma equivalente, a probabilidade $p_{k}$ de um vértice $v$, selecionado aleatoriamente, tenha grau $k$. Em geral, é relevante obter a probabilidade cumulativa do grau $P_{k}$, ou seja, a fração de vértices que possui grau maior ou igual a $k$, dado pelo complemento do somatório de todos os graus menores que $k$, Equação 2.5. A forma como a conectividade está distribuída na rede pode ser analisada por um histograma.

$$
P_{k}=1-\sum_{i=0}^{k-1} p_{i}
$$

\subsubsection{Densidade}

A densidade de uma rede representa a proximidade de seus vértices. Segundo Wasserman \& Faust (1994), quanto mais densa é uma rede, melhor o fluxo de informação entre seus vértices. O número máximo de arestas em uma redes com $n$ vértices ocorre quando cada vértice possui grau máximo $k_{v}=n-1$, portanto, o número máximo de arestas nessa rede é $n(n-1) / 2$. Desse modo, a densidade $\mu$ em uma rede com $n$ vértices e $m$ arestas é definida pelo número de arestas que realmente existem na rede em relação ao número máximo de arestas que podem existir na rede (Equação 2.6), sendo $0 \leq \mu \geq 1$.

$$
\mu=\frac{m}{n(n-1) / 2}=\frac{\langle k\rangle}{n-1}
$$




\subsubsection{Clique}

Um clique em uma rede $G$ é uma sub-rede (induzida) de $G$ que é completa, ou seja, uma sub-rede na qual todos os vértices têm grau máximo. O tamanho de um clique é igual a cardinalidade de seu conjunto de vértices. Um clique composto por $n$ vértices é chamado de $n$-clique. Por exemplo, a rede ilustrada pela Figura 2.3 possui 2 cliques de 3 vértices, formados pelas sub-redes $S_{1}=\{3,4,5\}$ e $S_{2}=\{3,4,2\}$.

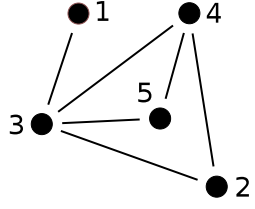

(a) $G$

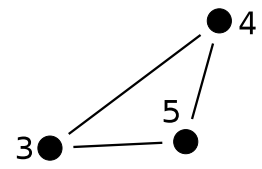

(b) $S_{1}=\{3,4,5\}$

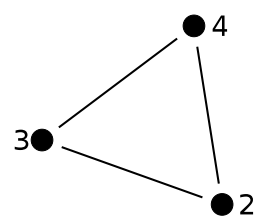

(c) $S_{2}=\{3,4,2\}$

Figura 2.3: Exemplo de cliques em uma rede simples.

\subsubsection{Coeficiente de Agrupamento}

O coeficiente de agrupamento quantifica a densidade de arestas próximas a um vértice. Especificamente, tal medida expressa a presença de ciclos com apenas três vértices, configurando um layout triangular. Pode-se fazer analogia a uma rede de amizades, na qual se $A$ é amigo de $B$ e $B$ é amigo de $E$, existe uma probabilidade de $A$ também ser amigo de $E$. Esse efeito é denominado pelos sociólogos como transitividade. Em outras palavras, o coeficiente de agrupamento define a probabilidade de quaisquer dois vértices, com um vizinho em comum, estarem conectados. O coeficiente de agrupamento $c c_{v}$ de um vértice $v$ é dado pela proporção real de arestas entre vértices dentro de uma vizinhança, dividido pelo número máximo de arestas que poderiam existir entre eles, isto é:

$$
c c_{v}=\frac{2 e_{v}}{|\Gamma(v)|(|\Gamma(v)|-1)},
$$

sendo $e_{v}$ o número de arestas entre os vizinhos de $v$ e $|\Gamma(v)|$ o número de vizinhos de $v$. Caso os vizinhos de $v$ vértices formem um clique, o número de arestas atinge o valor máximo. $\log o, c c_{v}=1$ indica que a vizinhança de $v$ está totalmente conectada. Por outro lado, $c c_{v}$ próximo de 0 significa que existem poucas ou nenhuma aresta entre os vizinhos de $v$. O coeficiente de agrupamento médio da rede $\langle C\rangle$ é definido como a média aritmética entre todos os $c c_{v}$.

$$
\langle C\rangle=\frac{1}{n} \sum_{v=1}^{n} c c_{v},
$$

A maioria das redes do mundo real, principalmente redes sociais, tende a criar grupos densamente conectados, em decorrência, possuem alto $\langle C\rangle$. 


\subsubsection{Coeficiente de Assortatividade}

A assortatividade mensura a correlação entre vértices com características similares. No geral, a assortatividade é relacionada ao grau do vértice, entretanto, outros atributos podem ser selecionados para compor sua definição.

Considere uma rede com $n$ vértices e $P_{k}$ com sendo a probabilidade de escolher aleatoriamente um vértice de grau $k$, como mostra a Equação 2.9 (Newman et al., 2001).

$$
P_{k}=\left(\begin{array}{c}
n-1 \\
k
\end{array}\right) p^{k}(1-p)^{n-1-k}
$$

De outro modo, considere um vértice selecionado a partir de uma aresta escolhida aleatoriamente. Nesse caso, o grau do vértice selecionado não segue a distribuição $p_{k}$. Em oposição, ele é tendencioso em favor dos vértices de alto grau, uma vez que existem mais arestas com extremidades em um vértice de alto grau do que em um vértice de baixo grau. Isto significa que o grau de distribuição para o vértice na extremidade de uma aresta escolhida aleatoriamente é proporcional à $(k+1) p_{k+1}$. Desse modo, define-se a distribuição de graus normalizada $q_{k}$ como (Newman, 2002):

$$
q_{k}=\frac{(k+1) p_{k+1}}{\sum_{j} j p_{j}}
$$

em que o termo $\sum_{j} j p_{j}$ indica um fator de normalização. A matriz de mistura normalizada $E=\left(e_{j, k}\right)$ é uma definição importante para caracterizar a assortatividade, cujo elemento $e_{j, k}$ denota a fração de arestas que conectam vértices do tipo $j$ e $k$, nesse caso, vértices de grau $j$ e $k$. Dado que $\sigma_{q}$ é o desvio padrão da distribuição $q_{k}$, o coeficiente de assortatividade para uma rede não direcionada é definido pela Equação 2.11.

$$
r=\frac{1}{\sigma_{q}^{2}}\left[\sum_{j, k} j k\left(e_{j, k}-q_{j} q_{k}\right)\right]
$$

Para efeitos práticos do cálculo do coeficiente de assortatividade em uma rede real, pode-se reescrever $r$ (Newman, 2002) como mostra a Equação 2.12.

$$
r=\frac{m^{-1} \sum_{i} j_{i} k_{i}-\left[m^{-1} \sum_{i} \frac{1}{2}\left(j_{i}+k_{i}\right)\right]^{2}}{m^{-1} \sum_{i} \frac{1}{2}\left(j_{i}^{2}+k_{i}^{2}\right)-\left[m^{-1} \sum_{i} \frac{1}{2}\left(j_{i}+k_{i}\right)\right]^{2}},
$$

em que $j_{i}$ e $k_{i}$ são os graus das duas extremidades da aresta $i$ selecionada. Valores positivos de $r$ indicam que vértices de grau similar tendem a se relacionar. Valores negativos de $r$ indicam correlação entre vértices de graus diferentes. Logo, $r$ situa-se entre -1 e 1 . Quando $r=1$, a rede apresenta padrões de assortatividade perfeitos; quando $r=0$ a rede é dita não-correlacionada, para $r=-1$ a rede é completamente não-assortativa. 


\subsubsection{Grau de Heterogeneidade}

O grau de heterogeneidade indica o quão sensível é uma rede em relação ao grau de seus vértices, ou seja, é uma medida global da heterogeneidade presente na conectividade da rede, é definida pela Equação 2.13.

$$
H=\frac{\left\langle k^{2}\right\rangle}{\langle k\rangle^{2}}
$$

se a rede é livre de escala $H \rightarrow \infty$, entretanto, para redes homogêneas $H \sim\langle k\rangle$.

\subsection{Modelos de Redes}

Diferentes autores tentaram explicar o processo de formação das redes, propondo diferentes modelos matemáticos. A seguir serão apresentados os três principais modelos: modelo de redes aleatória, modelo do mundo pequeno, e modelo da rede livre de escala.

\subsubsection{Redes Aleatórias}

Erdös \& Rényi (1960) abordaram redes através de estruturas aleatórias, conhecidas por random-graphs networks. Utilizando-se da visão e formalismos da Teoria dos Grafos, os autores estabeleceram, em meados de 1960, o modelo no qual considera-se a aresta entre cada par de vértices com igual probabilidade, produzindo uma rede estatisticamente homogênea, como mostra a Figura 2.4(a).

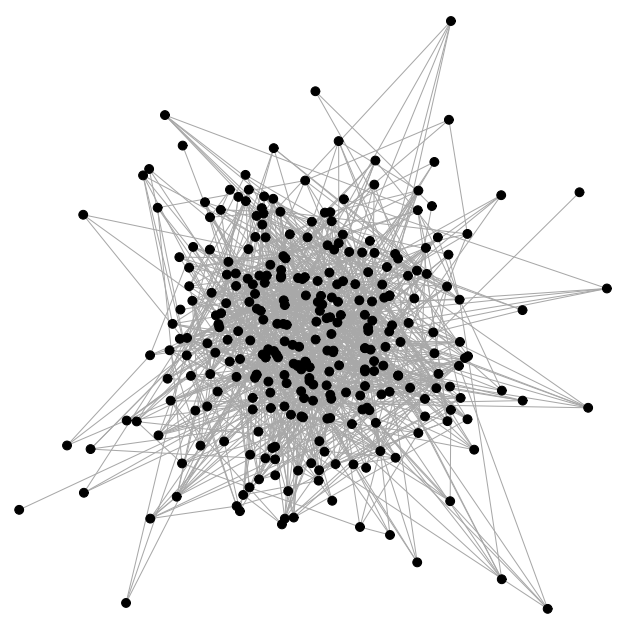

(a) Rede Aleatória

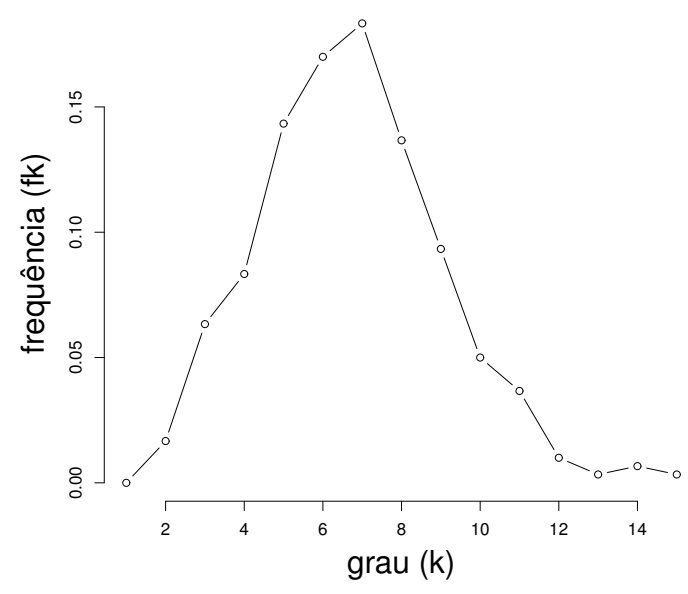

(b) Distribuição de conectividade

Figura 2.4: (a) Rede aleatória com 300 vértices e probabilidade $p=0.02$, gerado com base no modelo de Erdös e Rényi. (b) Distribuição da conectividade da rede (a).

Nas redes aleatórios é incomum encontrar vértices com concentração de arestas muito alta ou muito baixa. Erdös \& Rényi caracterizaram o modelo utilizando apenas os parâmetros $n$ e $p$, que representam o número de vértices e a probabilidade de ligações entre vértices, respectivamente. O grau esperado de um vértice qualquer é definido pela equação $\langle k\rangle=p(n-1)$. A probabilidade de que um vértice selecionado aleatoriamente possua 
grau um fixo $k$ é dado por $P_{k}$, como mostra a Equação 2.9 (Newman et al., 2001).

Ao considerar valores altos para $n$ e conectividade média fixa, a distribuição de ligações aproxima-se do modelo de Poisson, Figura 2.4(b), no qual cada vértice possui um número de arestas próximo a média dos graus. (Newman, 2003b).

\subsubsection{Rede Mundo Pequeno}

Watts \& Strogatz (1998) observaram que as redes reais apresentam tanto características de redes regulares, com alto coeficiente de aglomeração (efeito de vizinhança), quanto de redes aleatórias, com distâncias médias entre dois vértices pequenas. Seus estudos apontaram a necessidade da construção de um modelo mais sofisticado para a análise de redes reais, que complementasse o modelo aleatório sem privar-se das características das redes regulares.

Os autores propuseram um modelo próximo ao de Erdös e Rény, no qual a maior parte das arestas são estabelecidas entre os vizinhos mais próximos. O modelo foi desenvolvido a partir da análise de sistemas sociais, bem como da observação do estudo empírico realizado pelo psico-sociólogo Stanley Milgram (Milgram, 1967). Tal abordagem enfatiza que em uma Rede Social as pessoas, além das relações com seus vizinhos mais próximos, possuem relação com um ou mais pessoas fora de suas vizinhanças, como ilustrado pela Figura 2.5(c). O modelo foi denominado Mundo Pequeno, como analogia ao trabalho de Milgram.

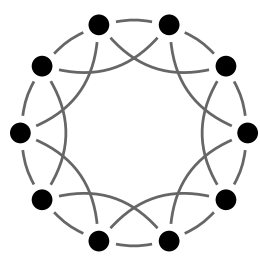

(a) Regular

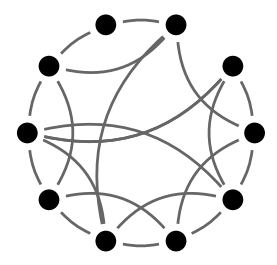

(b) Mundo Pequeno

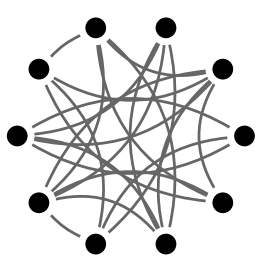

(c) Aleatória

Figura 2.5: Diferentes tipos de redes.

A construção do modelo inicia-se a partir de uma rede regular com $n$ vértices dispostos de modo circular (em forma de anel). Ainda na estrutura inicial são realizadas ligações com os $k$ vizinhos mais próximos. A partir da rede formada, uma fração de vértices são reconectados aleatoriamente. O processo de reconexão consiste em inspecionar todas as ligações da rede e reconectar, com probabilidade $p$, uma das extremidades a um novo vértice escolhido aleatoriamente. Ao final do processo, uma rede com característica de rede regular torna-se uma rede aleatória.

Dado $p=0$, representa-se uma rede regular (Figura 2.5(a)). Para $p=1$, tem-se uma rede aleatória (Figura 2.5(c)). Quando são considerados valores pequenos de $p$, a rede ainda apresenta coeficiente de agrupamento elevado e ao mesmo tempo características das redes de mundo pequeno (Figura 2.5(b)). Constata-se, portanto, que a partir de uma rede 
regular, a reconexão aleatória de um pequeno número de ligações é suficiente para reduzir drasticamente a distância média entre dois pares de vértices.

\subsubsection{Rede Livre de Escala}

Uma descoberta significativa recente no campo de Redes de Complexas foi a observação de que um grande número de redes reais, como a Internet, Word Wide Web, redes metabólicas e redes de proteínas, possuem alguns vértices com grau muito superior a média e muitos vértices com poucas ligações. Barabási et al. (2000) criaram o termo "redes livres de escala" (scale-free) para descrever classes de redes que seguem esse padrão.

Em 1999, pesquisadores da Universidade de Notre Dame, Estados Unidos, estudaram a estrutura da Word Wide Web a fim de analisar o efeito "Mundo Pequeno". Através de mecanismos de recuperação automáticos, conhecidos como Crawler, mapearam as conexões entre as páginas. Ao contrário do que se esperava encontrar, além do efeito "Mundo Pequeno", constatou-se uma topologia caracterizada pela presença de "hubs" (vértices com grau muito superior à média).

A partir das constatações, descobriu-se que a distribuição de ligações não se aproxima do modelo de redes aleatórias, e sim segue a lei de potência $P(k) \sim k^{-\gamma}$, na qual $k$ é o números de arestas (grau) e $\gamma$ é o expoente característico da distribuição, geralmente, $2 \leq \gamma \geq 3$. A Figura 2.6(a) ilustra uma rede seguindo o modelo de Barabási et al. (2000). Nestas redes a probabilidade de um vértice ter $k$ arestas decai conforme $k$ aumenta.

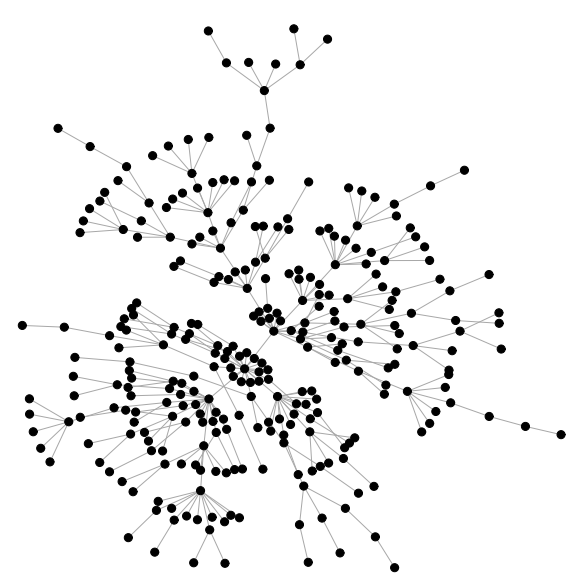

(a) Rede livre de escala

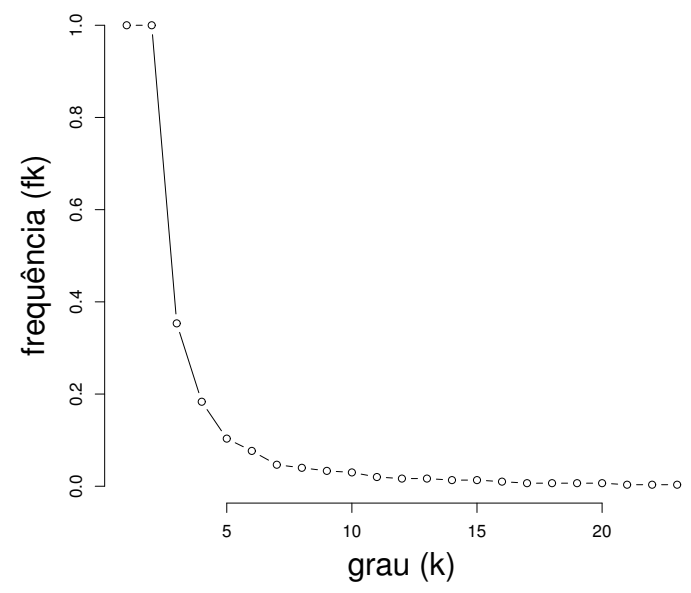

(b) Distribuição de conectividade

Figura 2.6: (a) Representação da rede mostrada em 2.4(a) pelo modelo de rede livre de escala com 300 vértices. (b) Distribuição da conectividade da rede (a).

Como visto, muitos sistemas reais podem ser modelados usando o paradigma de redes complexas, e muitos pesquisadores têm focado em propriedades que tais redes compartilham, tais como transitividade, efeito mundo pequeno e distribuição dos graus. Outra propriedade comum é a presença de estrutura de comunidades, caracterizada por grupos de vértices densamente conectados. No próximo capítulo, são apresentados os principais conceitos e os principais algoritmos relacionados à detecção de comunidades. 


\section{Capítulo \\ 3 \\ Detecção de Comunidades e Refinamento Multinivel}

lguns sistemas reais podem ser modelados usando o paradigma de redes aleatórias, porém, a maioria desses possui padrões de conexão heterogêneos com altos níveis de organização. Por exemplo, em algumas redes, o grau de distribuição segue a lei de potência, na qual vértices de baixo grau coexistem com poucos vértices de alto grau. Do mesmo modo, Girvan \& Newman (2002) apresentaram outra característica relevante presente em muitas redes reais, que é a concentração elevada de arestas dentro de grupos especiais de vértices, formando estruturas modulares locais, denominadas comunidades, também conhecidas como componentes, módulos, partições ou sub-redes.

Segundo Newman (2004a, 2010), as comunidades são constituídas por conjuntos de vértices densamente interconectados e esparsamente conectados com o restante da rede. Sob este ângulo, os vértices pertencentes a uma mesma comunidade, em geral, compartilham propriedades comuns e/ou desempenham papéis semelhantes. Logo, a divisão de uma rede em comunidades auxilia na compreensão de sua estrutura topológica (propriedades estruturais e funcionais) e de seus processos dinâmicos, obtendo informações e características pertinentes ao domínio da rede.

Inclusive, identificar comunidades e suas fronteiras permite classificar os vértices de acordo com sua posição estrutural. Por exemplo, vértices centrais, isto é, que possuem um grande número de arestas com os outros vértices da comunidade da qual fazem parte, podem ter uma função importante de controle e estabilidade dentro da comunidade em questão. Por outro lado, vértices localizados nas fronteiras de comunidades têm um papel importante de mediação, conduzindo as relações e as trocas de informações entre diferentes comunidades (Fortunato, 2010).

Deteç̧ão de comunidades possui importantes aplicações práticas. Um exemplo é a avaliação da estrutura topológica da rede para auxiliar na identificação de grupos de usuários com perfis semelhantes em uma rede social, permitindo o direcionamento de ações de marketing ou recomendação de serviços (Reddy et al., 2002; Yin et al., 2010). Da mesma forma, o agrupamento de clientes web com interesses semelhantes e geograficamente próximos uns dos outros pode melhorar o desempenho dos serviços prestados na 
web (Krishnamurthy \& Wang, 2000). Outro exemplo é a análise dos processos dinâmicos de uma rede usando comunidades, a fim de observar/analisar os aspectos e tendências comportamentais em redes de disseminação, tais como epidemia, inovação e informação (Pietilänen \& Diot, 2012). Além disso, o agrupamento de terminais (vértices) em uma rede de computador permite gerar tabelas de roteamento compactas, nas quais a escolha de vias de comunicação se torna mais eficiente (Steenstrup, 2001).

\subsection{Exemplo introdutório}

A rede Zachary Karate Clube (Zachary, 1977; Girvan \& Newman, 2002; Newman \& Girvan, 2004) é frequentemente utilizada como uma ilustração didática da aplicação de algoritmos de detecção de comunidade. Essa rede modela as interações sociais entre 34 membros de um clube de karatê em uma universidade dos EUA na década de 1970, o qual, devido a um conflito entre o instrutor e o dirigente, foi dividido em dois clubes menores. Zachary observou que era possível prever a repartição dos membros em dois subgrupos, dado apenas os detalhes das interações (arestas) entre os membros do ex-clube. Esse exemplo demonstra a maneira pela qual os algoritmos de detecção de comunidade podem auxiliar a entender a estrutura de uma rede.

A Figura 3.1 ilustra a estrutura de comunidades construída a partir do consenso das observações de Zachary, antes da divisão do clube. O instrutor e o dirigente são representados pelos vértices 1 e 34, respectivamente. Cada grupo é representado por uma forma geométrica, círculo ou quadrado.

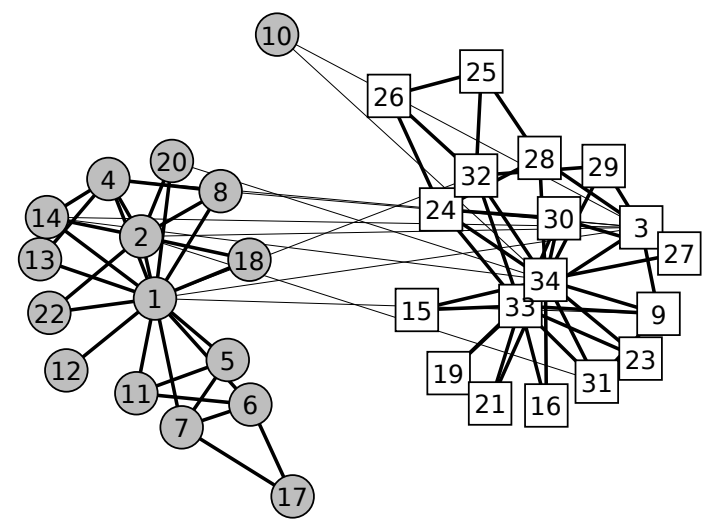

(a)

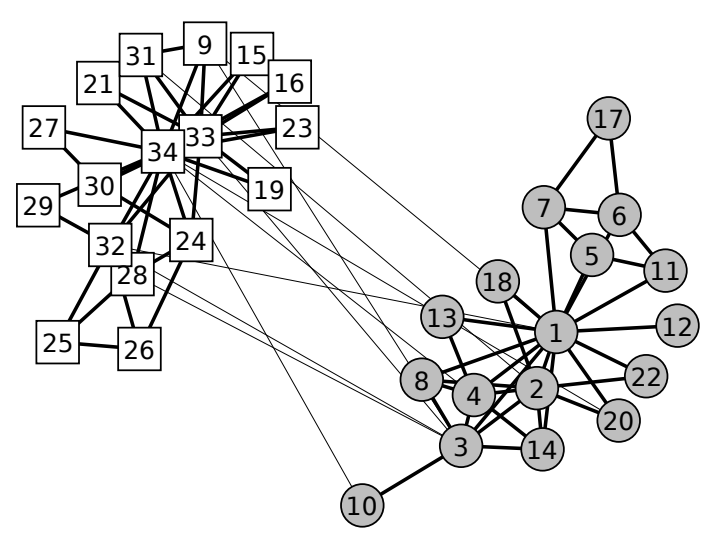

(b)

Figura 3.1: (a) Estrutura de comunidades original da rede Zachary; (b) divisão em comunidades produzida pelo algoritmo fastgreedy de Newman \& Girvan (2004).

A Figura 3.1 destaca a divisão em comunidades produzida pelo algoritmo fastgreedy de Newman \& Girvan (2004). Esta divisão corresponde quase perfeitamente à divisão real dos membros do clube após o desentendimento. Apenas o vértices 3 é agrupado incorretamente. Logo, pode-se concluir que a aplicação do algoritmo de detecção de comunidades, na rede de amizades, é um bom preditor da evolução social da rede. 


\subsection{Definições Básicas}

Formalmente, $P=\left\{P_{1}, \ldots, P_{c}\right\}$ é dado como o particionamento de $V$ em $c$-comunidades disjuntas não-vazias, tal que $P_{i} \cap P_{j}=\emptyset$ para $i \neq j$ e $P_{1} \cup P_{2} \cup \ldots \cup P_{c}=V$. Quando $c=2$, tem-se um bi-particionamento ou bi-secção. A comunidade que contém o vértice $v$ é definida por $P(v) \in P$. O tamanho do conjunto $P$ é definido por $|P|$, bem como $\left|P_{i}\right|$ denota o tamanho da comunidade $P_{i}$. Um particionamento $P$ é considerado trivial se $|P|=1$ ou $|P|=n$. Uma comunidade $P_{i}$ composta apenas por um vértice é chamada de singleton. Considera-se $\overline{P_{i}}=P-P_{i}$ o complemento da comunidade $P_{i} \in P$. Uma aresta incidente em $P_{i}$ possui pelo menos uma de suas extremidades pertencente à $P_{i}$. As arestas com extremidades incidentes em comunidades distintas são denominadas inter-comunidades, e as arestas cujo par de extremidades são incidentes em uma mesma comunidade são denominadas intra-comunidades.

Dado um vértice $v \in P_{i}$, o grau interno e externo de $v$ representam o número de arestas que conecta $v$ com os vértices de $P_{i}$ (Equação 3.1) e com o resto da rede (Equação 3.2), respectivamente. Naturalmente, $k_{v}=k_{v}^{i n t}+k_{v}^{\text {ext }}$. Denomina-se vértice de fronteira, qualquer vértice $v$ que possui pelo menos um vizinho $u$ pertencente a uma comunidade diferente da sua, isto é, $P(v) \neq P(u)$, tal que $e_{u, v} \in E$.

$$
k_{v}^{i n t}=\sum_{v, u \in P_{i}} w_{v, u} \quad(3.1) \quad k_{v}^{e x t}=\sum_{v \in P_{i}, u \in \overline{P_{i}}} w_{v, u}
$$

O grau de uma comunidade $P_{i}$ denota a soma dos graus internos dos vértices contidos em $P_{i}$, como mostra a Equação 3.3. Em contraste, o volume de uma comunidade $P_{i}$ representa a soma dos graus dos vértices contidos em $P_{i}$, dado pela Equação 3.4.

$$
k_{P_{i}}=\sum_{v \in P_{i}} k_{v}^{i n t} \quad(3.3) \quad \operatorname{Vol}_{P_{i}}=\sum_{v \in P_{i}}\left(k_{v}^{i n t}+k_{v}^{e x t}\right)
$$

Considere uma $b i$-secção $P=\left\{P_{1}, P_{2}\right\}$, o número de arestas cujos vértices pertencem a diferentes comunidades é chamado de corte e é definido pela Equação 3.5. Pode-se estender a definição de corte para uma quantidade de comunidades superior à dois, $P=\left\{P_{1}, \ldots, P_{c}\right\}$, com base na Equação 3.6.

$$
\operatorname{corte}\left(P_{1}, P_{2}\right)=\sum_{v \in P_{1}, u \in P_{2}} w_{v, u} \quad(3.5) \quad \operatorname{corte}\left(P_{1}, \ldots, P_{i}\right)=\frac{1}{2} \sum_{1}^{i} \operatorname{corte}\left(P_{i}, \overline{P_{i}}\right)
$$

Existem inúmeras definições na literatura para caracterizar um bom agrupamento; uma definição aceita e popularmente utilizada como função objetivo é que um particionamento ótimo reduz o número de arestas entre as comunidades, isto é, o particionamento que possui o corte mínimo. Sob este ângulo, se $k_{v}^{e x t}=0$, o vértice $v$ possui apenas vizinhos dentro de $P(v)$, assim, a atribuição de $v$ à comunidade atual é provável que seja uma boa 
escolha. Por outro lado, se $k_{v}^{\text {int }}=0$, o vértice $v$ esta separado de $P(v)$ e, provavelmente, deve ser atribuído à outra comunidade.

Entretanto, na prática, optar pelo corte mínimo favorece soluções com comunidades desbalanceadas, o que implica comunidades com poucos vértices e isoladas na rede. A Figura 3.2 expõe esse problema. Para evitar esse viés natural, pode-se utilizar uma função objetivo que considere o tamanho das comunidades encontradas. A seguir são apresentadas duas funções objetivo utilizadas por algoritmos de particionamento:

Corte proporcional: A medida Rcorte, definida pela equação 3.7, expressa o percentual entre o peso das arestas inter-comunidade em relação ao tamanho de cada comunidade (Hagen \& Kahng, 1992).

$$
\operatorname{Rcorte}\left(P_{1}, \ldots, P_{i}\right)=\sum_{1}^{i} \frac{\operatorname{corte}\left(P_{i}, \overline{P_{i}}\right)}{\left|P_{i}\right|}
$$

Corte normalizado: A medida NCorte, definida pela Equação 3.8, expressa o percentual entre o peso das arestas inter-comunidade em relação ao peso das arestas de toda a rede (Shi \& Malik, 2000).

$$
\operatorname{Ncorte}\left(P_{1}, \ldots, P_{i}\right)=\sum_{1}^{i} \frac{\operatorname{corte}\left(P_{i}, \overline{P_{i}}\right)}{\operatorname{Vol}_{P_{i}}}
$$

A Figura 3.2 ilustra a $b i$-secção de uma rede mediante diferentes funções objetivo. As formas (circulo e quadrado) representam objetos de comunidades distintas.

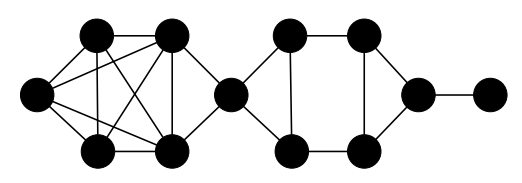

(a)

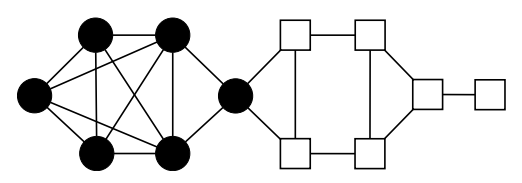

(c)

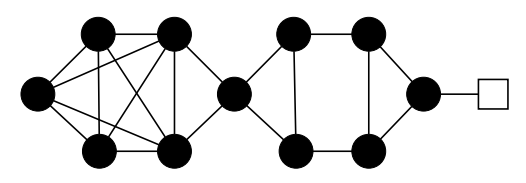

(b)

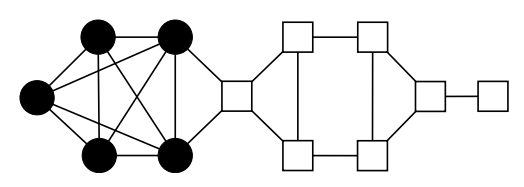

(d)

Figura 3.2: $B i$-secção de uma rede (a) mediante os critérios de: (b) corte mínimo; (c) corte proporcional; e (d) corte normalizado, adaptado de Fan \& Pardalos (2012).

\subsection{Modularidade}

Pode-se avaliar um particionamento $P$ com base na pontuação dada por uma medida de qualidade $Q(P)$, cujo objetivo é avaliar características esperadas em um bom agrupamento. Uma das principais medidas de qualidade usada em redes é a Modularidade (Newman \& Girvan, 2004). Essa medida compara a densidade real de arestas intra-comunidade e inter-comunidade em relação a uma rede aleatória com características semelhantes. A ideia se baseia no fato de que uma rede aleatória não possui estrutura de comunidades. 
Dado que $A_{v, u}$ é um elemento da matriz de adjacência $A$ na linha $v$ e coluna $u$, tal que $A_{v, u}=1$ se existe $e_{v, u}$, e zero caso contrário. Considere que o conjunto de vértices é dividido em comunidades tal que o vértice $v$ pertence a comunidade $P(v)$. Considere ainda que a fração intra-comunidades, isto é, arestas que conectam vértices da mesma comunidade, é dado por:

$$
\frac{\sum_{v, u} A_{v, u} \delta(P(v), P(u))}{\sum_{v, u} A_{v, u}}=\frac{1}{2 m} \sum_{v, u} \delta(P(v), P(u)),
$$

na qual, a função $\delta\left(P_{i}, P_{j}\right)$ é igual a 1 se $P(v)=P(u)$, e zero caso contrário. O número de arestas na rede é representado por $m=\frac{1}{2} \sum_{v u} A_{v, u}$. Logo, a modularidade é definida como:

$$
Q(P)=\frac{1}{2 m} \sum_{v, u}\left[A_{v, u}-\frac{k_{v} k_{u}}{2 m}\right] \delta(P(v), P(u)),
$$

na qual o termo $k_{v} k_{u} / 2 m$ indica a probabilidade da existência de uma aresta entre os vértices $v$ e $u$ caso as conexões sejam feitas ao acaso. Caso um particionamento forneça menos arestas do que seria esperado por conexões aleatórias, o valor da modularidade é zero, indicando que tal divisão é tão boa quanto a existente em uma rede aleatória. Para valores acima de zero, a rede passa a apresentar estrutura de comunidades, ou seja, aumentam-se as chances de que as comunidades não sejam formadas ao acaso. Logo, valores próximos de 1 indicam a formação de comunidades bem definidas. Segundo Newman \& Girvan (2004), valores de $Q \geq 0.3$ indicam uma boa qualidade no particionamento.

\subsection{Algoritmos de detecção de comunidades}

Existem inúmeras abordagens para tratar o problema de detecção de comunidades. O uso de diferentes métodos pode obter diferentes resultados quando aplicados em uma mesma rede. Cada algoritmo possui vantagens e limitações, que envolvem características como qualidade do resultado e tempo de execução. Logo, a escolha do algoritmo adequado depende do contexto da aplicação (Fortunato, 2010). Algumas técnicas populares de detecção de comunidades são: Edge betweenness (Newman \& Girvan, 2004); fastgreedy (Clauset et al., 2004); label propagation (Raghavan et al., 2007); leading eigenvector (Newman, 2006a); optimal community (Brandes et al., 2008); spinglass (Traag \& Bruggeman, 2009) e walktrap (Pons \& Latapy, 2005).

Segundo Schaeffer (2007), os algoritmos de detecção de comunidades podem ser divididos em duas categorias: métodos globais e locais. Os métodos globais utilizam informações de toda a estrutura da rede para obter a divisão em comunidades, porém, tal abordagem pode se tornar inviável quando o tamanho da rede for muito grande e possui estrutura esparsa. Os métodos locais focam na análise sob uma perspectiva parcial da rede (sub-redes), e podem ser utilizados em grandes redes, bem como em redes que não estão explicitamente disponíveis, isto é, exigem uma exploração sob demanda. 
Alternativamente, Fortunato (2010) apresenta os algoritmos de acordo com a estratégia utilizada no processo de formação das comunidades ou seleção de vértices, divididos em: hierárquicos, particionais e espectrais. Essa divisão permite uma melhor compreensão das características de cada grupo de algoritmos, discutidos a seguir.

\subsubsection{Algoritmos hierárquicos}

Em muitas redes reais, as comunidades podem estar ordenadas hierarquicamente. Por exemplo, em uma rede social, as pessoas de uma cidade podem ser agrupadas de acordo com o local em que trabalham, e, do mesmo modo, podem ser subdivididas em departamentos distintos. Logo, a rede possui diferentes níveis de organização. Para esses casos, utiliza-se métodos que induzem comunidades hierarquicamente aninhadas, permitindo a exploração dos dados em diferentes níveis de granularidade.

Uma maneira natural de representar a estrutura hierárquica de uma rede é através de um dendograma, como o ilustrado na Figura 3.3. Nesse exemplo, cada nível da hierarquia define um agrupamento diferente. As comunidades definidas nos níveis superiores contêm as comunidades dos níveis inferiores. Por exemplo, a comunidade $P_{i}=\{3,4,5\}$, no nível III, contém a comunidade $P_{j}=\{4,5\}$ e $P_{k}=\{3\}$, no nível II.
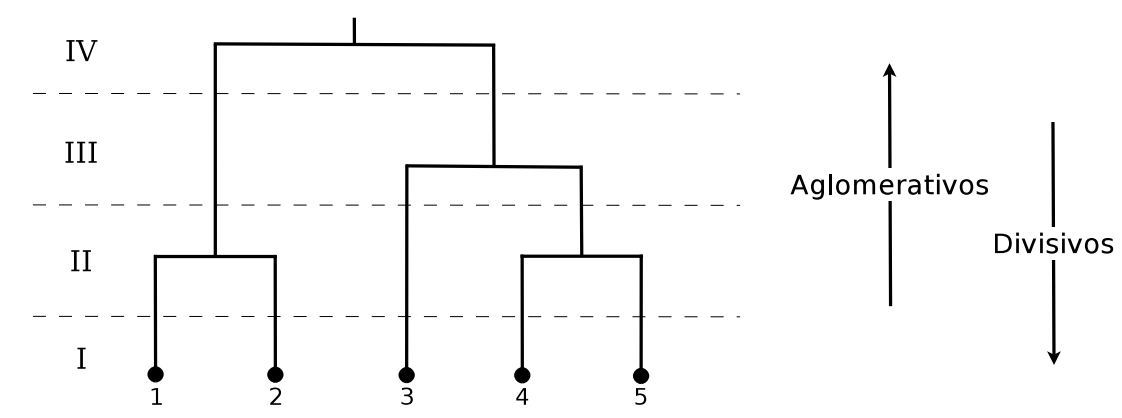

Figura 3.3: Dendograma ou árvore hierárquica. Na parte inferior (nível I), cada vértice corresponde a uma comunidade. Cada corte horizontal, indicado por linhas tracejadas, corresponde a um agrupamento (ou divisão em comunidades) específico.

Cada corte horizontal no dendograma, indicado por linhas tracejadas, corresponde a um agrupamento (ou divisão em comunidades) específico. Cortes próximos à base resultam em um maior número de comunidades, formadas por poucos vértices. Os algoritmos hierárquicos podem ser divididos em:

Divisivos (top-down): Essa estratégia divide a rede de forma iterativa ou recursiva em comunidades cada vez menores. Inicia-se com uma comunidade contendo todos vértices da rede, e, sucessivamente, divide as comunidades até a rede possuir apenas singletons.

Aglomerativos (bottom-up): Essa estratégia inicia com cada vértice constituindo uma comunidade (singletons), em seguida realiza sucessivas uniões formando comunidades maiores, até alcançar uma única comunidade contendo todos os vértices. 
Dentre os algoritmos hierárquicos divisivos, o algoritmo mais popular é o edge betweenness (BT), proposto por (Girvan \& Newman, 2002) (Algoritmo 3.4.1). O algoritmo se baseia na remoção de arestas com alto valor de betweenness (Equação 2.2). A intuição, é que as arestas com alto grau de intermediação, possivelmente, servem de "ponte" entre comunidades diferentes. O calcula do grau de intermediação de todas as arestas $m$ em uma rede de $n$ vértices é realizado em tempo $O(m n)$. Uma vez que este cálculo deve ser repetido para a remoção de cada aresta, a complexidade do BT, no pior caso, é de $O\left(m^{2} n\right)$.

\section{Algoritmo 3.4.1: Edge betweenness}

Entrada: rede $G$

1 dendograma $D \leftarrow \emptyset$;

2 calcular o grau de intermediação para todas as arestas de $G$;

3 repita

$4 \quad$ remover a aresta com maior valor de betweenness;

$5 \quad$ recalcular o betweenness para as arestas remanescentes;

6 atualizar $D$;

7 até até a rede possuir apenas singletons;

8 retorna $D$

Em relação aos algoritmos hierárquicos aglomerativos, o fastgreedy (FG), de Clauset et al. (2004), é amplamente utilizado (Algoritmo 3.4.2). Inicialmente, Newman (2004b) propôs um algoritmo aglomerativo hierárquico baseado na otimização da Modularidade $Q$. O algoritmo considera uma rede desconexa com $n$ vértices, na qual, inicialmente, cada vértice representa uma comunidade distinta (singletons). Posteriormente, Clauset et al. (2004) destacaram que o algoritmo de Newman (2004b) envolve um grande número de operações desnecessárias, devido à dispersão da matriz de adjacência. Estas operações podem ser realizadas com mais eficiência usando estruturas de dados específicas para matrizes esparsas, como max-heaps, que reorganizam os dados na forma de árvores binárias.

\section{Algoritmo 3.4.2: Fastgreedy}

Entrada: rede $G$

1 dendograma $D \leftarrow \emptyset$;

2 calcular o valor inicial de $Q$ para a rede;

3 calcular os valores de $\Delta Q$ para cada possível união;

4 preencher o max-heap $H$ com os valores de $\Delta Q$;

5 repita

6 unir o par de comunidades $i$ e $j$ com maior $\Delta Q_{i, j}$ em $H$;

7 atualizar $D, \Delta Q$, max-heap e incrementar o valor $Q \operatorname{com} \Delta Q_{i, j}$;

8 até até obter apenas 1 comunidade;

9 retorna $D$

A cada iteração duas comunidades selecionadas são agrupadas de forma a maximizar a 
variação da Modularidade $\Delta Q_{i, j}$ (Equação 3.12), isto é, $\Delta Q_{i, j}$ mensura a variação de $Q$ ao unir as comunidade $i$ e $j$.

Para simplificar o algoritmo, Clauset et al. (2004) definem algumas relações: $e_{i, j}$ é a fração de arestas na rede que conectam vértices da comunidade $i$ a vértices da comunidade $j$, e $a_{i}=\sum_{j} e_{i j}$ representa a fração de arestas incidentes nos vértices da comunidade $i$. Além disso, o traço da matriz de adjacência $\operatorname{Tr} e=\sum_{i} e_{i, i}$ fornece a fração de arestas na rede que conectam vértices na mesma comunidade $i$. Assim, temos que:

$$
Q=\sum_{i}\left(e_{i, i}-a_{i}^{2}\right)
$$

Como o Algoritmo 3.4.2 inicia com cada vértice sendo o único membro de uma comunidade, temos que $e_{i, j}=1 / 2 m$ e $a_{i}=k i / 2 m$. Assim, inicialmente, defini-se a variação $\Delta Q_{i, j}$ como:

$$
\Delta Q_{i, j}= \begin{cases}1 / 2 m-k_{i} k_{j} /(2 m)^{2} & \text { se } i \text { e } j \text { estão conectados } \\ 0 & \text { caso contrário }\end{cases}
$$

Em uma rede com $n$ vértices e $m$ arestas o FG tem complexidade de $O(m h \log n)$, sendo $h$ a profundidade do dendograma. Para redes esparsas $(m \sim n)$ e hierárquicas, o algoritmo tem complexidade de $O\left(n \log ^{2} n\right)$.

Os métodos hierárquicos não requerem que seja definido, a priori, o número de comunidades ideal. Esse valor é estabelecido com base na análise do dendograma. No caso dos algoritmos BT e FG, ambos inferem o número de comunidades ideal a partir do valor máximo de $Q$.

\subsubsection{Algoritmos particionais ou planos}

Em algumas aplicações, o número de comunidades é conhecido a priori, logo, há pouca utilidade em encontrar a hierarquia da rede. Nesse caso, é relevante recorrer a algoritmos particionais, que produzem uma divisão plana e disjunta da rede, na qual uma única estrutura de comunidades é obtida, isto é, não há traço de uma hierarquia. Algoritmos particionais são úteis para grandes conjuntos de dados, nos quais a construção de um dendograma é inviável ou proibitiva.

Uma das principais desvantagens dos métodos hierárquicos é a limitação em executar ajustes, ou seja, a capacidade de modificar e melhorar um agrupamento previamente obtido. Essa limitação impede que decisões ruins possam ser corrigidas em iterações futuras. Por outro lado, algoritmos particionais podem revisitar as comunidades depois de terem sido construídas, melhorando gradualmente o particionamento da rede.

O k-means (Algoritmo 3.4.3) é um dos algoritmos particionais mais utilizado. Esse, é um algoritmo iterativo que minimiza a soma das distâncias de cada vértice ao centróide ${ }^{1}$ em cada comunidade. Os centróides iniciais, em geral, são escolhidos aleatoriamente,

\footnotetext{
${ }^{1} \mathrm{O}$ centróide representa, tipicamente, o ponto médio em uma comunidade.
} 
portanto, os resultados variam de uma execução para outra. O k-means executa até que a função objetivo não se altere, altere muito pouco, ou até que o número de iterações máximo pré-determinado tenha sido alcançado.

\section{Algoritmo 3.4.3: K-means}

Entrada: rede $G, k$ centróides

1 particionamento $P \leftarrow \emptyset$;

2 escolher aleatoriamente um número $k$ de centróides para as comunidades;

3 repita

$4 \quad$ atribuir cada objeto para a comunidade $P$ cujo centróide seja mais próximo;

$5 \quad$ mover cada centróide para o ponto médio da comunidade correspondente;

6 até até que algum critério de convergência seja obtido;

7 retorna $P$

\subsubsection{Algoritmos espectrais}

Os métodos espectrais são baseados na análise dos autovalores, autovetores e propriedades algébricas por meio das representações matriciais de uma rede. Por exemplo, em teoria espectral, frequentemente, a representação da rede é dada pela matriz Laplaciana, construída com base na Equação 3.13, e sua relação com a matriz de adjacência se dá pela Equação 3.14.

$$
L_{v, u}= \begin{cases}k_{v} & \text { se } v=u \\ -1 & \text { se } v \neq u \text { e existe a aresta } e_{v, u}, \quad(3.13) \quad L=D-A \\ 0 & \text { caso contrário, }\end{cases}
$$

onde $D$ é a matriz diagonal formada a partir dos graus dos vértices na rede, isto é, $D_{v, v}=$ $k_{v} \forall v \in V$, e $A$ é a matriz de adjacência da rede. No entanto, existem outras definições para a matriz Laplaciana, por exemplo, a matriz Laplaciana Normalizada Generalizada $L_{G}$ $=D^{\frac{1}{2}} L D^{\frac{1}{2}}$. A escolha da melhor definição depende do contexto do problema (Fortunato, 2010). A Figura 3.4 ilustra um exemplo da representação de uma rede, Figura 3.4(a), a partir da matriz Laplaciana, Figura 3.4(c), cuja diagonal possui o grau de cada vértice.

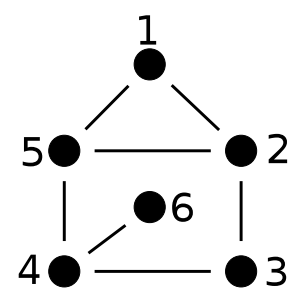

(a)

$$
A=\left[\begin{array}{llllll}
0 & 1 & 0 & 0 & 1 & 0 \\
1 & 0 & 1 & 0 & 1 & 0 \\
0 & 1 & 0 & 1 & 0 & 0 \\
0 & 0 & 1 & 0 & 1 & 1 \\
1 & 1 & 0 & 1 & 0 & 0 \\
0 & 0 & 0 & 1 & 0 & 0
\end{array}\right]
$$

(b)

$$
L=\left[\begin{array}{cccccc}
2 & -1 & 0 & 0 & -1 & 0 \\
-1 & 3 & -1 & 0 & -1 & 0 \\
0 & -1 & 2 & -1 & 0 & 0 \\
0 & 0 & -1 & 3 & -1 & -1 \\
-1 & -1 & 0 & -1 & 3 & 0 \\
0 & 0 & 0 & -1 & 0 & 1
\end{array}\right]
$$

Figura 3.4: Representação de uma rede (a) pelas matrizes de adjacência (b) e Laplaciana (c). 
Formalmente, dada uma matriz $L_{n, n}$, dizemos que $\lambda \in \mathcal{R}^{n}$ é autovalor de $L$ se existe um vetor $\vec{\gamma} \neq 0$ tal que $L \vec{\gamma}=\lambda \vec{\gamma}$. Em decorrência, $\vec{\gamma}$ é um autovetor de $\lambda$. O espectro Laplaciano é o conjunto de autovalores da matriz Laplaciana, geralmente, definido em ordem crescente, spec $=\left\{\lambda_{0} \geq \lambda_{1} \geq \ldots \geq \lambda_{n}\right\}$.

Existe uma série de propriedades algébricas e estruturais de redes que podem ser deduzidas a partir do espectro Laplaciano. Por exemplo, Fiedler (1973) mostrou que uma rede é conexa se, e somente se, o seu segundo menor autovalor Laplaciano $\lambda_{2}$ é positivo. O autovetor $\vec{\gamma}_{2}$ associado ao $\lambda_{2}$ é chamado de vetor de Fiedler. Além disso, $\lambda_{2}$ é denominado conectividade algébrica e desempenha um papel relevante em inúmeras aplicações. Outra propriedade, pode-se encontrar o número de componentes conexas da rede com base na multiplicidade do autovalor zero $\lambda_{0}$. No geral, todas as informações relevantes para determinar o agrupamento são obtidas a partir dos autovetores.

Os algoritmos de agrupamento espectral apresentam uma estrutura comum, como apresentado no Algoritmo 3.4.4. Nesse algoritmo, caso a matriz utilizada seja a de Laplace Normalizada $L \vec{\gamma}$, serão escolhidos os menores autovetores. Além disso, o número de autovetores calculados varia entre os vários algoritmos de particionamento espectral.

Algoritmo 3.4.4: Algoritmo Genérico para Agrupamento Espectral

Entrada: rede $G$

1 particionamento $P \leftarrow \emptyset$;

2 crie a matriz de Laplace $L$ a partir da rede $G$;

3 calcule os menores autovetores $\left\{\vec{\gamma}_{1}, \ldots, \vec{\gamma}_{k}\right\}$ de $L$ associados aos menores autovalores;

4 interprete os autovetores $\left\{\vec{\gamma}_{1}, \ldots, \vec{\gamma}_{k}\right\}$ gerando o agrupamento $P$;

5 retorna $P$

Em um trabalho relacionado Shi \& Malik (2000) desenvolveram um algoritmo de particionamento espectral utilizado em segmentação de imagens. A estratégia busca minimizar a função objetivo Ncorte (Equação 3.8) com base na análise do autovetor de Fiedler. Outro algoritmo espectral muito utilizado é o leading eigenvector (LE), proposto por Newman (2006a). O método se baseia na análise do espectro obtido pela matriz de modularidade $B$, definida por:

$$
B_{v, u}=w_{v, u}-\frac{k_{v} k_{u}}{2 m}
$$

onde $w_{v, u}$ corresponde ao peso da aresta entre os vértices $v$ e $u$. O método analisa o autovetor $\vec{\gamma}$ associado ao maior autovalor positivo da matriz de modularidade. A separação de dois vértices é definida pelo sinal corresponde a cada vértice em $\vec{\gamma}$. Vértices com sinais diferentes são incluídos em comunidades distintas. Caso todos os elementos de $\vec{\gamma}$ tenham o mesmo sinal, significa que a rede não possui estrutura de comunidades. 


\subsection{Estratégia multinível de detecção de comunidades}

As abordagens tradicionais de detecção de comunidades envolvem a otimização de uma função objetivo, como minimização do corte entre comunidades; os métodos espectrais são mais complexos de serem implementados e o cálculo dos autovetores pode ser computacionalmente caro, principalmente, quando é necessário obter o autovetor de Fiedler, segundo Karypis \& Kumar (1998b).

Alguns algoritmos utilizam técnicas para melhorar a eficácia da solução, porém tal abordagem é caracterizada pelo elevado custo computacional, limitando sua aplicação a casos de dimensionalidade não muito elevada. Por outro lado, existem algoritmos voltados a escalabilidade e baixo custo computacional, contudo a maioria apresenta limitações na solução gerada.

Recentemente, surgiram várias pesquisas sobre estratégias multinível para particionar redes com elevada quantidade de vértices e arestas (Bichot, 2013). O objetivo dessas estratégias é reduzir o custo do algoritmo de detecção de comunidades aplicando-o sobre uma versão reduzida da rede original. Pesquisas empíricas demonstraram que essa estratégia permite avaliar algoritmos com alto custo computacional de tempo e espaço em grandes redes, sem impacto significativo na qualidade da solução (Karypis \& Kumar, 1995a, 1998b; Almeida \& Lopes, 2009; Noack \& Rotta, 2009; LaSalle \& Karypis, 2013; Valejo et al., 2014b). Considerando uma rede original $G_{0}$, essa estratégia, possui três fases, descritas a seguir.

Contração: Nessa etapa é criada uma sequência de $N$ aproximações, $G_{1}, G_{2}, \ldots, G_{N}$, cada vez mais reduzida da rede original $G_{0}$, de modo que $\left|V_{0}\right|>\ldots>\left|V_{N}\right|$ (Seção 3.5.1).

Particionamento: Nessa etapa a rede $G_{N}$ é particionada em $c$-comunidades disjuntas usando algum algoritmo de detecção de comunidades (Seção 3.5.2).

Projeção: Nessa etapa a solução obtida em $G_{N}$ é projetada, sucessivamente, através das redes intermediárias, $G_{N-1}, G_{N-2}, \ldots, G_{0}$, até a rede original $G_{0}$ (Seção 3.5.3).

O Algoritmo 3.5.1 resume a abordagem multinível. Nesse algoritmo, $G_{0}$ indica a rede original, a qual é reduzida enquanto não for pequena o suficiente. Este passo é definido através de um número pré-determinado de níveis. Em cada nível, o fator de redução $(r f)$ define o número de pares de vértices contraídos. Além disso, cada nível pode reduzir $G_{i}$ em, no máximo, $50 \%$ do tamanho de $G_{i-1}$.

As linhas 2-5 indicam a fase de contração, a qual é repetida até que a rede do tamanho desejado seja atingida, o que pode ser definido pela quantidade absoluta de vértices, uma porcentagem do tamanho original da rede ou um certo número de iterações. A linha 6 corresponde ao particionamento da rede. As linhas 7-10 representam a fase de projeção, que é executada sucessivamente até a rede original. Nessa fase, é possível refinar a solução, a fim de melhorar a qualidade do particionamento, linha 9. 
Algoritmo 3.5.1: Algoritmo multinível de detecção de comunidades

Entrada: rede $G_{0}$, fato de redução $r f$

$1 G_{i} \leftarrow G_{0}$, inteiro $i \leftarrow 0$, vetor $C \leftarrow \emptyset$;

2 repita

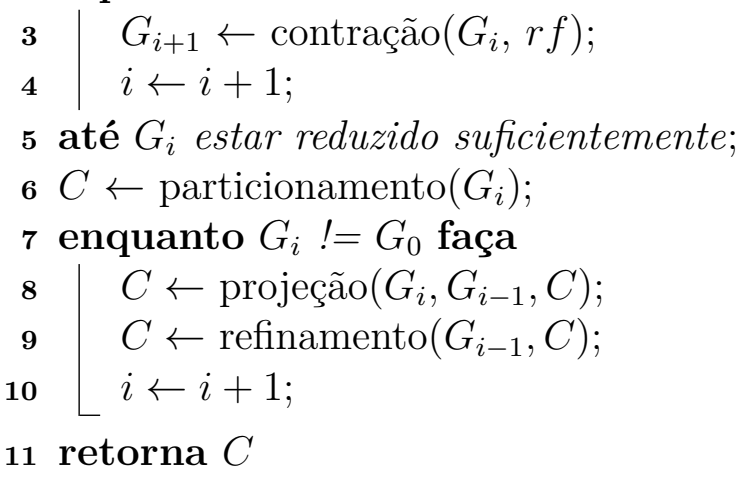

Por exemplo, para avaliar um algoritmo com complexidade de tempo quadrática em uma rede de grande escala, com 1 milhão de vértices, poder-se-ia adotar 10 níveis com fator de redução $r f=50 \%$. Nesse caso, a rede reduzida passa a ter aproximadamente 1.000 vértices. No Algoritmo 3.5.1, as três fases que formam a estratégia são representadas pelas funções: "contração()", "particionamento()" e "projeção()", e são detalhadas nas próximas subseções.

\subsubsection{Contração}

Na fase de contração, a rede $G_{0}$ é reduzida sucessivamente em uma sequência de aproximações, $G_{1}, G_{2}, \ldots, G_{N}$, de tal forma que $\left|V_{0}\right|>\left|V_{1}\right|>\ldots>\left|V_{N}\right|$, isto é, a cada nível o número de vértices e arestas diminui. A contração da rede pode ser obtida de diversas maneiras. Em geral, um conjunto de vértices $V_{i}$ de $G_{i}$ são combinados, formando um super-vértice $s V$ na rede reduzida $G_{i+1}$. Para que uma rede seja uma boa representação de sua versão original, o peso do vértice $s V=\{v, u\} \in V_{i+1}$ é dado pela soma dos pesos dos vértices $v$ e $u \in V_{i}$. Além disso, a fim de preservar as informações de conectividade, as arestas de $s V$ são obtidas pela união das arestas incidentes em $v, u \in V_{i}$. Esse processo é ilustrado na Figura 3.

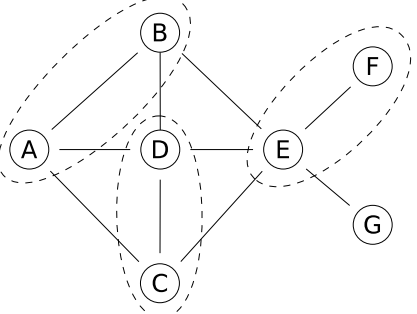

(a) $G_{i}$

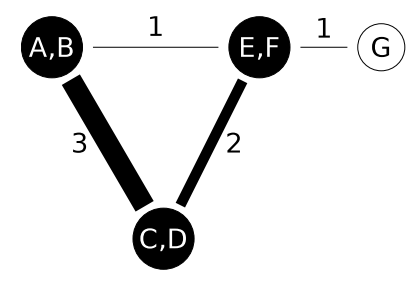

(b) $G_{i+1}$

Figura 3.5: Processo de contração de pares de vértices uma rede. As elipses tracejadas representam o conjunto de pares de vértices candidatos a contração. Em $G_{i}$, o peso das arestas é 1 . 
O conjunto de pares de vértices candidatos à contração (super-vértice), geralmente, é obtido com base em algum algoritmo de seleção de matching (conjunto de pares de vértices selecionados). A seguir são apresentados quatro métodos populares de seleção de matching.

Random Matching (RM): O método RM utiliza um algoritmo aleatório para encontrar o conjunto de vértices candidatos à contração. Os vértices são visitados aleatoriamente. Para cada vértice $v$ não marcado, o algoritmo busca entre seus vizinhos algum vértice $u$ que ainda não esteja marcado. Caso a condição seja satisfeita, os vértices $v$ e $u$ selecionados são marcados e adicionados ao matching.

Heavy-edge Matching (HEM): No método HEM o objetivo é selecionar o grupo de vértices que reduza ao máximo o peso das arestas na rede $G_{N}$. Essa estratégia utiliza um algoritmo randômico semelhante ao RM. Entretanto, o HEM seleciona o vértice $u$ adjacente a $v$, cuja aresta $e_{u, v}$ tenha maior peso.

Modified Heavy-edge Matching (MHEM): O MHEM, uma versão modificada do HEM, também utiliza um método aleatório para selecionar vértices candidatos ao matching. Entretanto, o vértice adjacente $u$ selecionado será o mais similar a $v$, por exemplo, pode-se selecionar o vértice $u$ que possua maior número de vértices vizinhos em comum com $v$.

Light Edge Matching (LEM): O objetivo da estratégia LEM é obter a rede reduzida com o maior grau médio. Ao contrário do HEM, o LEM busca maximizar o peso das arestas na rede $G_{N}$, incluindo no matching pares de vértices cujas arestas possuem menor peso.

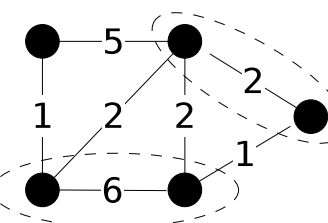

(a)

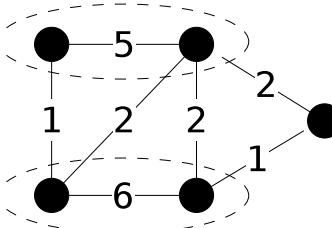

(b)

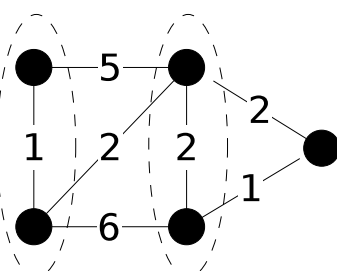

(c)

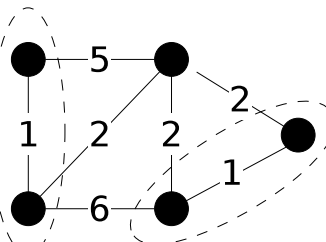

(d)

Figura 3.6: Diferentes estratégias de seleção de matching: (a) Random Matching; (b) Heavyedge Matching; (c) Modified Heavy-edge Matching e (d) Light Edge Matching.

O Algoritmo 3.5.2 sumariza o processo de contração com base na estratégia Heavy Edge Matching (HEM) (Karypis \& Kumar, 1995a). Nesse algoritmo, $G_{i}$ é a rede a ser contraída. O fator de redução $(r f)$ limita o número de pares de vértices contraídos. Quando $r f=0.5$ (valor máximo em cada nível), o número de vértices da rede é reduzido à metade. Com base nisso, o tamanho do conjunto de vértices a serem contraídos (mergeCount) é definido pelo fator de redução $(r f)$ multiplicado pelo número de vértices em $G_{i}$. 


\section{Algoritmo 3.5.2: Contração}

Entrada: rede $G_{i}=\left(V_{i}, E_{i}\right)$, fator de redução $r f$

1 mergeCount $\leftarrow r f *$ número de vértices $G_{i}+1$;

$2 V_{i+1}, E_{i+1} \leftarrow \emptyset$;

3 enquanto mergeCount $>0$ faça

$4 \quad$ selecione um vértice aleatório $v \in V_{i}$;

$5 \quad$ selecione a aresta $(v, u) \in E_{i}$ com maior peso;

$6 \quad$ remover $v$ e $u$ de $V_{i}$;

$7 \quad$ adicionar $s V=\{v, u\}$ em $V_{i+1}$;

$8 \quad w(s V)=w(v)+w(u)$;

$9 \quad$ para cada edge $(v, z) \in E_{i}$ faça

10 remover $(u, z)$ de $E_{i}$;

13 Adicionar em $V_{i+1}$ e $E_{i+1}$ os vértices e arestas não contraídos;

14 retorna $G_{i+1}=\left(V_{i+1}, E_{i+1}\right)$

A linha 1 define o critério de parada do algoritmo de contração. As linhas 4-6 mostram o processo de seleção do par de vértices com base na aresta mais pesada. As linhas 78 indicam a criação do super-vértice. Por fim, a projeção da conectividade de $G_{i+1}$, a partir de $G_{i}$, é apresentada nas linhas 9-12. A complexidade do HEM é linear em relação ao número de arestas, isto é, $O(m)$. Esta fase representa a função "contração()" no Algoritmo 3.5.1.

\subsubsection{Particionamento inicial}

Esta fase é responsável por encontrar o conjunto inicial de comunidades $P$ na rede $G_{N}$. Considerando uma rede $G_{N}$ como parâmetro de entrada e um vetor $P$ como saída (representando o conjunto de comunidades de $G_{N}$ ), diferentes algoritmos de detecção comunidades podem ser utilizados. Dependendo da configuração da fase de contração, a rede $G_{N}$ pode pequena o suficiente para aplicar algoritmos computacionalmente caros sem impacto no desempenho geral (Karypis \& Kumar, 1995a). Por exemplo, pode-se utilizar algoritmos hierárquicos, particionais, espectrais, dentre outros. Esta fase é implementada pela função "particionamento()" no Algoritmo 3.5.1.

\subsubsection{Projeção}

Durante o processo de projeção, a rede particionada $G_{N}$ é sucessivamente expandida até a rede original $G_{0}$. Em cada nível, o super-vértice $s V \in V_{i+1}$ é expandido em seus vértices de origem $v, u \in V_{i}$. As arestas que ligam os $s V$ são distribuídas entre $u$ e $v$ mantendo a estrutura original. Da mesma forma, $P$ é projetado através dos níveis intermediários, $G_{N-1}, G_{N-2}, \ldots, G_{0}$, até a rede original $G_{0}$. Ao decompor um $s V$, seus vértices de origem $u$ e $v$ são adicionados à comunidade $P(s V)$. O Algoritmo 3.5.3 resume o processo de projeção para cada nível. 


\section{Algoritmo 3.5.3: Projeção}

Entrada: rede $G_{i}$, rede $G_{i-1}$

1 para cada $s V \in G_{i}$ faça

$2 \quad(v, u) \leftarrow$ expandir $s V$;

$3 \quad$ adicionar $v, u \in G_{i-1}$ à comunidade $P(s V)$;

4 retorna $G_{i-1}$

A Figure 3.7 ilustra um exemplo de projeção e o problema do mínimo local. Dado um particionamento, Figure 3.7(a), $P=\left\{P_{i}, P_{j}\right\}$, onde $P_{i}=\{1,3,4, s V\}$ e $P_{j}=\{6,7,8,9\}$, tal que $s V=\{2,5\}$. Após o processo de projeção, Figura 3.7(b), tem-se $P_{i}=\{1,2,3,4,5\}$ e $P_{j}=\{6,7,8,9\}$.

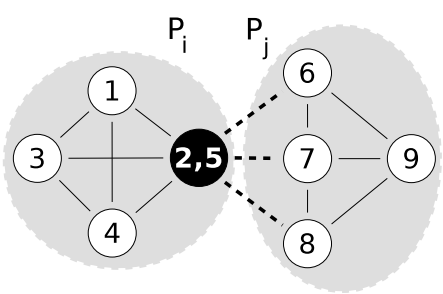

(a) $G_{i}$

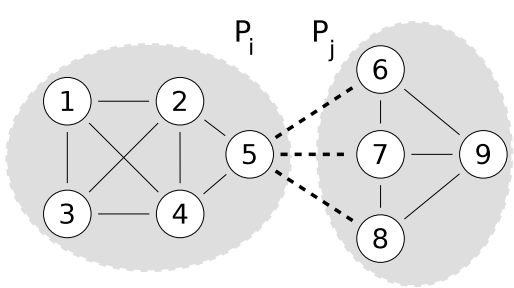

(b) $G_{i-1}$

Figura 3.7: Processo de projeção multinível. As linhas tracejadas representam arestas entre comunidades distintas.

Essa fase seria muito simples caso a projeção direta da partição de $G_{N}$ para $G_{0}$ levasse a um particionamento local ideal. Entretanto, o particionamento em $G_{i}$ pode ser de baixa qualidade quando projetado em $G_{i-1}$, dado que, $G_{i-1}$ apresenta um número maior de arestas e vértices (Bichot, 2013). Portanto, nessa fase é possível refinar o particionamento obtido em cada nível, movendo vértices entre comunidades adjacentes. Esse processo é realizado usando heurísticas de refinamento local, descritas a seguir.

\subsection{Refinamento multinível}

Como afirmado anteriormente, um algoritmo de refinamento pode ser acoplado à fase de projeção. Esse processo é feito através de operações locais, movendo vértices entre comunidades (veja a Figura 1.3). Dado um particionamento $P=\left\{P_{1}, P_{2}\right\}$, o objetivo é selecionar $P_{1}^{\prime} \subset P_{1}$ e $P_{2}^{\prime} \subset P_{2}$, de modo que o novo particionamento obtido $P^{\prime}=$ $\left\{\left[\left(P_{1}-P_{1}^{\prime}\right) \cup P_{2}^{\prime}\right],\left[\left(P_{2}-P_{2}^{\prime}\right) \cup P_{1}^{\prime}\right]\right\}$ maximize ou minimize o valor da função objetivo, por exemplo, o corte mínimo (Karypis \& Kumar, 1995b).

Durante a fase de projeção, o algoritmo pode atingir um particionamento que esteja em um mínimo local (ou ótimo local²), no qual qualquer operação pode aumentar ou manter o número de arestas entre as comunidades, e, consequentemente, diminuir a qualidade da solução. Entretanto, embora $G_{i}$ esteja em um mínimo local, o particionamento projetado

\footnotetext{
${ }^{2}$ Um agrupamento em que uma heurística gananciosa não pode melhorar a qualidade é chamado de ótimo local.
} 
em $G_{i-1}$ pode não estar, dado que, $G_{i-1}$ possui um grau maior de liberdade, ou seja, maior número de arestas a serem analisadas (Karypis \& Kumar, 1998a,b; Valejo et al., 2014b).

Considere o exemplo ilustrado pela Figure 3.7, e assumindo o problema de minimização do corte, nota-se que o particionamento em $G_{i}$ (Figura 3.7(a)) está em um mínimo local, pois, não é possível reduzir o número de arestas entre as comunidades. Por outro lado, em $G_{i-1}$ (Figura 3.7(b)), o particionamento não está em um mínimo local, pois, é possível diminuir o número de arestas entre as comunidades, movendo o vértice 5 da comunidade $P_{i}$ para $P_{j}$. Logo, é possível melhorar a qualidade da solução utilizando heurísticas de refinamento local.

Existem vários métodos de refinamento, sendo que todos possuem duas características em comum: i. começar a partir de um particionamento existente; e ii. a otimização deve ser local. Além disso, dado que o refinamento não pertence ao processo multinível padrão, sua inclusão não deve prejudicar a escalabilidade do algoritmo, isto é, o refinamento deve, por exemplo, ter complexidade de tempo linear. A seguir, são apresentadas as principais heurísticas de refinamento.

\subsubsection{Kernighan-Lin}

Na literatura a maioria das abordagens de refinamento são baseadas no algoritmo de Kernighan-Lin (KL) (Kernighan \& Lin, 1970). O KL realiza operações contínuas sob os vértices entre comunidades adjacentes. O objetivo é reduzir o corte e manter o balanceamento das comunidades em uma $b i$-secção. A complexidade do KL é $O\left(n^{3}\right)$, porém, pode ser reduzida para $O(|E| \log |E|)$ ao utilizar estruturas de dados adequadas (Fiduccia \& Mattheyses, 1982).

Considere uma bi-secção $P=\left\{P_{1}, P_{2}\right\}$ perfeitamente equilibrada, ou seja, $P_{1}$ e $P_{2}$ possuem o mesmo número de vértices. O método introduz dois conceitos: o custo interno e o custo externo de $v$ na comunidade $P_{i}$, dado pelo grau interno $k_{v}^{i n t}$ e externo $k_{v}^{\text {ext }}$ de $v$, respectivamente. Seja $D(v)$ a diferença entre o custo interno e o custo externo de $v$. Tais conceitos são definidos por:

$$
D(v)=k_{v}^{e x t}-k_{v}^{i n t}
$$

Além disso, considere dois vértices pertencentes à comunidades distintas, $v^{1} \in P_{1} \mathrm{e}$ $v^{2} \in P_{2}$. O ganho $g$ resultante da permuta dos vértices entre as comunidades é definido por:

$$
g\left(v^{1}, v^{2}\right)=D\left(v^{1}\right)+D\left(v^{2}\right)-2 w_{v^{1}, v^{2}}
$$

O Algoritmo 3.6.1 sumariza o processo de refinamento com base no modelo proposto por Kernighan \& Lin (1970). Considere uma bi-secção $P=\left\{P_{1}, P_{2}\right\}$ perfeitamente equilibrada, tal que $P_{1}=\left\{v_{i}^{1} \mid 1 \leq i \leq n / 2\right\}$ e $P_{1}=\left\{v_{j}^{2} \mid 1 \leq j \leq n / 2\right\}$. O algoritmo encontra 
uma série ótima de operações de troca mútua entre os elementos de $P_{1}$ e $P_{2}$ que maximiza $g$. Considere que o algoritmo execute $q$ iterações. Inicialmente, calcula-se os conjuntos ordenados $D_{1}$ e $D_{2}$ com base na Equação 3.18.

$$
\begin{aligned}
& D_{1}=D\left(v_{1}^{1}\right) \geq D\left(v_{2}^{1}\right) \geq \ldots \geq D\left(v_{n / 2}^{1}\right) \\
& D_{2}=D\left(v_{1}^{2}\right) \geq D\left(v_{2}^{2}\right) \geq \ldots \geq D\left(v_{n / 2}^{2}\right)
\end{aligned}
$$

Os vértices $v_{i}^{1}$ e $v_{j}^{2}$, selecionados na iteração $q$ e bloqueados, não serão analisados nas próximas iterações, portanto, os valores de $D_{1}$ e $D_{2}$ devem ser recalculados considerando apenas os vértices desbloqueados e a nova $b i$-secção $P^{\prime}=\left\{P_{1}-v_{i}^{1}, P_{2}-v_{j}^{2}\right\}$, Equação 3.19 .

$$
\begin{aligned}
& D_{1}^{\prime}\left(v^{1}\right)=D_{1}\left(v^{1}\right)+2 w_{v^{1}, x}-2 w_{v^{1}, x} \forall x \in P_{1}-v_{i}^{1} \\
& D_{2}^{\prime}\left(v^{2}\right)=D_{2}\left(v^{2}\right)+2 w_{u^{2}, x}-2 w_{v^{2}, x} \forall x \in P_{2}-v_{j}^{2}
\end{aligned}
$$

A iteração termina quando não há mais vértices desbloqueados. Em seguida, executa-se as operações de troca, gerando um novo particionamento $P$ refinado.

\section{Algoritmo 3.6.1: Kernighan Lin}

Entrada: rede $G=\{V, E\}, b i$-secção $P=\left\{P_{1}, P_{2}\right\}$

$1 E_{1} \leftarrow \emptyset ; E_{2} \leftarrow \emptyset ; G \leftarrow \emptyset ;$

\section{2 repita}

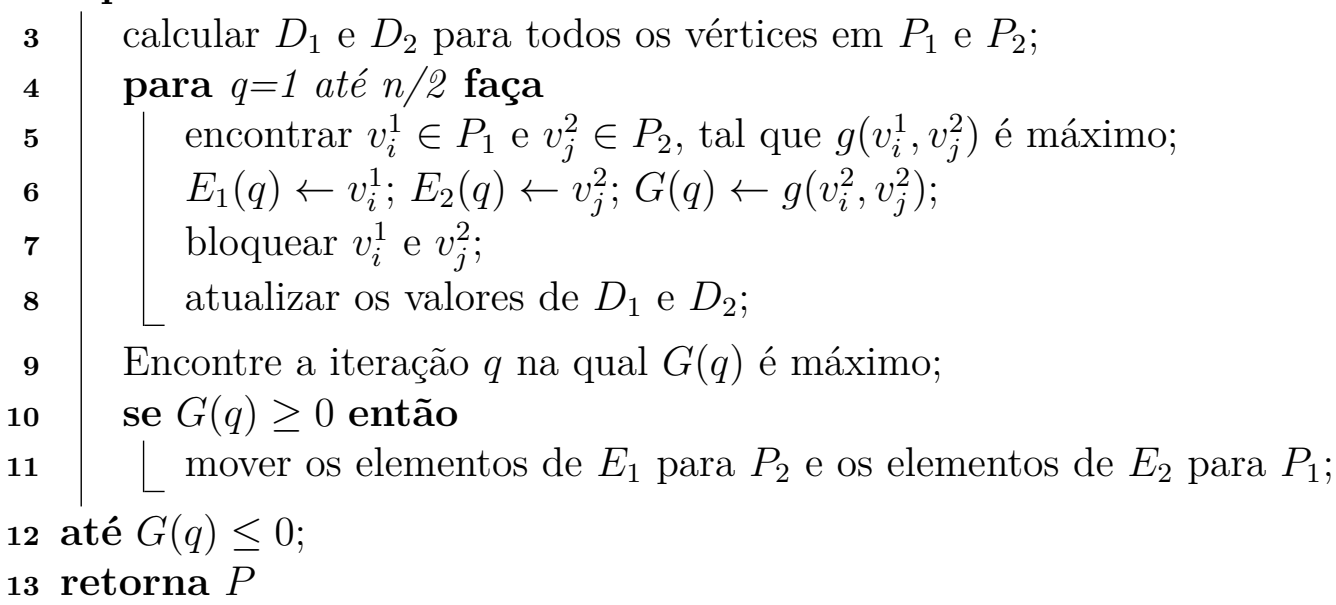

Uma das desvantagens desse algoritmo é sua limitação a uma $b i$-secção, bem como as duas comunidades devem ser perfeitamente equilibradas. Outra desvantagem é que o KL analisa todos os pares de vértices, tornando o processo computacionalmente caro. Além disso, segundo Kernighan \& Lin (1970), o KL é mais rápido e mais eficiente se a $b i$-secção inicial tem boa qualidade. Apesar das limitações, o KL foi um dos precursores da área e serve como base teórica para a maioria dos algoritmos de refinamento da literatura. 


\subsubsection{Fidducia Matheyses}

Uma das primeiras adaptações do KL e, também, uma das mais populares, foi o algoritmo de refinamento FM, proposto por Fiduccia \& Mattheyses (1982), cujo objetivo é particionar um hipergrafo ${ }^{3}$. No entanto, o algoritmo também é limitado a uma $b i$-secção.

O FM é uma heurística iterativa que utiliza o conceito de ganho proposto por Kernighan \& Lin (1970). Uma das vantagens do FM, em relação ao KL, é possibilidade de lidar com comunidades desequilibradas, isto é, comunidades com número de vértices diferentes. Essa vantagem possibilita movimentar um único vértice de cada vez, ao contrário do KL, que necessita movimentar pares de vértices, a fim de manter o equilíbrio das comunidades. Outra vantagem, é a utilização de uma estrutura de dados especial capaz de atualizar o ganho dos vértices e movimentar vértices entre comunidades em tempo hábil.

Essa estrutura de dados consiste em manter, para cada $b i$-secção, uma tabela ordenada de ganhos $T_{g}^{1}$ e $T_{g}^{2}$. Em especial, uma lista duplamente encadeada é associada a cada posição de $T_{g}^{1}$ e $T_{g}^{2}$. Essa lista duplamente encadeada contém os vértices cujos ganhos correspondem a posição das listas em $T_{g}^{1}$ ou $T_{g}^{2}$. Por exemplo, na Figura 3.8, os vértices $v_{1}^{1} \in P_{1}$ e $v_{2}^{2} \in P_{2}$ possuem um ganho de 2 e 3 , respectivamente, portanto formam as listas em $T_{g}^{1}$ ou $T_{g}^{2}$ nas respectivas posições.

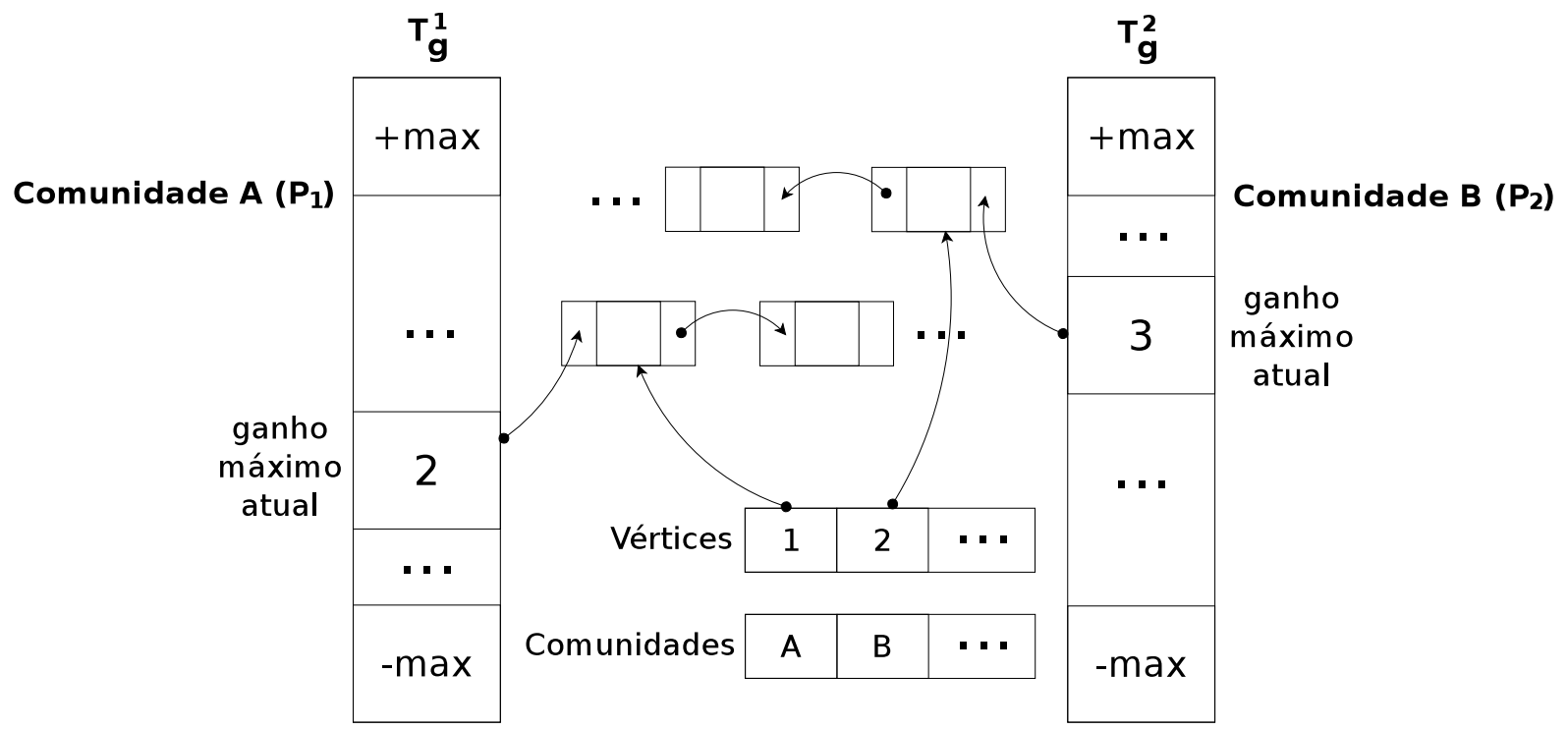

Figura 3.8: Estrutura de dados utilizada pelo FM, adaptado de Fiduccia \& Mattheyses (1982).

Com base nessa estrutura, o acesso a um vértice é executado em tempo constante, e sua transferência de um ganho para outro, durante a atualização dos ganhos, também é executado em tempo constante. Entretanto, a inicialização do ganho para cada vértice tem complexidade $O(m)$.

\footnotetext{
${ }^{3} \mathrm{Um}$ hipergrafo é uma generalização de um grafo, no qual uma aresta pode ligar quaisquer quantidade positiva de vértices, isto é, uma aresta pode ter várias extremidades.
} 


\subsubsection{Otimização da Modularidade}

Uma das abordagens de refinamento mais utilizada e pesquisada é a baseada na variação da modularidade $\Delta Q$. Essa abordagem realiza o refinamento local movendo vértices individuais entre comunidades adjacentes, de modo que a Modularidade $Q$ aumente. Formalmente, a variação da modularidade $\Delta Q_{v \rightarrow P_{j}}$ em relação à mudança de um vértice $v$ da comunidade $P_{i}$ para $P_{j}$ é dado por:

$$
\Delta Q_{v \rightarrow P_{j}}=\frac{k_{v}^{P_{j}}-k_{v}^{P_{i}}}{k_{G}}-\frac{k_{v}\left(k_{P j} k_{P_{i / v}}\right)}{2 k_{G}^{2}},
$$

onde $k_{v}$ é o grau do vértice $v, k_{v}^{P_{j}}$ é o grau externo de $v$ em uma comunidade $P_{j}, k_{v}^{P_{i}}=k_{v}^{i n t}$ define o grau interno de $v$ na comunidade $P_{i}, k_{G}$ é a soma do peso de todas as arestas da rede $G, k_{P_{j}}$ é o grau da comunidade $P_{j}$ e $k_{P_{i} / v}$ ou $k_{P_{i}-v}$ corresponde ao grau da comunidade $P_{i}$ sem o vértice $v$ (Newman, 2006b; Schuetz \& Caflisch, 2008; Ye et al., 2008; Rotta \& Noack, 2011).

A primeira definição do refinamento baseado na otimização da Modularidade foi em Newman (2006b). O algoritmo proposto é uma variação do KL, e também é limitado a uma $b i$-secção. O Algoritmo 3.6.2 descreve de forma resumida o processo de refinamento com base na maximização da Modularidade. A variável de entrada $i t r_{\max }$ determina o número de iterações máxima que o algoritmo executa sem que haja variação de Modularidade. O algoritmo executa até que algum critério de convergência seja obtido, por exemplo, número máximo de iterações ou qualquer variação positiva no valor da Modularidade.

Algoritmo 3.6.2: Kernighan Lin baseado na modularidade

Entrada: rede $G=\{V, E\}, b i$-secção $P=\left\{P_{1}, P_{2}\right\}$, itr $\max$

1 repita

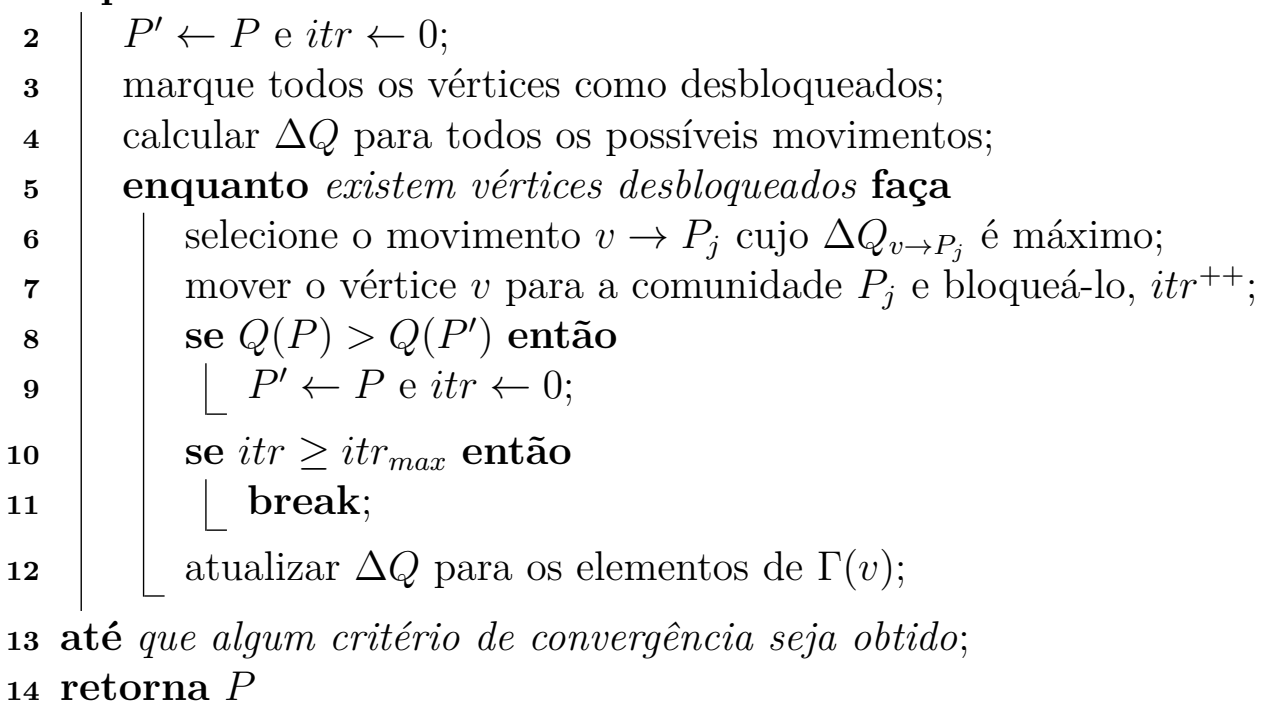

Do mesmo modo, outros trabalhos também exploraram o conceito de Modularidade 
no processo refinamento. Schuetz \& Caflisch (2008) propuseram um algoritmo de refinamento, chamado vertex mover (VM). O algoritmo analisa a lista de vértices em ordem crescente de grau, e cada vértice é movido para a comunidade adjacente com o $\Delta Q$ máximo. Analogamente, Ye et al. (2008) também apresentaram uma abordagem baseada na maximização da Modularidade. Ainda, Rotta \& Noack (2011) analisaram empiricamente heurísticas de contração e refinamento multinível que priorizam a Modularidade. Uma características de tais algoritmos é que todos podem ser executados em redes com $c$-comunidades desbalanceadas.

Ao analisar tais trabalhos, é possível observar que existem duas versões eficientes e eficazes de algoritmos de refinamento baseados na Modularidade: Complete Greedy (RCG) e Fast Greedy (RFG). No entanto o RFG mostrou ser mais estável e rápido quando aplicado em redes com diferentes características e de tamanhos variados.

O Algoritmo 3.6.3 (RCG) calcula todos os possíveis movimentos de vértices entre comunidades, em seguida, executa o movimento $\Delta Q_{v \rightarrow P_{j}}$ máximo até que não haja mais movimentos positivos, isto é, $\Delta Q_{v \rightarrow P_{j}} \leq 0$. Os vértices são movidos em tempo constante usando um vetor de mapeamento entre vértices e comunidades. Para calcular todas os possíveis movimentos entre vértices e comunidades, todos os $n$ vértices e $m$ arestas são visitados pelo menos uma vez, além disso, o peso de cada aresta pode ser adicionado em uma árvore de busca $O(\log n)$. Portanto, no pior caso, o algoritmo executa em $O(n m \log n)$.

\section{Algoritmo 3.6.3: Refinamento Complete Greedy RCG}

Entrada: rede $G=\{V, E\}$, particionamento $P$

1 calcular $\Delta Q$ para todos os possíveis movimentos;

2 repita

$3 \quad$ selecione o movimento $v \rightarrow P_{j}$ cujo $\Delta Q_{v \rightarrow P_{j}}$ é máximo;

$4 \quad$ se $\Delta Q_{v \rightarrow P_{j}}>0$ então

$5 \quad\left\lfloor\right.$ mover o vértice $v$ para a comunidade $P_{j}$;

6 atualizar $\Delta Q$ para os elementos de $\Gamma(v)$;

7 até $\Delta Q_{v \rightarrow P_{j}} \leq 0$

8 retorna $P$

O Algoritmo 3.6.4 (RFG), em contraste com o Complete Greedy, percorre todos os vértices um a um, e encontra o melhor movimento para cada um deles separadamente. A ideia se baseia no fato de que encontrar o melhor movimento para um vértice em particular é, consideravelmente, mais rápido do que encontrar o melhor movimento de um vértice considerando toda a rede, como no caso do Complete Greedy. O RFG possui complexidade $O(m \log n)$.

Ambos os algoritmos foram baseados na implementação de Rotta \& Noack (2011) e suas complexidades podem ser garantidas utilizando a estrutura de dados proposta por Blondel et al. (2008). A seguir outros algoritmos relevantes de refinamento local são apresentados. 


\section{Algoritmo 3.6.4: Refinamento Fast Greedy (RFG)}

Entrada: rede $G=\{V, E\}$, particionamento $P$

1 calcular $\Delta Q$ para todos os possíveis movimentos;

2 repita

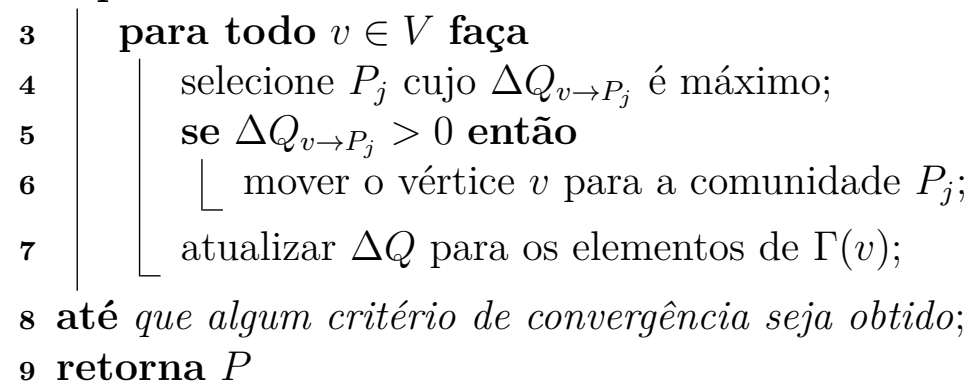

\subsubsection{Outros algoritmos}

Em muitos contextos, o particionamento não está limitado a uma $b i$-section, no entanto refinar $c$-comunidades é mais complexo do que refinar uma $b i$-section, pois aos vértices podem mover-se para várias comunidades (Rotta \& Noack, 2011), aumentando o espaço combinatório.

Uma das primeiras adaptações do algoritmo de KL para refinar $c$-comunidades foi proposto por Sanchis (1989), porém, em um contexto de hipergrafos. Hendrickson \& Leland (1995) propuseram um algoritmo multinível para $c$-comunidades utilizando uma estratégia de refinamento local, no entanto, a complexidade do algoritmo depende do número de comunidades, ou seja, $O(\mathrm{~cm})$, consequentemente, este algoritmo pode ser usado apenas quando $c$ é pequeno.

Outra classe de algoritmos de refinamento, variações do KL, buscam exclusivamente minimizar o número de arestas entre comunidades com base no grau dos vértices (Karypis \& Kumar, 1998b; Walshaw \& Cross, 2000; LaSalle \& Karypis, 2013). Tais algoritmos, em comum, buscam manter o balanceamento entre as comunidades. Karypis \& Kumar (1998b) propuseram um algoritmo (KK), onde a complexidade é independente do número de comunidades. O KK, utiliza o conceito de ganho com base no grau dos vértices para movimentá-los entre comunidades adjacentes. Sua principal vantagem, em relação aos demais algoritmos da literatura, é que as operações de refinamento são realizadas apenas em vértices de fronteira. Essa abordagem se baseia em: se $k_{v}^{e x t}=0$, o vértice $v$ possui apenas vizinhos dentro de $P(v)$, assim, a atribuição de $v$ a comunidade atual é provável que seja uma boa escolha, portanto, não há necessidade de analisá-lo. Por outro lado, se $k_{v}^{e x t}>0$, o vértice $v$ possui uma probabilidade de ser atribuído à outra comunidade, e deve ser considerado no processo de refinamento. Avaliações empíricas demostraram que, apesar da simplicidade, o KK produz um particionamento de alta qualidade em tempo hábil.

Além disso, Karypis \& Kumar (1998b) modificaram o conceito de ganho considerando um fator de balanceamento entre as comunidades. Seja $W$ um vetor de $c$ elementos, tal que $c$ é o total de comunidades, e $W\left[P_{i}\right]$ é o peso da partição $P_{i}$ em uma rede $G$. Além 
disso, $W_{\min }=0.9 n / i$ e $W_{\max }=C n / c$. Um vértice $v$, cujo peso é $w_{v}$ pode ser deslocado à uma comunidade $P_{j}$ adjacente, caso cumpra duas restrições:

$$
\left\{\begin{array}{l}
W_{i}\left[P_{j}\right]+w_{v} \leq W_{\max } \\
W_{i}\left[P_{i}\right]+w_{v} \leq W_{\min }
\end{array}\right.
$$

onde $C$ é um fator de desiquilíbrio entre as comunidades. Se $C=1$, cada partição deve ter o mesmo peso. Por exemplo, caso $C=1.03$, o fator de desiquilíbrio é de $3 \%$. A primeira condição certifica que o movimento de um vértice não torna o peso da comunidade que irá recebê-lo seja superior à $W_{\max }$. A segunda condição garante que nenhuma comunidade fique com poucos vértices.

É fundamental destacar que, embora as soluções propostas para o refinamento multinível se mostrem eficientes, as mesmas não concentram esforços em explorar características inerentes em certos tipos de redes. As abordagens habituais focam em definições gerais de um agrupamento ótimo, sendo que a maioria se concentra em minimizar o conceito de corte ou maximizar a Modularidade. Nesse sentido, no próximo capítulo é apresentado um algoritmo de refinamento baseado em similaridade de vizinhança, que difere das soluções existentes pois explora a elevada transitividade e assortatividade presente em muitas redes reais, em particular, em redes sociais. 


\section{Capítulo}

\section{Refinamento multinivel baseado em similaridade de vizinhança}

este capítulo é apresentado um algoritmo de refinamento com base na similaridade de vizinhança, RSim, que realiza operações locais com base nos conceitos de assortatividade e transitividade, em particular, presentes em redes sociais. Para isso, foram utilizadas como base medidas de similaridade local entre pares de vértices, que observam as relações entre os vizinhos que dois vértices compartilham para determinar a similaridade entre eles (Lü \& Zhou, 2011; Yin et al., 2010; Valverde-Rebaza \& Lopes, 2012, 2013). Em vista disso, as medidas de similaridade usadas como base da proposta são sumarizadas, em seguida, o algoritmo RSim é descrito, uma análise de suas propriedades e complexidade computacional também são realizadas. Por fim, é apresentada uma extensão do RSim baseada no coeficiente de agrupamento.

\subsection{Medidas de similaridade}

No contexto de redes complexas, medidas de similaridade quantificam as características que dois vértices compartilham e podem ser definidas usando atributos de vértices. Por exemplo, dois vértices são considerados similares se possuem muitos vizinhos em comum, ou se possuem o mesmo grau. As medidas de similaridade que se baseiam unicamente na estrutura da rede observada são denominadas medidas de similaridade estrutural (ou topológica), e podem ser classificadas como: similaridade baseada em informações locais ou globais (consulte Lü \& Zhou (2011) para mais detalhes).

Liben-Nowell \& Kleinberg (2003) e Zhou et al. (2009) compararam sistematicamente uma série de medidas de similaridade estrutural em redes reais. Segundo os autores, as medidas baseadas em informações globais usam todas as informações topológicas disponíveis a partir da rede e, consequentemente, podem ser mais eficazes que medidas baseadas em informações locais. No entanto seu cálculo é computacionalmente custoso e, normalmente, inviável para redes de grande escala. Alternativamente, medidas locais utilizam apenas informações sobre pares de vértices, e, consequentemente, possuem menor custo computacional, porém, são menos eficazes que as medidas globais. 
Visto que um algoritmo de refinamento deve realizar otimização local e, além disso, ter baixa complexidade, torna-se inviável a utilização de medidas de similaridade global para essa finalidade. Considerando este aspecto, avaliou-se apenas a utilização de medidas que consideram apenas informações locais.

Dentre as medidas de similaridade local, a principal, denominada vizinhos comuns (CN), mensura a quantidade de vizinhos comuns que existem entre um par vértices $u$ e $v$, e é definida por $S_{v, u}^{C N}=\left|\Lambda_{v, u}\right|=|\Gamma(v) \cap \Gamma(u)|$. No geral, as demais medidas utilizam como base o cálculo da medida $\mathrm{CN}$, porém, adicionam um fator de ponderação, maximizando alguma propriedade ou atributo de interesse. As medidas mais populares são: Salton (Sal), Jaccard (Jac), Sorensen (Sor), Hub Promovido (HP), Hub deprimido (HD), LeichtHolme-Newman (LHN), Adâmica-Adar (AA) e Alocação de Recursos (RA), sumarizadas na Tabela 4.1.

Entretanto, outra característica importante dos algoritmos de refinamento é iniciar a partir de um particionamento existente. Sob este aspecto, recentemente, foram propostas algumas medidas de similaridade que usam outras informações da rede, tais como informações sobre a comunidade dos vértices. Valverde-Rebaza \& Lopes (2012) propuseram medidas de similaridade híbridas com base em informações locais das comunidades: A medida WIC e as medidas da forma W, que possuem como base o conceito de vizinhança entre pares de vértices em relação a cada comunidade. Por definição, tais medidas podem ser utilizadas no processo de refinamento, visto que, existe um particionamento inicial de boa qualidade.

Considere que $\Lambda_{v, u}=\Lambda_{v, u}^{W} \cup \Lambda_{v, u}^{I}$, em que $\Lambda_{v, u}^{W}=\left\{z \in \Lambda_{v, u} \mid v, u, z \in P_{i}\right\}$ indica o conjunto de vizinhos comuns interno (W) e seu complemento $\Lambda_{v, u}^{I}=\Lambda_{v, u}-\Lambda_{v, u}^{W}$ representa o conjunto de vizinhos comuns externo (I). Portanto, $\Lambda_{v, u}^{W} \cap \Lambda_{v, u}^{I}=\emptyset$. Com base nessas definições, pode-se definir a medida WIC e as medidas da forma $W$.

\subsubsection{Medidas da forma $W$}

As medidas da forma $W$ correspondem à reformulação das medidas de similaridade local usando informações apenas dos vizinhos comuns intra-comunidade ao invés de contabilizar todos os vizinhos comuns na rede. A Figura 4.1 ilustra a diferença entre $\Lambda_{v, u}, \Lambda_{v, u}^{W}$ e $\Lambda_{v, u}^{I}$.

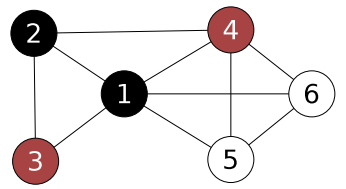

(a) $\Lambda_{1,2}=|\{3,4\}|=2$

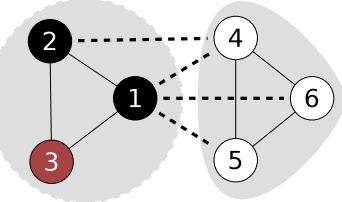

(b) $\Lambda_{1,2}^{W}=|\{3\}|=1$

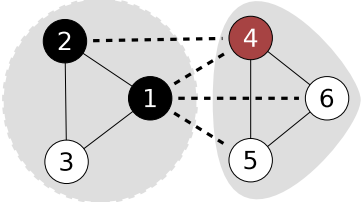

(c) $\Lambda_{1,2}^{I}=|\{4\}|=1$

Figura 4.1: Diferença entre a medida $\Lambda_{v, u}$ tradicional e as medidas híbridas $\Lambda_{v, u}^{W}$ e $\Lambda_{v, u}^{I}$ que utilizam informações de comunidades.

Os vizinhos comuns intra-comunidade (W) capturam os relacionamentos existentes entre vértices que pertencem a mesma comunidade. Por outro lado, os vizinhos comuns 
inter-comunidade (I) capturam os relacionamentos existentes entre vértices que pertencem à diferentes comunidades. Desse modo, os índices de similaridade foram reformulados usando o conjunto de vizinhos $W$ do par de vértices $v$ e $u$, isto é, $\Lambda_{v, u}^{W}$, sumarizados na Tabela 4.1.

\begin{tabular}{|l|l|l|}
\hline Medida & Definição Padrão & Definição na Forma $W$ \\
\hline \hline Vizinhos comuns (CN) & $S_{v, u}^{C N}=|\Gamma(v) \cap \Gamma(u)|=\left|\Lambda_{v, u}\right|$ & $S_{v, u}^{\mathrm{CN}-\mathrm{W}}=\left|\Lambda_{v, u}^{W}\right|$ \\
Salton (Sal) & $S_{v, u}^{S a l}=\frac{\left|\Lambda_{v, u}\right|}{\sqrt{k(u) \times k(y)}}$ & $S_{v, u}^{\mathrm{Sal}-\mathrm{W}}=\frac{\left|\Lambda_{v, u}^{W}\right|}{\sqrt{k(u) \times k(y)}}$ \\
Jaccard (Jac) & $S_{v, u}^{J a c}=\frac{\left|\Lambda_{v, u}\right|}{|\Gamma(x) \cup \Gamma(y)|}$ & $S_{v, u}^{\mathrm{Jac}-\mathrm{W}}=\frac{\left|\Lambda_{v, u}^{W}\right|}{|\Gamma(x) \cup \Gamma(y)|}$ \\
Sorensen (Sor) & $S_{v, u}^{S o r}=\frac{2\left|\Lambda_{v, u}\right|}{k(x)+k(y)}$ & $S_{v, u}^{\mathrm{Sor}-\mathrm{W}}=\frac{2\left|\Lambda_{v, u}^{W}\right|}{k(x)+k(y)}$ \\
Hub Promovido (HP) & $S_{v, u}^{H P}=\frac{\left|\Lambda_{v, u}\right|}{\min \{k(x), k(y)\}}$ & $S_{v, u}^{\mathrm{HP}-\mathrm{W}}=\frac{\left|\Lambda_{v, u}^{W}\right|}{\min \{k(x), k(y)\}}$ \\
Hub deprimido (HD) & $S_{v, u}^{H D}=\frac{\left|\Lambda_{v, u}\right|}{\max \{k(x), k(y)\}}$ & $S_{v, u}^{\mathrm{HD}-\mathrm{W}}=\frac{\left|\Lambda_{v, u}^{W}\right|}{\max \{k(x), k(y)\}}$ \\
Leicht-Holme-Newman (LHN) & $S_{v, u}^{L H N}=\frac{\left|\Lambda_{v, u}\right|}{k(u) \times k(y)}$ & $S_{v, u}^{\mathrm{LHN}-\mathrm{W}}=\frac{\left|\Lambda_{v, u}^{W}\right|}{k(u) \times k(y)}$ \\
Adâmica-Adar (AA) & $S_{v, y}^{A A}=\sum_{z \in \Lambda_{v, u} \frac{1}{\log k(z)}}$ & $S_{v, y}^{\mathrm{AA}-\mathrm{W}}=\sum_{z \in \Lambda_{v, u}, \frac{1}{\log k(z)}}$ \\
Alocação de Recursos (AR) & $S_{v, y}^{R A}=\sum_{z \in \Lambda_{v, u} \frac{1}{k(z)}}^{\mathrm{RA}-\mathrm{W}}=\sum_{z \in \Lambda_{v, u} \frac{1}{k(z)}}$ \\
\hline
\end{tabular}

Tabela 4.1: Medidas de similaridade local e suas respectivas definições na forma $W$.

\subsubsection{Medida WIC}

A WIC utiliza as informações dos vizinhos comuns intra-comunidade e dos vizinhos comuns inter-comunidades do par $u$ e $v$ avaliado. Considerando que cada vértice pertence a uma única comunidade, o WIC é definido por:

$$
S_{v, u}^{W I C}= \begin{cases}\left|\Lambda_{v, u}^{W}\right| & \text { se } \Lambda_{v, u}^{W}=\Lambda_{v, u} \\ \left|\Lambda_{v, u}^{W}\right| /\left|\Lambda_{v, u}^{I}\right| & \text { caso contrário }\end{cases}
$$

\subsection{RSim}

O RSim é um algoritmo de refinamento para $c$-comunidades não balanceadas, baseado na otimização de medidas de similaridade local híbridas entre vértices. O objetivo é maximizar a transitividade e a assortatividade no processo de refinamento. Para isso, o RSim usa como base a medida WIC e as medidas da forma $W$.

Cabe salientar que, inicialmente, essas medidas foram definidas no contexto de previsão links (Valverde-Rebaza \& Lopes, 2012), cuja pontuação $S_{v, u}$ é calculada para qualquer par $e_{v, u} \notin E$. Uma vez que o objetivo não é prever futuras conexões, mas melhorar a solução de um particionamento inicial com base nas conexões existentes, a similaridade 
é calculada para qualquer par $e_{v, u} \in E$, levando em conta todas as comunidades para as quais $v$ e $u$ possam ser movidos.

O Algoritmo 4.2.1 descreve os passos do RSim. Semelhante ao KK (algoritmo de refinamento baseado no corte mínimo, vide Seção 3.6.4), o RSim também utiliza o conceito de fronteira para minimizar o tempo de execução do algoritmo. Um vértice $v$ pode moverse para qualquer uma das comunidades nas quais possua uma aresta incidente, isto é, comunidades que fazem fronteira com $v$. Tais comunidades formam o conjunto $D_{v}$. Desse modo, para cada vértice de fronteira $v$ calcula-se seu ganho para todas as comunidades em $D_{v}$, definido como:

$$
g_{s i m}\left(v, P_{i}\right)=\frac{1}{k_{P_{i}}} \sum_{u \in P_{i}} S_{v, u}^{W},
$$

em que $S_{v, u}^{W}$ indica uma medida de similaridade da forma $W$ ou a WIC. Logo, o RSim permite o uso de diferentes medidas, porém, é limitado às medidas baseadas no comportamento dos vértices nas comunidades. Essa característica permite calibrar o algoritmo com no mínimo dez variantes: WIC e nove medidas da forma $W$ (Tabela 4.1). Cada medida gera uma variante do RSim, por exemplo, RSim-CN utiliza a medida de similaridade CN na forma $W$.

\section{Algoritmo 4.2.1: RSim}

Input: rede $G=\{V, E\}$, particionamento $P$

1 repita

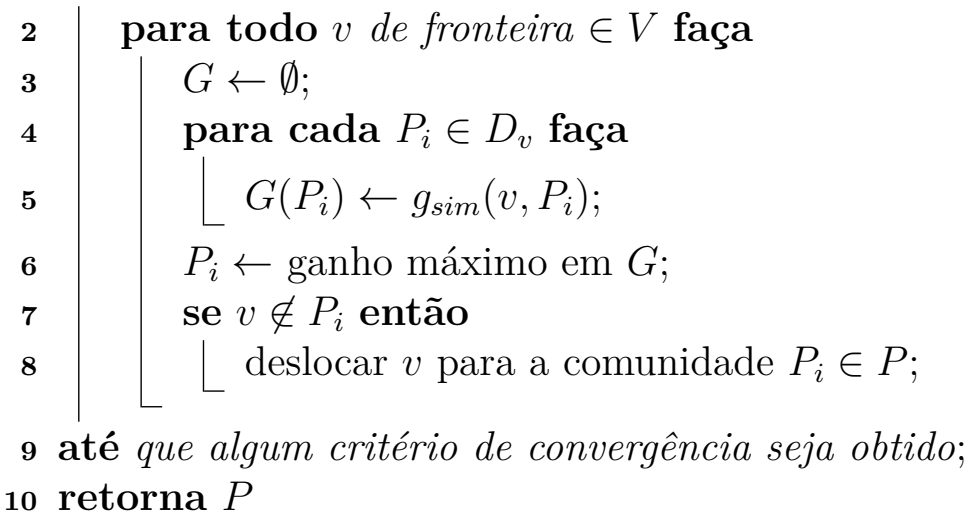

O Algoritmo 4.2.1 sumariza os passos do RSim. Considere que as operações são feitas em tempo constante usando um mapeamento de vértices em comunidades, similar à Blondel et al. (2008); Rotta \& Noack (2011). Para cada vértice de fronteira $v$ é calculado a semelhança com sua vizinhança em cada comunidade, ou seja, todos os vizinhos de $v$ são visitados, independentemente do número de comunidades. No pior caso, em que todos os vértices são de fronteira, todas as arestas são verificadas. Portanto, a complexidade do algoritmo não depende do número de partições e possui complexidade linear em relação ao número de arestas, ou seja, $O(m)$.

A Figura 4.2 ilustra o processo de refinamento do vértice de fronteira 5 usando a vari- 
ante RSim-CN, que corresponde ao algoritmo RSim usando a medida CN-W. Dado um particionamento inicial $P=\left\{P_{i}, P_{j}\right\}$, em que $P_{i}=\{1,3,4, s V\}$ e $P_{j}=\{6,7,8,9\}$, tal que $s V=\{2,5\}$, ilustrado na Figura 4.2(a), após a fase de projeção, ilustrado pela Figura 4.2(b), temos:

$$
\begin{gathered}
g\left(5, P_{i}\right)=\frac{1}{k_{P_{i}}(v)} \sum_{u \in P_{i}} S_{5, u}^{C N-W}=\frac{\left|\Lambda_{5,2}^{P_{i}}\right|+\left|\Lambda_{5,4}^{P_{i}}\right|}{k_{P_{i}}(v)}=\frac{|\{4\}|+|\{2\}|}{2}=\mathbf{1} \\
g\left(5, P_{j}\right)=\frac{1}{k_{P_{j}}(v)} \sum_{u \in P_{j}} S_{5, u}^{C N-W}=\frac{\left|\Lambda_{5,6}^{P_{j}}\right|+\left|\Lambda_{5,7}^{P_{j}}\right|+\left|\Lambda_{5,8}^{P_{j}}\right|}{k_{P_{j}}(v)}=\frac{|\{7\}|+|\{6,8\}|+|\{7\}|}{3}=\mathbf{1 , 3 3}
\end{gathered}
$$

como $g\left(5, P_{i}\right)<g\left(5, P_{j}\right)$, o vértice 5 é transferido da comunidade $P_{i}$ para $P_{j}$. Assim, $P_{i}=\{1,2,3,4\}$ e $P_{j}=\{5,6,7,8,9\}$, Figura $4.2(\mathrm{c})$.

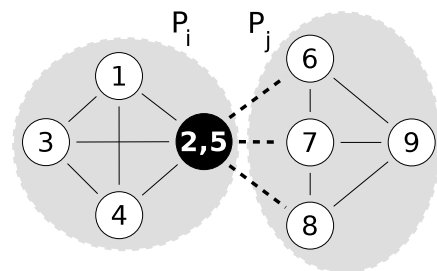

(a) Particionamento inicial

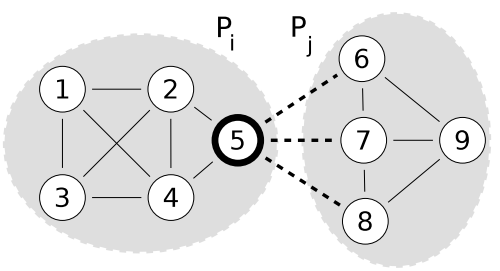

(b) Projeção

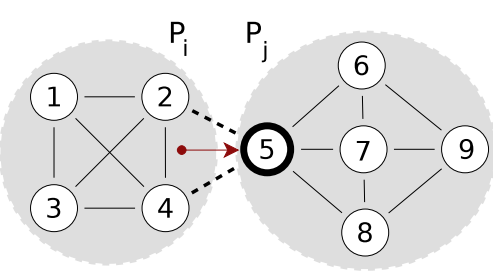

(c) Refinamento

Figura 4.2: Exemplo do processo de refinamento usando a variante RSim-CN. Durante o processo de refinamento o vértice 5 é transferido da comunidade $P_{i}$ para $P_{j}$.

Como visto, o RSim têm inúmeras variantes, sendo que todas se baseiam no conjunto de vizinhos comuns. Dessa forma, é possível que, em alguns cenários, todas as variantes tomem as mesmas decisões. Com base no exemplo anterior, a Tabela 4.2 mostra os valores obtidos por três variantes do RSim ao refinar o vértice 5 . Com base nos valores obtidos,

\begin{tabular}{|c|c|c|c|c|c|c|}
\hline \multirow{3}{*}{ Variante } & \multicolumn{2}{|c|}{$s V=\{2,5\}$} & \multicolumn{4}{|c|}{$s V=\{2,4\}$} \\
\hline & \multicolumn{2}{|c|}{ refinar o vértice 5} & \multicolumn{2}{|c|}{ refinar o vértice 2} & \multicolumn{2}{|c|}{ refinar o vértice 4} \\
\hline & $g_{\text {sim }}\left(5, P_{i}\right)$ & $g_{s i m}\left(5, P_{j}\right)$ & $g_{\operatorname{sim}}\left(2, P_{i}\right)$ & $g_{s i m}\left(2, P_{j}\right)$ & $g_{s i m}\left(4, P_{i}\right)$ & $g_{s i m}\left(4, P_{j}\right)$ \\
\hline RSim-CN & 1,00 & 1,33 & 2,00 & 0,00 & 2,00 & 0,00 \\
\hline RSim-HP & 0,25 & 0,38 & 0,66 & 0,00 & 0,66 & 0,00 \\
\hline RSim-HD & 0,20 & 0,26 & 0,55 & 0,00 & 0,55 & 0,00 \\
\hline
\end{tabular}
todas as variantes transferem o vértice 5 da comunidade $P_{i}$ para $P_{j}$.

Tabela 4.2: Exemplo de refinamento usando três variantes do RSim. São sumarizados os valores obtidos por três variantes do RSim ao refinar o vértice 5 a partir do $s V=\{2,5\}$, Figura 4.2 , bem como os valores obtidos ao refinar o vértice 2 e 4 a partir do $s V=\{2,4\}$, Figura 4.3 .

Analogamente, a Figura 4.3 ilustra outro cenário no qual $s V=\{2,4\}$. Neste caso, as três variações também tomam as mesmas decisões para refinar os vértices 2 e 4 , apresentado na Tabela 4.2. Pode-se concluir, a partir das informações da tabela, que as variantes do RSim produziram as mesmas soluções. As soluções podem ser diferentes em cenários 
cuja vizinhança do vértice analisado não esteja bem estabelecida. Nesse caso, o fator de ponderação de cada medida pode ter grande influência nas decisões do algoritmo.

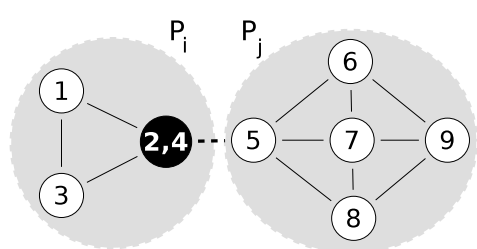

(a) Particionamento inicial

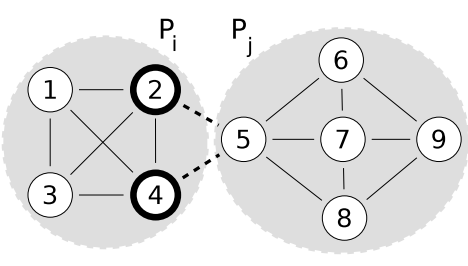

(b) Projeção

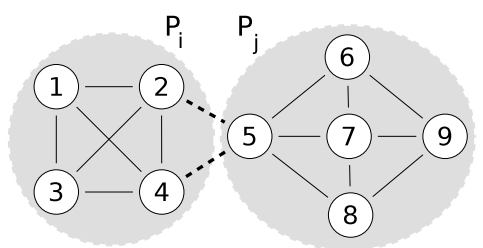

(c) Refinamento

Figura 4.3: Exemplo do processo de refinamento usando RSim. Durante o processo de refinamento os vértices 2 e 4 permanecem na comunidade $P_{i}$.

A Figura 4.4 ilustra o refinamento do vértice 5 mediante diferentes estratégias. A Figura 4.4(b) ilustra a solução obtida usando o algoritmo RSim-CN. Nesse caso, observa-se que a solução não reduz o número de arestas entre as comunidades, ou seja, não favorece o corte mínimo. Em contraste, a Figura 4.4(c) ilustra a solução obtida com base na minimização do corte, o qual reduz o número de arestas entre as comunidades. Entretanto, a solução obtida com base na minimização do corte é menos coesa, em termos de Modularidade, quando comparada a solução obtida pelo RSim, dado que, a Modularidade em (b) é 0.2500 e a Modularidade em (c) é 0.21679. Esse exemplo expõe uma evidência na qual explorar o corte mínimo pode não ser uma boa estratégia em todos os cenários.

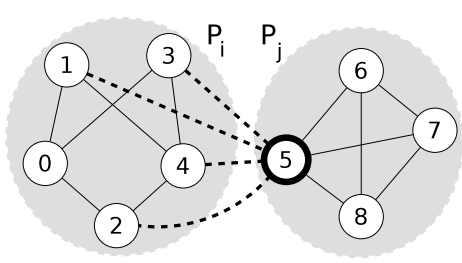

(a) Particionamento inicial

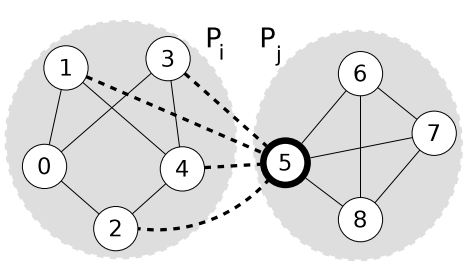

(b) RSim-CN

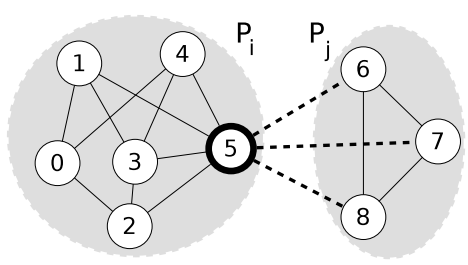

(c) Corte mínimo

Figura 4.4: Refinamento de um vértice mediantes diferentes estratégias. Em (b) a solução obtida pelo RSim possui Modularidade 0,2500; em (c) a solução obtida pela minimização do corte possui Modularidade 0,21679.

\subsection{Extensão do RSim com base no coeficiente de agrupamento}

Almeida (2009) apresentou um estudo de escalabilidade do algoritmo fastgreedy em um contexto multinível. Apesar do trabalho centrar-se na otimização da Modularidade, Almeida (2009) expôs a possibilidade do refinamento com base no coeficiente de agrupamento. Entretanto, o trabalho não define a utilização do coeficiente de agrupamento considerando uma divisão em comunidades, nem apresenta algum algoritmo sumarizando o processo.

Com base na ideia apresentada por Almeida (2009), pode-se adaptar o RSim usando uma extensão do coeficiente de agrupamento local, o qual considera informações da estrutura de comunidades ao invés de utilizar toda a informação da rede. Para isso, definimos o 
ganho $g_{c c}$ com base na extensão do coeficiente de agrupamento. Como visto, $\Gamma(v)$ denota o conjunto de vizinhos do vértice $v$, de outro modo, ao considerarmos uma divisão em comunidades, pode-se definir $\Gamma(v)=\Gamma(v)^{W} \cup \Gamma(v)^{I}$, em que $\Gamma(v)^{W}=\left\{u \in \Gamma(v) \mid u, v \in P_{i}\right\}$, isto é, $\Gamma(v)^{W}$ denota os vizinhos internos $(\mathrm{W})$ de $v$ em uma comunidade $P_{i}$. Em contraste, $\Gamma(v)^{I}=\left\{u \in \Gamma(v) \mid v \in P_{i}, u \in \overline{P_{i}}\right\}$ denota o conjunto de vizinhos de $v$ que não pertencem a comunidade $P_{i}$, e, consequentemente, $\Gamma(v)^{W} \cap \Gamma(v)^{I}=\emptyset$.

Similarmente, $e_{v}$ representa o número de arestas entre os vizinhos de $v$ considerando todos os vértices da rede. Por outro lado, ao considerar uma estrutura de comunidades, pode-se definir $e_{v}=e_{v}^{W} \cup e_{v}^{I}$, em que:

$$
e_{v}^{W}=\sum_{u, z} w_{u, z}, \text { tal que } v, u, z \in P_{i} \text { e } e_{v, u}, e_{v, z}, e_{u, z} \in E
$$

e o seu complemento é definido por $e_{v}^{I}$, tal que $e_{v}^{W} \cap e_{v}^{I}=\emptyset$. Com base nessas definições, pode-se calcular o coeficiente de agrupamento $c c_{v}^{W}$ do vértice $v$ em uma comunidade $P_{i}$ por:

$$
c c_{v}^{W}=\frac{2 e_{v}^{W}}{\left|\Gamma(v)^{W}\right|\left(\left|\Gamma(v)^{W}\right|-1\right)}
$$

A reformulação do $c c_{v}$, dada pela Equação 4.3, considera as informações da estrutura de comunidades, em contraste com o método tradicional que considera toda a informação da vizinhança de um vértice. Desse modo, foi desenvolvido uma extensão do RSim, denominada algoritmo de refinamento com base no coeficiente de agrupamento (Rcc). Ao contrário do RSim, o qual explora a similaridade entre vértices, o Rcc maximiza uma medida de centralidade, ou seja, observa a importância de um vértice em um determinado grupo. O ponto em comum é que ambos utilizam o conceito de vizinhança. No algoritmo Rcc, o ganho de um vértice $v$ em uma comunidade $P_{i}$ é dado por:

$$
g_{c c}\left(v, P_{i}\right)=c c_{v}^{W}
$$

O Algoritmo 4.2.1 pode ser modificado simplesmente alterando a função de ganho para $g_{c c}$. A diferença entre o algoritmo RSim e o Rcc pode ser observada no exemplo ilustrado pela Figura 4.5. Ao refinar o vértice 5 usando o Rcc, Figura 4.5(b), temos:

$$
\begin{gathered}
g_{c c}\left(5, P_{i}\right)=\frac{2 e_{5}^{P_{i}}}{\left|\Gamma(5)^{P_{i}}\right|\left(\left|\Gamma(5)^{P_{i}}\right|-1\right)}=\frac{2}{|\{4,2\}|(|\{4,2\}|-1)}=\frac{2}{2}=\mathbf{1}, \\
g_{c c}\left(5, P_{j}\right)=\frac{2 e_{5}^{P_{j}}}{\left|\Gamma(5)^{P_{j}}\right|\left(\left|\Gamma(5)^{P_{j}}\right|-1\right)}=\frac{4}{|\{6,7,8\}|(|\{6,7,8\}|-1)}=\frac{4}{6}=\mathbf{0 , 6 6 ,}
\end{gathered}
$$

como $g_{c c}\left(5, P_{i}\right)>g_{c c}\left(5, P_{j}\right)$, o vértice 5 permanece na comunidade $P_{i}$, diferente da decisão tomada pelo algoritmo RSim, ou seja, $P_{i}=\{1,2,3,4,5\}$ e $P_{j}=\{6,7,8,9\}$, como mostra a Figura 4.5(b). 


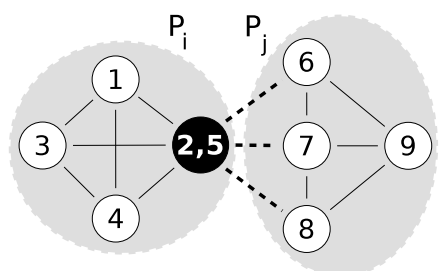

(a) Particionamento inicial

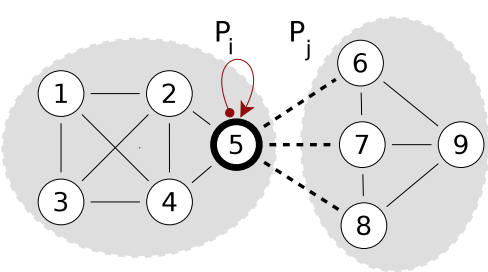

(b) Rcc

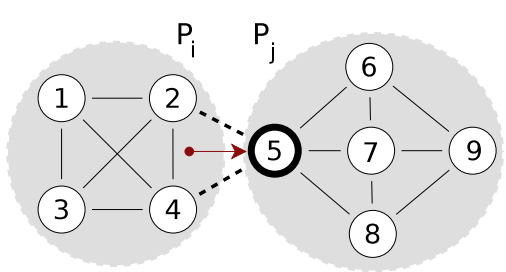

(c) RSim-CN

Figura 4.5: Comparação entre os algoritmos de refinamento RSim-CN e Rcc.

Uma variante possível, seria, ao invés de calcular o $c c_{v}^{W}$ do vértice, calcular o coeficiente de agrupamento da comunidade com o vértice fora $c c_{P_{i} /\{v\}}$ e dentro $c c_{P_{i} \cup\{v\}}$ dela, optando por deixar o vértice na comunidade que têm um maior ganho relativo no $c c_{P_{i}}$ (Mislove et al., 2007).

No próximo capítulo são apresentados e discutidos os experimentos realizado para avaliar o desempenho dos algoritmos propostos em relação à eficácia (qualidade da solução) e eficiência (tempo de execução), considerando doze redes reais comumente utilizadas em benchmark. Além disso, é apresentado um estudo de caso que aborda o problema de citações ambíguas em redes de cooperação científica. 


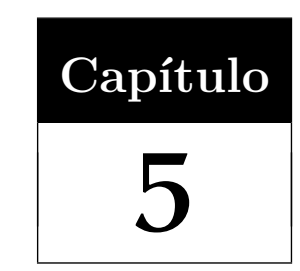

\section{Avaliação Experimental}

$\mathcal{N}$

este capítulo são apresentados os experimentos realizados para a avaliação dos métodos propostos neste trabalho, e, também, as discussões sobre os resultados obtidos. No primeiro conjunto de experimentos, considerando conjuntos de dados de benchmark, buscou-se, principalmente, determinar a eficácia e eficiência dos algoritmos, isto é, a capacidade de encontrar soluções factíveis próximas o suficiente de um determinado referencial em tempo hábil. No segundo, buscou-se avaliar o comportamento dos algoritmos em uma aplicação real. Desse modo, são apresentadas as redes que foram avaliadas no benchmark, bem como detalhes a respeito do estudo de caso considerando uma aplicação real. Também são apresentadas a metodologia de testes usada para obtenção dos resultados, bem como a análise comparativa dos resultados obtidos pelas propostas apresentadas neste trabalho e pelas abordagens tradicionais.

\subsection{Benchmark}

O principal objetivo dos experimentos realizados e apresentados nessa seção é mostrar a viabilidade do uso das propostas deste trabalho dado seu desempenho no processo de refinamento de partições, bem como avaliar a proposta de forma comparativa e sistemática a partir de análises qualitativas e quantitativas.

\subsubsection{Conjuntos de dados}

Para avaliar o desempenho das propostas foram consideradas doze redes reais com características topológicas distintas e tamanhos variados, comumente utilizadas como benchmark. Tais redes estão divididas em: redes tecnológicas, redes de informação, redes biológicas e redes sociais. Em particular, selecionou-se seis redes sociais e seis redes de outros domínios. A seguir são apresentadas breves descrições de cada uma delas.

Airline: Rede de tecnologia que modela linhas aéreas de voos comerciais nos EUA entre os anos de 1987 à 2006 (Batagelj \& Mrvar, 2006).

Power: Rede de tecnologia representando a topologia da rede de centrais elétricas dos Estados Unidos (Newman, 2013). 
Router: Rede de tecnologia que representa a topologia de uma rede de computadores na qual os roteadores são representados por vértices e arestas representam as conexões (Spring et al., 2002).

Yeast: Rede biológica representando o mapa de interação proteína-proteína (PPI) (Newman, 2013).

Political Blogs: Rede de informação representando hiperlinks entre blogs sobre política dos EUA, registrados em 2005. Na rede original as arestas são direcionadas, porém, neste trabalho são consideradas como não direcionadas (Newman, 2013).

Industry: Rede de informação na qual indústrias são relacionadas por co-ocorrência em notícias obtidas na web no período de Abril de 2003 a Setembro de 2003 (Newman, 2013).

Zachary Karate: Rede social de amizade entre 34 membros de um clube de karatê de uma universidade dos EUA na década de 1970 (Newman, 2013).

DBLP: Rede colaboração extraída da base de dados sobre publicações em computação $\operatorname{DBLP}^{1}$ (Han et al., 2004).

IMDB: Rede de informação sobre coleções de filmes extraídas do site IMDB $^{2}$. Dois filmes estabelecem uma ligação caso compartilhem uma produtora (Neville et al., 2003).

NetScience: Rede de colaboração entre cientistas que trabalham em Teoria de Redes (Newman, 2013).

High-energy theory: Rede de colaboração entre cientistas que tiveram algum trabalho incluso no High-Energy Theory E-Print ${ }^{3}$ entre 1995 e 1999. (Newman, 2013).

Astrophysics: Rede de colaboração entre cientistas que tiveram algum trabalho incluso no Astrophysics E-Print Archive entre 1995 e 1999. (Newman, 2013).

A Tabela 5.1 sumariza as propriedades estruturais básicas das redes utilizadas; nelas $|V|$ e $|E|$ representam o número de vértices e arestas, respectivamente, $\langle C\rangle$ e $r$ representam a média do coeficiente de agrupamento global e coeficiente de assortatividade, respectivamente e $H$ denota o grau de heterogeneidade. Tais redes são de livre acesso e possuem uma quantidade considerável de vértices e arestas e a complexidade da estrutura topológica é refletida nos altos valores de coeficiente de agrupamento global e grau de heterogeneidade, bem como o valor negativo que algumas redes têm no seu coeficiente de assortatividade.

\footnotetext{
${ }^{1}$ http://www.informatik.uni-trier.de/ ley/db/

${ }^{2}$ http: //www.imdb.com/

${ }^{3}$ http://arxiv.org/archive/hep-th

${ }^{4}$ http://arxiv.org/archive/astro-ph
} 


\begin{tabular}{l|l|l|r|r|r|r|r}
\hline Domínio & Rede & Acrônimo & $|V|$ & $|E|$ & $\langle C\rangle$ & $r$ & $H$ \\
\hline \hline \multirow{3}{*}{ Tecnológica } & Airline & AL & 332 & 2126 & 0,7494 & $-0,2079$ & 3,4639 \\
& Power & PW & 4941 & 6594 & 0,0801 & 0,0034 & 1,4504 \\
& Router & RT & 5022 & 6258 & 0,0116 & $-0,1384$ & 5,5031 \\
\hline Biológica & Yeast & YT & 2362 & 7182 & 0,2443 & $-0,0587$ & 2,7643 \\
\hline \multirow{2}{*}{ Informação } & Political Blogs & PB & 1224 & 16716 & 0,3203 & $-0,2211$ & 2,9749 \\
& Industry & ID & 2189 & 11666 & 0,3297 & 0,1842 & 3,4122 \\
\hline & Zachary Karate & ZK & 34 & 78 & 0,5879 & $-0,4756$ & 1,6933 \\
& DBLP & DB & 1011 & 5754 & 0,8677 & 0,0651 & 2,5485 \\
& IMDB & IM & 1441 & 20317 & 0,5843 & 0,3492 & 2,0982 \\
\multirow{5}{*}{ Social } & NetScience & NS & 1461 & 2742 & 0,6937 & 0,4616 & 1,8486 \\
& High-energy theory & HT & 8361 & 7875 & 0,2939 & 0,3402 & 2,3057 \\
& Astrophysics & AP & 16706 & 121251 & 0,2355 & 0,4305 & 3,0946 \\
\hline \hline
\end{tabular}

Tabela 5.1: Propriedades estruturais básicas de doze redes divididas em quatro domínios.

\subsubsection{Configuração do algoritmo multinível e fluxograma}

Como visto, os algoritmos multinível possuem três fases: i. contração, ii. particionamento, e iii. projeção. Dado que o objetivo é avaliar a performance, exclusivamente, dos algoritmos de refinamento, é necessário fixar as estratégias utilizadas em cada fase do processo multinível.

Contração: Os algoritmos mais utilizados nessa etapa são: RM, HEM, MHEM e LEM. Alguns trabalhos realizaram uma análise empírica comparativa entre os diferentes algoritmos em diferentes cenários de avaliação (Karypis \& Kumar, 1995b; Hendrickson \& Leland, 1995; Karypis \& Kumar, 1996, 1998a; Almeida \& Lopes, 2009). No geral, a análise entre os métodos mostrou uma diferença pequena, tanto em relação à performance quanto à qualidade da solução. Pode-se ressaltar que os métodos têm as curvas de crescimento do tempo de execução muito próximas umas das outras. Em relação ao algoritmo HEM, os experimentos apontam que sua utilização favorece boas partições iniciais. Portanto, neste projeto, utiliza-se o algoritmo HEM na fase de contração, devido ao seu comportamento consistente e estável em diferentes cenários.

Particionamento: Para a detecção das comunidades foi investigado o algoritmo fastgreedy que, além de inferir a quantidade de comunidades para a rede com base na Modularidade, possui menor tempo de processamento em relação a outros métodos. Além disso, atualmente o fastgreedy é um dos poucos algoritmos que pode ser utilizado para estimar a máxima Modularidade em redes de grandes dimensões.

Projeção: A fase de projeção da solução, devido à sua simplicidade, não possui uma técnica específica. Basicamente, ao decompor um $s V$, seus vértices de origem $u$ e $v$ são adicionados à comunidade $P(s V)$.

Essa configuração é utilizada como base para a avaliação de todos os algoritmos de refinamento. Com base nisso, a fim de avaliar a confiabilidade dos resultados obtidos pelos algoritmos de refinamento, naturalmente, é utilizada como base referencial para os 
experimentos o algoritmo multinível sem a utilização de refinamento, de agora em diante referido como baseline (Almeida \& Lopes, 2009).

Considerando a configuração da estratégia multinível selecionada, foram avaliadas dez variantes $^{5}$ do RSim, cada qual usa uma medida de similaridade diferente (WIC ou medidas da forma $W$ ), bem como sua variação Rcc, que utiliza uma função de ganho baseada no coeficiente de agrupamento. Comparou-se, sistematicamente, o RSim e o Rcc com dois métodos amplamente utilizados: KK (Karypis \& Kumar, 1998b) e RFG (Schuetz \& Caflisch, 2008; Ye et al., 2008; Rotta \& Noack, 2011).

Os algoritmos foram implementados em C++ e compilados com GCC 4.7.3 e Linux Ubuntu kernel 3.8.0-34-generic. A estrutura de dados é baseada na plataforma LPmade (Lichtenwalter \& Chawla, 2011). Os experimentos foram realizados em um computador Intel (R) Core (TM) i5-2430M CPU @ 2.40GHz e 4 GBytes de memória.

A Figura 5.1 resume a metodologia a partir de um fluxograma. Em i. a rede original é reduzida sucessivamente utilizando o algoritmo HEM. Em ii. a rede reduzida é particionada usando o algoritmo fastgreedy (Clauset et al., 2004). Por fim, em iii. a solução obtida na rede reduzida é projetada até a rede original e um algoritmo de refinamento selecionado é executado em cada nível. O passo iii é repetido individualmente para cada algoritmo de refinamento avaliado.

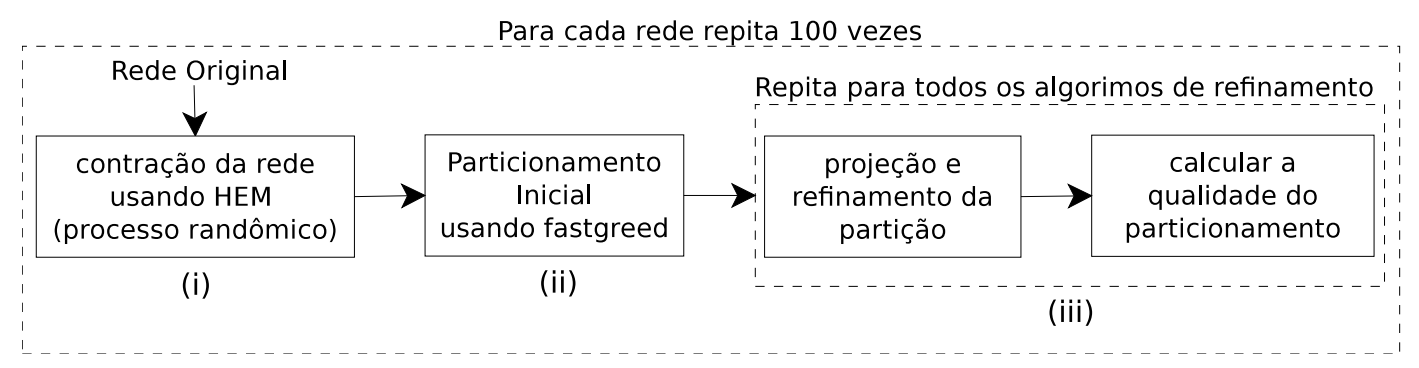

Figura 5.1: Fluxograma da metodologia experimental.

O critério de parada da fase de contração foi: reduzir a rede até atingir $n \leq 1000$. Caso a rede tenha menos de 1000 vértices a contração é executada uma única vez. Além disso, o fator de redução foi configurado para reduzir a rede em $50 \%$ a cada nível, isto é, $r f=0.5$. Como o algoritmo de contração utiliza um critério randômico de seleção de vértices, o processo foi executado 100 vezes para cada algoritmos de refinamento, logo, o resultado é obtido usando a média dos resultados das 100 execuções.

\subsubsection{Medidas de desempenho}

Os principais aspectos da avaliação são a eficácia, confiabilidade e eficiência. Neste projeto, um algoritmo é eficaz quando encontra melhores divisões em comunidades em termos de Modularidade em comparação com as alternativas. Esse desempenho está relacionado com a confiabilidade, isto é, se o algoritmo é capaz de encontrar bons agrupamentos sistematicamente e não ao acaso. A eficiência lida com a análise da escalabilidade, a fim

\footnotetext{
${ }^{5}$ As variantes só diferem com relação à medida de similaridade usada.
} 
de verificar como o tempo de execução dos algoritmos se comporta em relação à redes de diferentes tamanhos.

Para avaliar a qualidade das soluções (eficácia) obtidas pelos algoritmos adotou-se a medida Modularidade, apesentada no Capítulo 3. Essa medida mapeia um agrupamento obtido em uma rede para um número racional $Q(P)$ que representa sua qualidade. Assim, um agrupamento $P$ é tão bom quanto um agrupamento $P^{\prime}$, se $Q(P) \geq Q\left(P^{\prime}\right)$.

Os resultados obtidos pela Modularidade foram submetidos a análise da diferença estatística significativa através de um teste post-hoc, proposto por Demšar (2006). Tais análises foram feitas com base em um contexto geral, isto é, considerando todas as doze redes complexas do conjunto de backmarck. Em contraste, também foi realizada uma análise considerando apenas seis redes sociais, bem como outros cenários de interesse. Esse teste fornece uma diferença estatística significativa entre os algoritmos avaliados considerando todas as redes avaliadas, bem como um ranking que permite determinar o desempenho geral de cada um dos algoritmos avaliados. A Figura 5.2 ilustra o diagrama da diferença estatística. No eixo horizontal são enumeradas as posições obtidas pelos algoritmos avaliados, formando um ranking com suas respectivas médias de desempenho. O valor da média fornece o desempenho global de cada índice, além das informações necessárias para computar o teste de Friedman e determinar o valor da diferença crítica. A diferença crítica (CD) é localizada no topo do diagrama. O desempenho de dois algoritmos é estatisticamente diferente se os valores de suas médias diferem em no mínimo o valor de CD. Cada algoritmo é indicado pelo seu respectivo nome.

Por exemplo, na Figura 5.2, foram avaliados quatro algoritmos: primeiro, segundo, terceiro e quarto. Os algoritmos mais próximos do valor 1 possuem melhor desempenho. Além disso, os algoritmos que não têm diferença estatística significativa estão conectados por uma linha preta contínua.

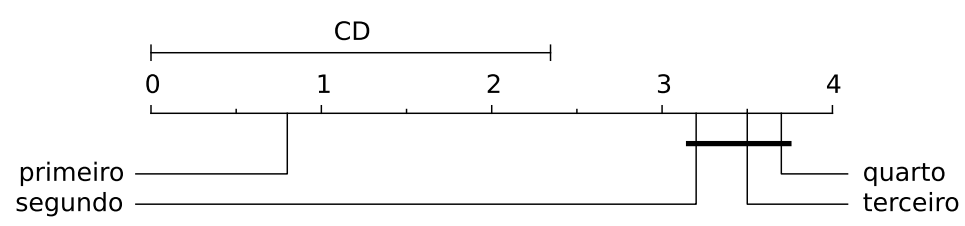

Figura 5.2: Gráfico ilustrativo da diferença estatística utilizado para representar o ranking do desempenho de diferentes métodos avaliados em diferentes conjuntos de dados.

Por fim, os algoritmos foram submetidos a uma avaliação de eficiência com base no tempo de execução mediante um histograma. A Figura 5.3 ilustra um histograma. No eixo horizontal são incluídos os diferentes tamanhos das redes avaliadas. No eixo vertical são incluídos os valores obtidos pelo tempo de execução dos algoritmos. Cada algoritmo é representado por um tipo de linha diferente. Logo, um ponto no histograma indica o valor do tempo de execução de um algoritmo em uma rede de tamanho determinado. 


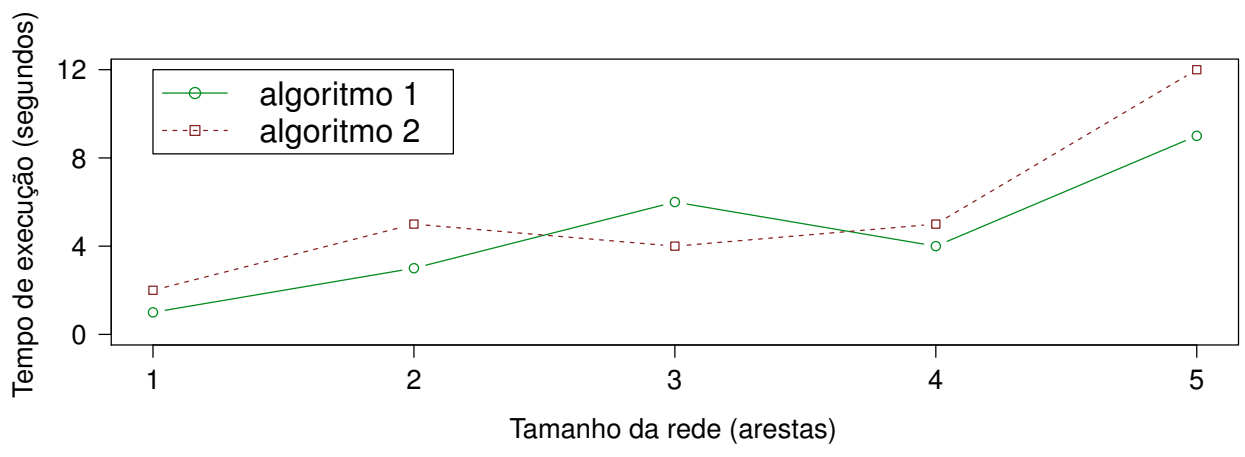

Figura 5.3: Gráfico ilustrativo de um histograma.

\subsubsection{Resultados e análise}

A Tabela 5.2 resume os resultados obtidos pela média da Modularidade considerando todos os algoritmos de refinamento avaliados, isto é, dez variantes do RSim, Rcc, KK, RFG, bem como o baseline. Na última coluna da tabela estão dispostos os valores das médias do ranking de desempenho global obtido por cada algoritmo em relação às redes avaliadas.

\begin{tabular}{|c|c|c|c|c|c|c|c|c|c|c|c|c|c|}
\hline \multirow{2}{*}{ Algoritmo } & \multicolumn{12}{|c|}{ Rede } & \multirow{2}{*}{$\begin{array}{l}\text { Média do } \\
\text { ranking }\end{array}$} \\
\hline & $\mathrm{AL}$ & PW & RT & $\mathrm{YT}$ & $\mathrm{PB}$ & ID & ZK & DB & NS & IM & HT & $\mathrm{AP}$ & \\
\hline RSim-AA & 0,3160 & 0,9165 & 0,8650 & 0,6869 & 0,4218 & \begin{tabular}{|l|}
0,4801 \\
\end{tabular} & 0,3553 & 0,9128 & 0,9553 & 0,5912 & 0,6522 & 0,6243 & 6,375 \\
\hline RSim-CN & 0,3165 & 0,9165 & 0,8650 & 0,6869 & 0,4218 & 0,4801 & 0,3560 & 0,9130 & 0,9553 & 0,5912 & 0,6479 & 0,6128 & 5,917 \\
\hline RSim-HD & 0,3160 & 0,9165 & 0,8650 & 0,6869 & 0,4218 & 0,4801 & 0,3553 & 0,9128 & 0,9553 & 0,5912 & 0,6479 & 0,6243 & 6,792 \\
\hline RSim-HP & 3160 & 0,9165 & 0,8650 & 0,6869 & 0,4218 & 0,4801 & 0,3553 & 0,9128 & 0,9553 & 0,5912 & 0,6479 & 0,6243 & 6,792 \\
\hline RSim-Jac & 0,2930 & 0,9144 & 0,8599 & 0,6860 & 0,4151 & 0,4592 & 0,3828 & 0,9117 & 0,9548 & 0,6474 & 0,6479 & 0,6471 & 9,250 \\
\hline RSim-LH & 0,3160 & 0,9165 & 0,8650 & 0,6869 & 0,4218 & 0,4801 & 0,3553 & 0,9128 & 0,9553 & 0,5912 & 0,6479 & 0,6243 & 6,792 \\
\hline RSim-RA & 0,3160 & 0,9165 & 0,8650 & 0,6869 & 0,4218 & 0,4801 & 0,3553 & 0,9128 & 0,9553 & 0,5912 & 0,6479 & 0,6243 & 6,792 \\
\hline RSim-Sal & 0,3160 & 0,9165 & 0,8650 & 0,6869 & 0,4218 & 0,4801 & 0,3553 & 0,9128 & 0,9553 & 0,5912 & 0,6479 & 0,6243 & 6,792 \\
\hline RSim-Sor & 0,3160 & 0,9165 & 0,8650 & 0,6869 & 0,4218 & 0,4801 & 0,3553 & 0,9128 & 0,9553 & 0,5912 & 0,6479 & 0,6243 & 6,792 \\
\hline RSim-WIC & 0,3160 & 0,9165 & 0,8650 & 0,6869 & 0,4218 & 0,4801 & 0,3553 & 0,9130 & 0,9553 & 0,5912 & 0,6522 & 0,6128 & 6,333 \\
\hline Rcc & 0,3165 & 0,9144 & 0,8599 & 0,6735 & 0,4119 & 0,4693 & 0,3501 & 0,9130 & 0,9553 & 0,5869 & 0,6429 & 0,6120 & 10,500 \\
\hline RFG & 0,3165 & 0,9301 & 0,8840 & 0,6920 & 0,4236 & 0,4871 & 0,3667 & 0,9123 & 0,9549 & 0,5869 & 0,6429 & 0,6120 & 6,125 \\
\hline KK & 0,2632 & 0,9311 & 0,8870 & 0,7081 & 0,4257 & 0,4693 & 0,3798 & 0,9128 & 0,9459 & 0,6385 & 0,6422 & 0,6128 & 6,500 \\
\hline baseline & 0,2884 & 0,9228 & 0,8611 & 0,6607 & 0,4204 & 0,4782 & 0,3483 & 0,9113 & 0,9403 & 0,5785 & 0,5864 & 0,6058 & 13,250 \\
\hline
\end{tabular}

Tabela 5.2: Eficácia quantificada através da Modularidade para dez variantes do RSim, Rcc, RFG, KK e baseline em doze redes reais. Cada valor modularidade é obtido calculando a média de 100 execuções.

Os maiores valores de Modularidade estão destacados na tabela. Desse modo, observase que, na rede Airline (AL), o melhor desempenho foi obtido pelos algoritmos RSim-CN, Rcc e RFG. Nas redes Power (PW), Router (RT), Yest (YT) e PoolBlogs (PB), o melhor desempenho foi obtido pelo algoritmo KK. Na rede Industry (ID), o melhor desempenho foi obtido pelo algoritmo RFG. Nas redes Zakary (ZK), Imdb (IM) e Astrophysics (AP), o melhor desempenho foi obtido pelo algoritmo RSim-Jac. Na rede DBLP (DB), o melhor desempenho foi obtido pelos algoritmos RSim-CN, RSim-WIC e Rcc. Na rede High-energy theory (HT), o melhor desempenho foi obtido pelos algoritmos RSim-AA e RSim-WIC. 
Na rede NetScienc (NS), o melhor desempenho foi obtido por todas as variações do RSim, exceto pelo RSim-Jac.

Outras considerações podem ser feitas a partir da análise da Tabela 5.2. Observa-se que o algoritmo RSim tem o melhor desempenho em sete das doze redes avaliadas, além disso, esse desempenho é observado em redes com um alto coeficiente de agrupamento e assortatividade significativa, sendo elas AL, ZK, DBLP, NS, IM, HT e AP. O algoritmo Rcc teve melhor desempenho em três redes, em particular, tais redes possuem os maiores coeficientes de agrupamento dentre todas as redes avaliadas. Os algoritmos RFG e KK obtiveram melhor desempenho em seis redes, as quais são caracterizadas pelo baixo coeficiente de assortatividade.

Muitas redes reais têm alto coeficiente de agrupamento. Esse conceito pode ser generalizado, assumindo que conjuntos de vértices similares indicam coesão e transitividade, ou seja, a maioria dos vizinhos de um vértice são vizinhos entre si. Com base nessa intuição, o RSim-CN, RSim-WIC e Rcc maximizam o número de ciclos de comprimento três, consequentemente, têm melhor desempenho em redes com alto coeficiente de agrupamento, como observado nas redes AL e DBLP. As outras variantes do RSim têm melhor desempenho em redes com alto coeficiente de assortatividade, tais como NS, MI, HT e $\mathrm{AP}$, uma vez que, além de considerar a vizinhança do vértice avaliado também é incorporado, no cálculo, um fator de balanceamento referente ao grau dos vértice. Ou seja, além de considerarem o número de vizinhos comuns, também verificam o quão similar é o grau de tais vizinhos. Alternativamente, todas as variações do RSim, bem como o Rcc, são menos eficientes em redes com baixo coeficiente de agrupamento e assortatividade. Adicionalmente, observou-se que algumas variantes do RSim têm exatamente os mesmos resultados. Esse fato, discutido no Capítulo 4, ocorre devido a todas as variantes do RSim terem como base o conjunto de vizinhos comuns.

Para analisar a diferença estatística e o desempenho individual de cada algoritmo de refinamento utilizou-se um teste post-hoc, realizado com base nos dados da Tabela 5.2. Os resultados estatísticos e ranking são sumarizados nos diagramas da Figura 5.4 e Figura 5.5. No diagrama da Figura 5.4, analisou-se os algoritmos de refinamento em um contexto geral, ou seja, com base em todas as redes. No diagrama da Figura 5.5, analisou-se os top-cinco algoritmos de refinamento, selecionados com base na classificação geral dada pelo diagrama da Figura 5.4, bem como o baseline. Nesse caso o diagrama compõe o ranking considerando todas as redes sociais (ZK, DB, IM, NS, HT, AP).

No diagrama da Figura 5.4, o valor da diferença crítica (CD) é 5.27, dado um intervalo de confiança de $95 \%(p<0.05)$. Desse modo, dois algoritmos são estatisticamente diferentes caso a diferença entre a média de seus ranking seja maior que 5.27. Sob este aspecto, apesar de não haver diferença significativa entre os algoritmos de refinamento, todos possuem uma diferença estatística significativa em relação ao baseline, exceto o RSim-Jac e Rcc.

Observa-se, também, que o RSim-CN, RFG, KK, RSim-AA e RSim-WIC compõem as 
cinco melhores posições do ranking. Entretanto, RSim-CN possui a melhor média global. Além disso, nota-se que dois grupos de variantes do RSim têm o mesmo desempenho. O primeiro grupo é formado por RSim-WIC e RSim-AA. O segundo grupo é formado por RSim-HD, RSim-HP, RSim-Sor, RSim-Sal, RSim-LH e RSim-RA. Outra observação, é que os algoritmos RSim-Jac e Rcc têm as piores classificações.

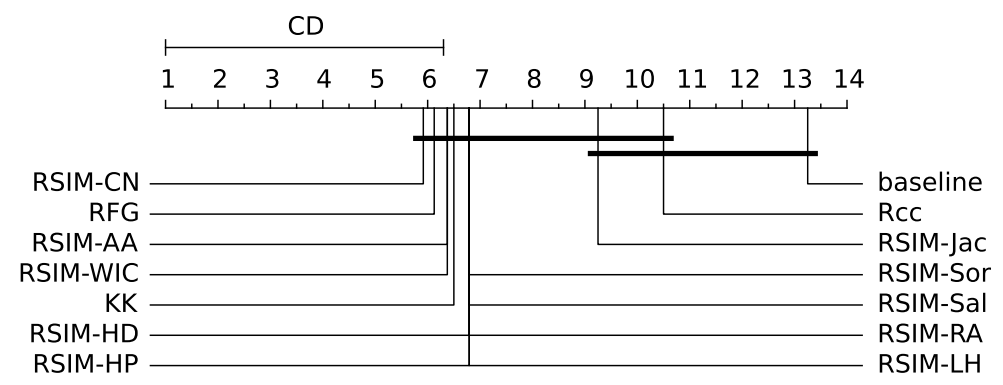

Figura 5.4: Diferença estatística considerando todos os algoritmos de refinamento e um baseline em doze redes reais.

No diagrama da Figura 5.5 o valor da diferença crítica (CD) é 3.08, dado um intervalo de confiança de 95\% ( $p<0.05)$. Em vista disso, nota-se, que não há diferença significativa entre os top-cinco algoritmos. No entanto, observa-se que as variantes RSim têm uma classificação média melhor que, por sua vez, é consideravelmente maior do que a classificação média do KK e RFG. Além disso, é importante destacar que, nesse cenário, existe diferença estatística significativa entre as variantes do RSim e o baseline. Ao contrário, não existe diferença estatística entre os algoritmos da literatura KK e RFG e o baseline, evidenciando que os métodos da literatura não têm clara vantagem sobre o baseline.

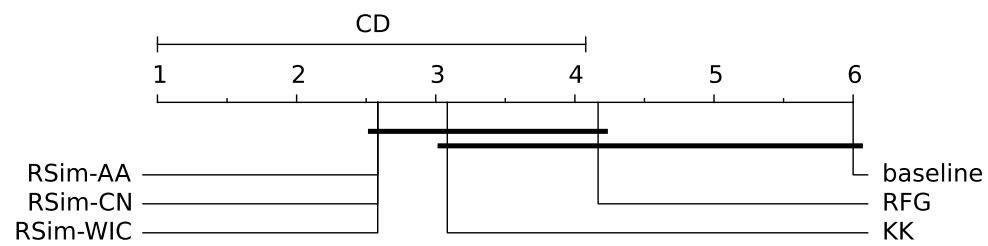

Figura 5.5: Diferença estatística dos top-cinco algoritmos de refinamento, obtidos com base na classificação geral dada pelo diagrama da Figura 5.4, bem como o baseline, considerando seis redes sociais.

Portanto, a análise inicial indica que o RSim supera os algoritmos de refinamento habituais em redes sociais e é competitivo com os métodos avaliados em um contexto geral. Adicionalmente, analisou-se estatisticamente as três melhores variações do RSim, selecionadas a partir do digrama da Figura 5.4, bem como os algoritmos Rcc, KK, RFG e o baseline em diferentes cenários de interesse. A Figura 5.6(a) ilustra o diagrama com o ranking obtido com base nas cinco redes com maior coeficiente de agrupamento (AL, ZK, DB, IM, NS). A Figura 5.6(b) ilustra o diagrama com o ranking obtido com base nas cinco redes com menor coeficiente de agrupamento (PW, RT, YT, HT, AP). A Figura 5.7 
sumariza o ranking com base nas cinco redes com menor assortatividade (AL, RT, YT, $\mathrm{PB}, \mathrm{ZK})$.

Observa-se, a partir do diagrama da Figura 5.6(a), que apesar de não haver diferença estatística significativa entre os algoritmos, as variantes do RSim, inclusive o Rcc, possuem melhor média do ranking geral. Além disso, o RSim-CN é o único algoritmo que possui diferença estatística significativa em relação ao baseline, realçando sua relevância nesse cenário. Em contraste, os algoritmos alternativos Rcc, RFG e KK não apresentam diferença estatística em relação ao baseline. Em um cenário oposto, ilustrado pelo diagrama da Figura 5.6(b), os algoritmos da literatura RFG e KK superaram os algoritmos RSim e Rcc, porém, não há diferença estatística entre eles.

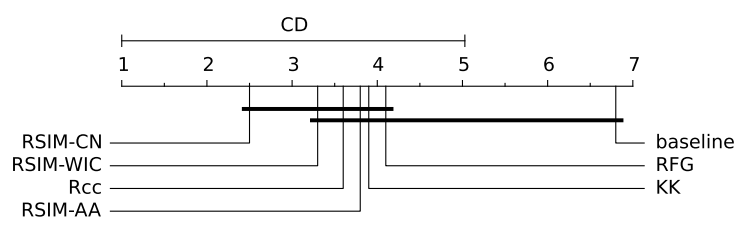

(a)

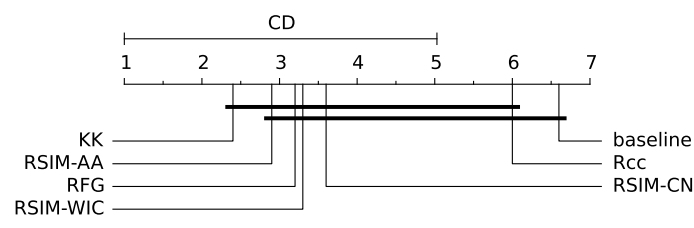

(b)

Figura 5.6: Diferença estatística dos algoritmos de refinamento em dois cenários de interesse: (a) considera as cinco redes com maior coeficiente de agrupamento; (b) considera as cinco redes com menor coeficiente de agrupamento.

Ainda, considerando as cinco redes com menor assortatividade, cenário ilustrado pela Figura 5.7, observa-se que não há diferença estatística significativa entre os algoritmos de refinamento, entretanto, nesse caso, o KK e RFG superam o baseline estatisticamente, em oposição ao RSim que não apresenta relevância estatística em relação ao baseline.

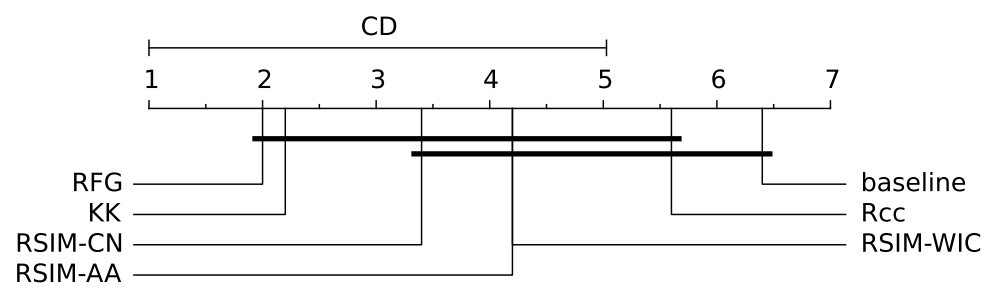

Figura 5.7: Diferença estatística dos algoritmos de refinamento em redes com baixa assortatividade.

Por fim, avaliamos a eficiência dos algoritmos de refinamento com base no tempo de execução. A Figura 5.8 sumariza o tempo de execução dos algoritmos de refinamento em relação as doze redes avaliadas.

O eixo-x superior mostra os acrônimos das redes avaliadas, o eixo-x inferior mostra o tamanho de cada rede mensurado pelo número de arestas, e o eixo-y indica o tempo de execução. Para uma melhor visualização do gráfico, os eixos foram construídos em escala logarítmica. 


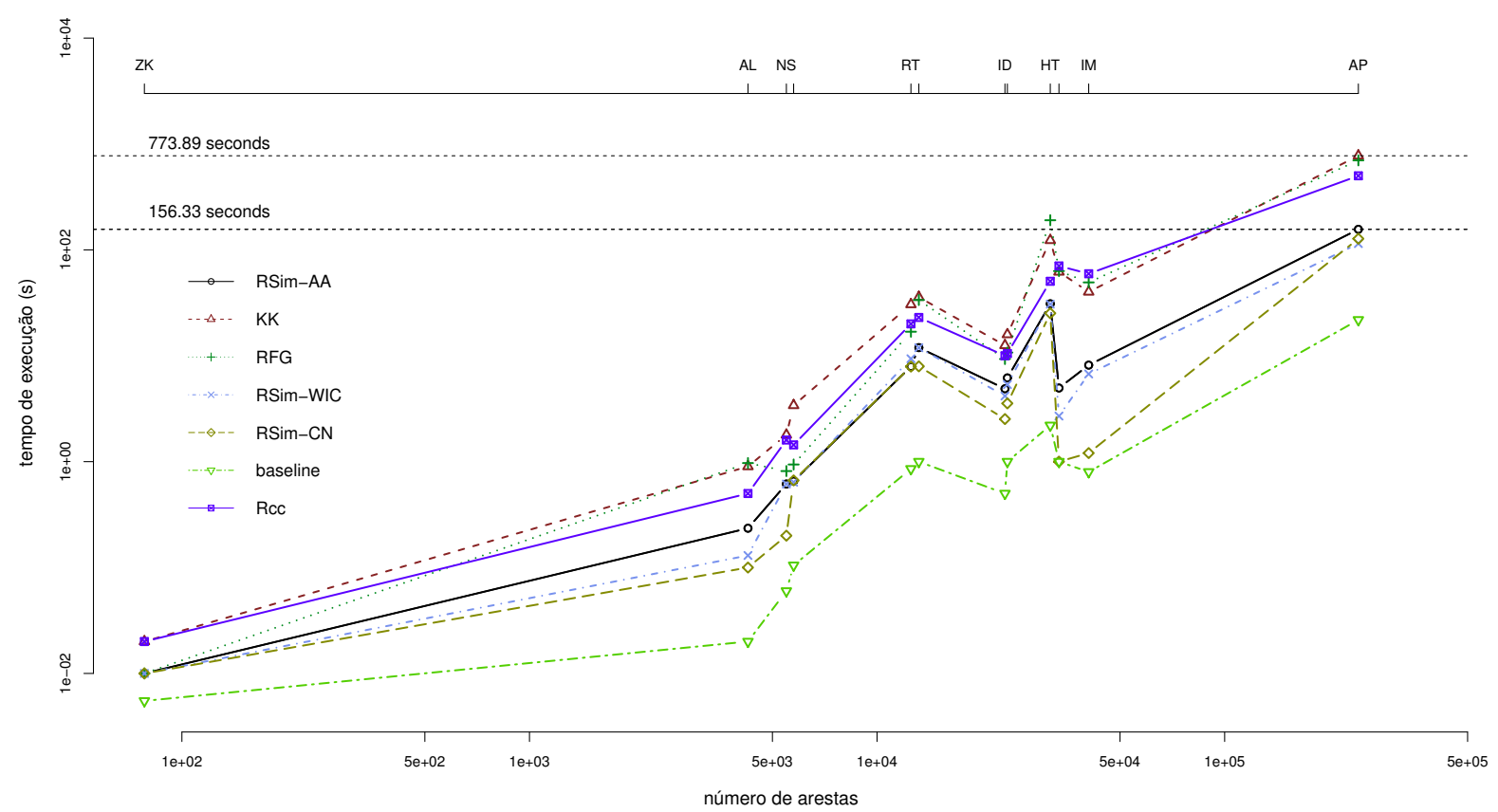

Figura 5.8: Tempo de execução dos algoritmos de refinamento considerando a configuração multinível HEM+fastgreedy. A linha pontilhada horizontal marca o tempo de execução mais longo do RSim-AA (156.33) e do KK (773.89).

Observa-se que o tempo de execução mais longo do RSim foi de 153.33 segundos, alternativamente, KK e RFG levaram cerca de 700 segundos na maior rede. Além disso, percebe-se que as variantes do RSim tem uma curva de crescimento menor do que o Rcc, KK e RFG. Tal fato ocorre, pois, além de realizar apenas operações em vértices de fronteira, as medidas de similaridade usadas têm baixo custo computacional, cujas operações são realizadas em tempo constante. Ao contrário, o RFG maximiza a variação da Modularidade $\Delta Q$, a qual têm maior custo computacional em relação ao cálculo das medidas de similaridade local. Do mesmo modo, o KK reque operações extras para verificar o balanceamento, além de cálculos adicionais para iniciar/atualizar a pilha de ganhos e o computar o balanceamento das partições. É importante destacar, que a principal desvantagem do KK e RFG ocorre na primeira iteração, a qual é necessário computar os ganhos iniciais de cada componente considerada no cálculo. Portanto, independentemente do tipo de rede avaliada, a análise experimental indica que o RSim é mais rápido do que as alternativas.

\subsection{Estudo de caso}

A fim de avaliar o desempenho do RSim em uma aplicação real, foi realizado um estudo de caso abordando o problema de citações ambíguas (sinônimos e homônimos) em bibliotecas digitais, tais como Springer ${ }^{6}, \mathrm{ACM}^{7}, \mathrm{DBLP}^{8}$ e CiteSeer ${ }^{9}$. Esse estudo de

\footnotetext{
${ }^{6}$ http://www.springer.com/

${ }^{7}$ http://dl.acm.org/

${ }^{8}$ http://www.informatik. unitrier.de/ ley/db/

${ }^{9}$ http://citeseer.ist.psu.edu/
} 
caso possui dois objetivos específicos: i. verificar a viabilidade da estratégia multinível no contexto de citações ambíguas em bibliotecas digitais; ii. verificar a relevância da utilização e escolha de algoritmos de refinamento em aplicações envolvendo redes sociais.

Bibliotecas Digitais são complexos sistemas que integram diversos serviços dedicados a catalogação, armazenamento, busca, recuperação, preservação e apresentação de coleções online de informações. Os registros bibliográficos, geralmente, são derivados de diversas fontes, que em sua maioria não fornecem informações padronizadas. Logo, a qualidade dos dados é comprometida, podendo conduzir a redundâncias, imprecisões em processamento de consultas e extração de conhecimento, atribuição indevida de crédito, dentre outros problemas.

Nesse contexto, é comum ocorrer ambiguidade em citações bibliográficas, nas quais, duas ou mais citações indicam o mesmo autor. Segundo Lee et al. (2005), pode-se classificar esse problema em duas categorias: i. sinônimos ou split citation, ocorre quando um autor utiliza variações de citação, como "Ronald W. Williams" e "R. W. Williams"; e ii. homônimos ou mixed citation, ocorre quando autores diferentes possuem citação semelhante, como "Mohammed Zaki" (Professor da Universidade de Al-Zhar, Cairo, Egito) e "Mohammed Zaki" (Instituto Politécnico Rensselaer dos Estados Unidos).

Recentemente, alguns estudos utilizaram redes de cooperação científica e algoritmos de detecção de comunidades para tratar o problema de desambiguação de citações em coleções de artigos científicos (Han et al., 2004; Junior et al., 2011; Amancio et al., 2013). Tais abordagens, em geral, possuem três fases de processamento. Inicialmente, é construída uma rede baseada na colaboração entre autores em artigos científicos. Uma aresta é estabelecida entre dois autores quando há coautoria em um ou mais artigos científicos. A partir da rede de coautoria o método detecta grupos de vértices fortemente conectados (comunidades). A terceira etapa, caracteriza-se pelo processamento individual de cada comunidade, na qual pares de citações são comparados mediante algum método de interesse, por exemplo, utilizar a similaridade entre cadeias de caracteres (strings). Os resultados indicam que a utilização da estrutura de comunidades melhora a precisão da identificação de ambiguidades, bem como reduz o custo computacional da tarefa mediante a minimização dos pares de citações comparados.

No entanto, a escalabilidade e qualidade da solução ainda é um fator crítico em bancos de dados bibliográficos de grande escala. Por exemplo, a base de dados sobre publicações em computação DBLP contém cerca de 2 milhões de registros. A fim de aumentar a escalabilidade e qualidade da solução, é relevante conciliar a utilização de redes de cooperação científica a um algoritmo de detecção de comunidades multinível (escalabilidade), bem como um algum algoritmo de refinamento (qualidade da solução).

\subsubsection{Conjuntos de dados}

Nesse experimento foi utilizado um conjunto de registros de autoria extraídos da biblioteca digital DBLP. Os registros foram rotulado manualmente, usando a home page do 
autor da publicação, afiliação, e-mail e nomes de coautores, além disso, foram enviados e-mails para alguns autores a fim de confirmar sua autoria. A coleção está disponível em Han et al. (2004).

A coleção de registros de autoria extraídos da DBLP resume 4.287 registros associados com 220 autores distintos, ou seja, aproximadamente 20 registros por autor. Tais registros foram agrupados em conjuntos de autores ambíguos, cujo objetivo é facilitar as avaliações empíricas e análise dos resultados. Desse modo, foram selecionados os quatro conjuntos de autores ambíguos com maior número de registros, que são: i. "A. Gupta", que possui sinônimos, tais como "A. Gupta" e "Amit Gupta", e homônimos, tais como "Ajay Gupta K.", "Amit Gupta" e "Anoop Gupta.", esse conjunto possui 576 registros e 26 autores "A. Gupta" distintos; ii. "J. Smith", que possui sinônimos, tal como "Jim Smith", e homônimos, tais como "Jeffrey S. Smith" e "James e Smith", esse conjunto possui 921 registros e 29 autores "J. Smith" distintos; iii. "M. Miller", que possui sinônimos, tais como "Mike W. Miller" e "Mark Miller", e homônimos, tais como "Michael Miller" e "Mirka Miller", esse conjunto possui 405 registros e 12 autores "M. Miller" distintos; e iv "M. Jones", que possui sinônimos, tais como "Matthew C. Jones" e "Matthew Jones", e homônimos, tais como "Michael Jones" e "Mark P. Jones", esse conjunto possui 260 registros e 13 autores "M. Jones" distintos. Para uma melhor análise dos resultado, foram removidas entradas com autores indefinidos e autores isolados.

Desse modo, duas citações são consideradas ambíguas caso sejam sinônimos ou homônimos. A Figura 5.9 ilustra uma saída esperada para o conjunto de dados "M. Jones".

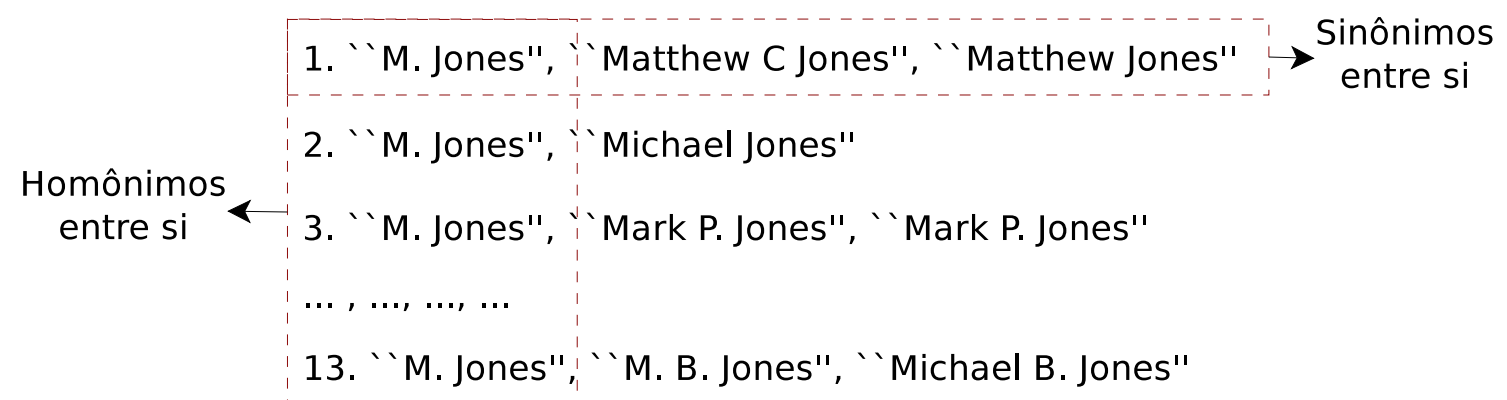

Figura 5.9: Representação de citações ambíguas para o conjunto de dados "M. Jones".

\subsubsection{Método}

Deve-se ressaltar que o objetivo desse estudo de caso não é superar os métodos existentes na literatura, mas sim, validar e verificar a relevância do algoritmo de refinamento RSim em uma aplicação real, considerando um cenário envolvendo redes sociais. Para isso, utilizou-se como base o método descrito em Junior et al. (2011), dado sua simplicidade e facilidade na análise da influência de cada algoritmo de detecção de comunidades na qualidade da solução. Tal método possui três fases de processamento: i. Construção da rede de cooperação científica; ii. detecção de comunidades; e iii detecção dos duplicados. Tais etapas são sumarizadas a seguir. 
Construção da rede de cooperação científica: As redes de cooperação científica são construídas assumindo que dois autores estabelecem uma relação ao produzirem uma escrita científica em conjunto, independente da forma de apresentação de seus nomes (autor x coautor).

Detecção das comunidades: Esta etapa constitui a principal contribuição desse estudo de caso. Em contraste com outros métodos, utiliza-se um algoritmo multinível de detecção de comunidades, descrito na Subseção 5.1.2, bem como os algoritmos de refinamento RSim-CN, RSim-AA, RSim-WIC, Rcc, KK e RFG. Além disso, para uma melhor visualização da eficácia da abordagem, faz-se necessário uma análise comparativa com o algoritmo fastgreedy, sem considerar o contexto multinível. A Tabela 5.3 sumariza a configuração de cada algoritmo avaliado.

\begin{tabular}{l|l|l|l|l}
\hline Estratégia & Nome & Contração & Particionamento & Refinamento \\
\hline \hline \multirow{4}{*}{ Multinível } & RSim-CN & HEM & fastgreedy & RSim-CN \\
\cline { 2 - 5 } & RSim-WIC & HEM & fastgreedy & RSim-WIC \\
\cline { 2 - 5 } & RSim-AA & HEM & fastgreedy & RSim-AA \\
\cline { 2 - 5 } & Rcc & HEM & fastgreedy & Rcc \\
\cline { 2 - 5 } & RFG & HEM & fastgreedy & RFG \\
\cline { 2 - 5 } & KK & HEM & fastgreedy & KK \\
\cline { 2 - 5 } & baseline & HEM & fastgreedy & - \\
\hline Único nível & um-nível & - & fastgreedy & - \\
\hline \hline
\end{tabular}

Tabela 5.3: Configuração dos algoritmos avaliados. O algoritmo baseline não utiliza refinamento na fase de projeção. O algoritmo um-nível não utiliza a abordagem multinível.

Similaridade entre citações de autores: Por fim, cada comunidade é processada individualmente usando algum método de interesse. A abordagem mais simples consiste em utilizar medidas de similaridade entre strings para detectar a proximidade entre citações de autores formatadas de maneira distinta. Para isso, seguindo o modelo proposto por Junior et al. (2011), utilizou-se a Distância de Levenshtein (ED). Tal medida consiste em contar o número de edições (inserção, deleção ou substituição) necessárias para transformar uma string em outra, penalizando cada operação em 1 ponto. Por exemplo, a distância entre as cadeias "appropriate meaning" e "approximate matching" é igual a 7, pois são necessárias 7 operações de substituição para que a segunda cadeia seja idêntica a primeira. O resultado pode ser normalizado em escala de 0 e 1, dividindo a distância pelo tamanho da maior string. Nesse caso, a similaridade entre as duas cadeias é de 0.65. Note que quanto mais próximo de 0 , maior a similaridade entre duas strings. Neste trabalho, duas strings $A$ e $B$ são consideradas similares caso a distância $E D(A, B) \leq 40 \%$ ou similaridade $\geq 60 \%$. Este valor, sugerido em Junior et al. (2011), foi selecionado pois as variantes das citações ocorrem principalmente devido à abreviação, isto é, duas citações de um mesmo autor podem ser muito diferentes, como "A. Gupta" e "Ashish Kumar Gupta". Em outro cenário, caso existam mais erros ortográficos, como em "A. Gupta" e "A. 
Gopta", do que abreviações, é possível definir um limiar menor, por exemplo, em $10 \%$.

\subsubsection{Medidas de desempenho}

Para avaliar a qualidade das soluções (eficácia) obtidas pelos algoritmos, além da medida de Modularidade, adotou-se a medida F-measure. Os resultados obtidos a partir dessas métricas foram submetidos a duas análises: i. análise da tendência central mediante um gráfico boxplot; e ii. análise da diferença estatística significativa através de um teste post-hoc (Demšar, 2006).

A Figura 5.10 representa um gráfico de caixa ou boxplot constituído com base em alguns parâmetros descritivos: mediana (Q2), quartil superior (Q3), quartil inferior (Q1), limite superior (Max) e limite inferior (Min).

Esse gráfico apresenta uma tendência central indicado mela mediana Q2, bem como a medida de dispersão ou interquartil $I Q R=Q 3-Q 1$. O ponto outlier representa valores atípicos, que são valores muito afastados da grande maioria dos dados. Neste trabalho, utiliza-se tal gráfico para representar as médias de qualidade obtidas pelos algoritmos no estudo de caso.

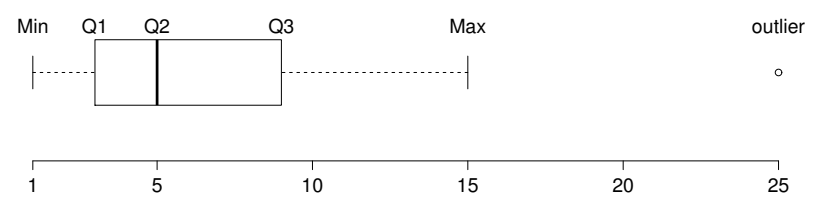

Figura 5.10: Exemplo de gráfico de caixa.

Dado uma partição de referência, pode-se avaliar a qualidade da solução usando índices de qualidade externos, cujo objetivo é compara os resultados obtidos com os resultados conhecidos. Neste trabalho, é utilizada a medida F-measure (Equação 5.3) derivada das medidas de Precisão P (Equação 5.1) e Cobertura $C$ (Equação 5.2). Fundamentalmente, a medida de Precisão avalia se um dado método extrai da fonte de dados unicamente itens relevantes. Já a medida de Cobertura avalia se o método extrai todos os itens interessantes.

$$
P=\frac{N_{d}}{N_{r}} \quad(5.1) \quad C=\frac{N_{r}}{N_{t}} \quad(5.2) \quad F=\frac{2 C P}{(C+P)}
$$

Neste trabalho, a medida $P$ é definida pela razão entre a quantidade de citações que são realmente ambíguas (sinônimos ou homônimos) $N_{d}$, e o número total de registros ambíguos encontrados $N_{r}$. Já a medida $C$ refere-se ao percentual de registros ambíguos encontrados $N_{r}$ dentre os existentes na base de dados $N_{t}$. Logo, pode-se combinar as medidas de Precisão e Cobertura a fim de expressá-las com um único valor. Para isso, utiliza-se a medida F-measure que representa uma média entre $P$ e $C$. 


\subsubsection{Resultados e análise}

A Tabela 5.4 sumariza os resultados obtidos pelos algoritmos, considerando a eficácia (Modularidade, F-measure) e eficiência (tempo de execução). As maiores pontuações estão destacadas na tabela. Desse modo, observa-se que, considerando o conjunto "A. Gupta", o RSim-CN, RSim-WIC e Rcc obtiveram um desempenho melhor em relação a Modularidade e F-measure. Ainda, observa-se que o RSim-AA têm melhor F-measure em relação ao KK, embora ambos tenham a mesma média da Modularidade, consequentemente, nota-se que a seleção do algoritmo de refinamento irá influenciar na qualidade final da solução. Além disso, o RSim-AA supera o KK e RFG quanto ao tempo de execução. Nota-se, que o baseline e a abordagem um-nível obtiveram o mesmo resultado, porém, de fato, o baseline tem menor tempo de processamento.

Considerando o conjunto "J. Smith", observa-se que os algoritmos RSim-CN e RSimAA superam os outros métodos avaliados em relação a Modularidade e F-measure, além disso, o RSim-CN possui menor tempo de execução. Nesse conjunto, destaca-se, também, que a abordagem um-nível supera o baseline e o KK quanto à eficácia (Modularidade $\mathrm{e}$ F-measure). Considerando o conjunto "M. Miller", o Rcc supera os demais algoritmos avaliados em termos de Modularidade, o RSim-WIC em termos de F-measure e o RSimCN em termos de tempo de execução. Considerando o conjunto "M. Jones", o RSimCN supera os demais algoritmos considerando todas as medidas utilizadas. No geral, o RSim supera todos os algoritmos avaliados em termos de F-measure e tempo de execução considerando todos os conjuntos de dados, bem como em termos de Modularidade ao considerar os conjuntos "A. Gupta", "J. Smith" e "M. Jones".

\begin{tabular}{l|c|c|c|c|c|c|c|c|c|c|c|c}
\hline \multirow{2}{*}{ Algoritmo } & \multicolumn{3}{|c|}{ A. Gupta } & \multicolumn{3}{c|}{ J. Smith } & \multicolumn{3}{c|}{ M. Miller } & \multicolumn{3}{c}{ M. Jones } \\
\cline { 2 - 14 } & $Q$ & $F$ & $t / s$ & $Q$ & $F$ & $t / s$ & $Q$ & $F$ & $t / s$ & $Q$ & $F$ & $t / s$ \\
\hline \hline RSim-CN & 0.9130 & 0.6730 & 06.81 & 0.3112 & 0.6274 & 44.02 & 0.1610 & 0.5452 & 26.11 & 0.2855 & 0.6759 & 03.21 \\
\hline RSim-WIC & 0.9130 & 0.6730 & 06.91 & 0.2509 & 0.5482 & 48.02 & 0.1585 & 0.5478 & 29.15 & 0.2810 & 0.6642 & 03.21 \\
\hline RSim-AA & 0.9128 & 0.6628 & 06.79 & 0.3112 & 0.6274 & 45.13 & 0.1590 & 0.5352 & 27.03 & 0.2804 & 0.6667 & 03.21 \\
\hline Rcc & 0.9130 & 0.6730 & 09.78 & 0.2509 & 0.5482 & 51.12 & 0.1793 & 0.5208 & 31.28 & 0.2798 & 0.6642 & 03.21 \\
\hline RFG & 0.9123 & 0.6501 & 11.02 & 0.2460 & 0.5475 & 70.10 & 0.1470 & 0.4521 & 32.57 & 0.2798 & 0.6642 & 03.38 \\
\hline KK & 0.9128 & 0.6501 & 12.02 & 0.2337 & 0.5317 & 68.33 & 0.1570 & 0.4921 & 31.98 & 0.2768 & 0.6642 & 03.36 \\
\hline baseline & 0.9113 & 0.5551 & 06.12 & 0.2337 & 0.5317 & 29.36 & 0.1387 & 0.4533 & 21.25 & 0.2742 & 0.6510 & 03.01 \\
\hline um-nivel & 0.9113 & 0.5551 & 26.12 & 0.2437 & 0.5470 & 89.36 & 0.1380 & 0.4433 & 51.25 & 0.2742 & 0.6510 & 04.12 \\
\hline \hline
\end{tabular}

Tabela 5.4: Valores da Modularidade, F-measure e tempo de execução, obtidos pelos algoritmos de refinamento considerando o problema de citação ambígua na rede DBLP.

Para analisar a diferença estatística e o desempenho individual de cada algoritmos de refinamento, do mesmo modo que no benchmark, utilizou-se um teste post-hoc (Demšar, 2006), realizado com base nos dados da Tabela 5.4. Os resultados estatísticos e ranking são sumarizado nos diagramas da Figura 5.11. No diagrama da Figura 5.11(a) analisouse o desempenho dos algoritmos em relação a Modularidade. No diagrama da Figura 5.11(b), analisou-se o desempenho dos algoritmos em termos de F-measure. Em ambos, a diferença crítica é 5.25, com base em um intervalo de confiança de $95 \%(p<0.05)$. 
Na Figura 5.11(a), observa-se que o RSim-CN possui diferença estatística significativa em relação aos algoritmos baseline e o um-nível. Além disso, todas as variações do RSim e o Rcc possuem ranking muito superior aos demais algoritmos. Esse resultado é um indício da relevância do RSim nessa aplicação, em termos de Modularidade. Em contraste, os algoritmos RFG e KK não possuem diferença estatística significativa em relação ao baseline e a abordagem um-nivel. Analogamente, na Figura 5.11(a), observa-se que o RSim-CN também supera o baseline e o um-nível estatisticamente. Do mesmo modo, todas as variações do RSim e o Rcc possuem ranking muito superior aos demais algoritmos. Ainda, KK e RFG não apresentam relevância estatística em relação ao baseline e ao umnível.

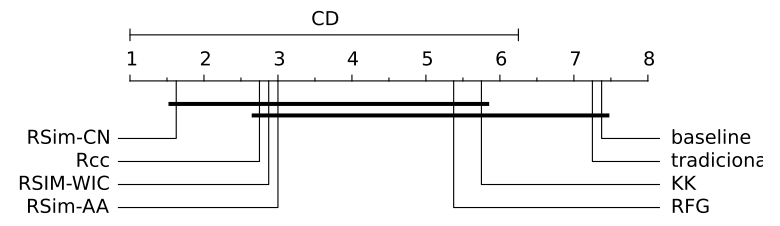

(a)

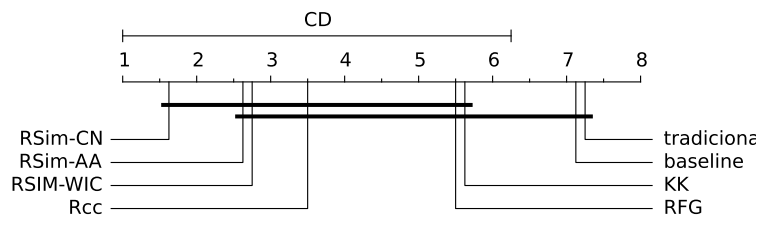

(b)

Figura 5.11: Diferença estatística dos algoritmos considerando duas medidas de qualidade: (a) ranking do desempenho dos algoritmos em relação a Modularidade; (b) ranking do desempenho dos algoritmos em termos de F-measure.

Por fim, para complementar a análise e distinção do desempenho geral dos algoritmos de refinamento, a partir dos dados da Tabela 5.4, foram gerados os gráficos boxplot. A Figura 5.12(a) ilustra o gráfico da distribuição dos resultados da Modularidade e a Figura 5.12(b) ilustra o gráfico da distribuição dos resultados do F-measure.

Na Figura 5.12, observa-se, considerando a Modularidade (a) e F-measure (b), que os valores da mediana da distribuição do desempenho dos algoritmos RSim-CN e RSim-AA superam todos os demais algoritmos avaliados. Em contraste, considerando a Modularidade (a) o algoritmo KK possui uma média similar ao baseline, indicando que, nesse cenário, sua utilização pode não ser relevante em termos de qualidade da solução. Inclusive, os algoritmos KK e baseline possuem uma mediana pior que o algoritmo um-nível. Além disso, pode-se observar que os algoritmos Rcc, RSim-WIC e RFG e um-nível possuem a mediana muito próxima uns dos outros em termos de Modularidade e F-measure.

Considerando o problema de citações ambíguas, no geral, a análise empírica confere indícios de que a estratégia multinível é competitiva em termos de qualidade da solução quando comparado à abordagem um-nível (único nível). Além disso, a estratégia multinível se mostrou superior a abordagem um-nível quanto ao tempo de execução, de fato. Adicionalmente, observou-se que a utilização e escolha do algoritmo de refinamento interfere qualitativamente na solução. Em particular, a utilização do algoritmo RSim-CN mostrou ser relevante, superando estatisticamente as alternativas KK e RFG, bem como o baseline e a abordagem um-nivel. 


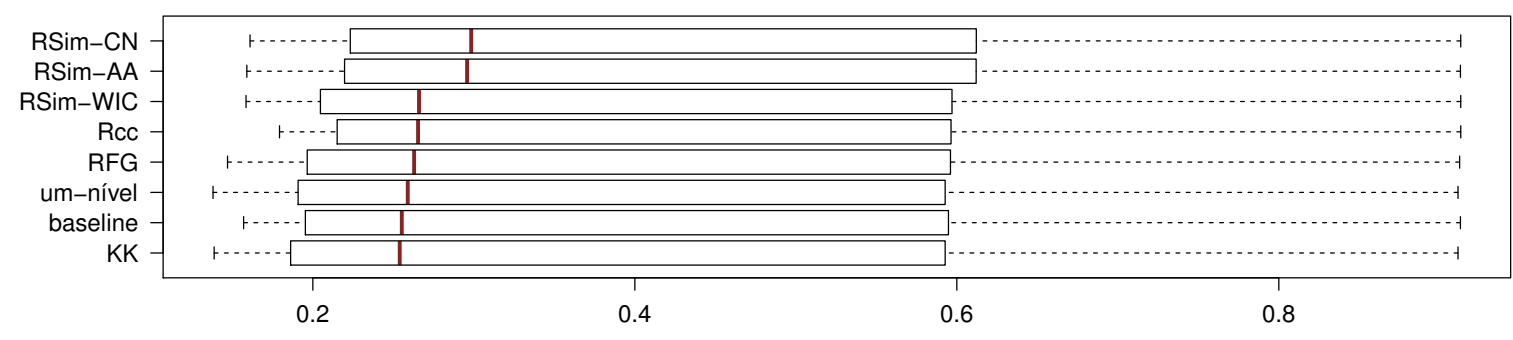

(a)

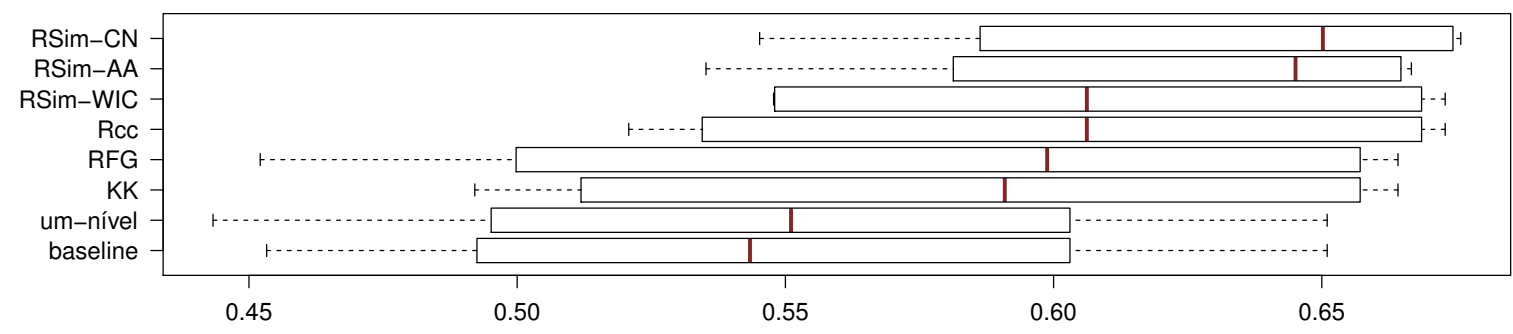

(b)

Figura 5.12: Distribuição estatística do desempenho dos algoritmos de refinamento avaliados, considerando os quatro conjuntos de autores ambíguos selecionados. A linha dentro de cada caixa indica a mediana do desempenho. Em (a), o boxplot é construído com base na Modularidade. Em (b), o boxplot é construído mediante o F-measure.

\subsection{Considerações finais}

Neste capítulo foram apresentados os experimentos realizados para avaliar o desempenho dos algoritmos propostos (RSim e Rcc). Para tanto, dois conjuntos de experimentos foram planejados e realizados: no primeiro buscou-se avaliar a proposta de forma comparativa e sistemática em relação à outros algoritmos da literatura; no segundo, por meio de um estudo de caso, o objetivo foi avaliar o comportamento do RSim em uma aplicação real, bem como verificar a viabilidade da estratégia multinível na aplicação em questão.

A partir dos experimentos, pode-se evidenciar que o algoritmo proposto foi capaz de encontrar soluções próximas ao referencial adotado dentro de um intervalo de tempo hábil, não prejudicando a escalabilidade do processo multinível. O benchmark indicou que o RSim supera os métodos avaliados quanto à qualidade da solução, não somente em redes sociais, mas em redes com alto coeficiente de agrupamento e assortatividade, independente do domínios de aplicação. Porém, os resultados também indicam que o RSim é menos eficiente em redes caracterizadas por baixo coeficiente de agrupamento e assortatividade. Além disso, o RSim é mais rápido do que os algoritmos avaliados independente da rede avaliada.

Adicionalmente, o estudo de caso evidenciou a relevância do RSim quando avaliado em uma aplicação envolvendo redes sociais. Nesse caso, o RSim supera todos os métodos avaliados quanto à Modularidade, F-measure e tempo de execução, considerando todos os conjuntos de dados selecionados. 



\section{Conclusão e Trabalhos Futuros}

objetivo principal deste trabalho foi desenvolver e avaliar um algoritmo de refinamento multinível, denominado RSim, que explora características de alto grau de transitividade e assortatividade presentes em algumas redes reais, em particular, redes sociais. Para isso, adotou-se medidas de similaridade híbridas entre pares de vértices, que utilizam os conceitos de vizinhança e informações de comunidades para interpretar a semelhança entre um par de vértices. Além disso, também foi definido uma extensão do algoritmo RSim, chamado Rcc, baseado na reformulação do coeficiente de agrupamento local, considerando informações da estrutura de comunidades ao invés de utilizar toda a informação da rede.

A proposta deste trabalho foi comparada sistematicamente com dois algoritmos populares da literatura, RFG e KK, e um método baseline, o qual não utiliza refinamento na fase de projeção. A análise em doze redes reais de domínios diferentes evidenciou que o RSim supera os algoritmos de refinamento habituais em redes com alto coeficiente de agrupamento e assortatividade significativa. Além disso, o RSim é competitivo com os métodos avaliados considerando um contexto geral. Adicionalmente, a eficiência é uma questão importante ao avaliar redes de grande escala, e a principal vantagem da abordagem multinível é a redução do tempo de execução. Sob este ângulo, a análise de eficiência (tempo de execução) indica que o RSim é mais rápido que os algoritmos avaliados, independente do domínio da aplicação, devido o uso de operações com baixo custo computacional.

Por fim, avaliou-se o comportamento dos algoritmos de refinamento em uma aplicação real a partir de um estudo de caso que aborda o problema de citações ambíguas em bibliotecas digitais. Nesse cenário, o RSim superou todos os métodos avaliados quanto à qualidade da solução e o tempo de execução, considerando todos os conjuntos de dados selecionados. Cabe destacar que o estudo de caso também mostrou a viabilidade da utilização de estratégias multinível de detecção de comunidades para tratar o problema de detecção de citações ambíguas em bibliotecas digitais. Os resultados indicam que a estratégia multinível, sem considerar o processo de refinamento, é tão eficaz quanto o método tradicional de um único nível, porém, em vantagem, é mais eficiente quanto ao tempo de execução. 
Durante o desenvolvimento desta pesquisa várias ideias surgiram para a continuação do trabalho a fim de ampliar o campo de análise e contribuição científica. No entanto, tais propostas não foram desenvolvidas ou devido ao tempo ou por estarem fora do escopo. Desse modo, tem-se o objetivo de dar continuidade à pesquisa na área de detecção de comunidades considerando as seguintes direções:

- Avaliar a eficácia e eficiência dos algoritmos de refinamento propostos considerando outros algoritmos de detecção de comunidades populares, tais como walktrap, leading eigenvector e edge betweenness;

- Avaliar a eficácia e eficiência dos algoritmos de refinamento ao utilizar, na fase de contração, diferentes estratégias de matching, tais como LEM e MHEM;

- Investigar aplicações reais relevantes, nas quais o RSim possa contribuir com soluções adequadas sem, necessariamente, estar associado a algum algoritmo multinível ou algum algoritmo de detecção de comunidades;

- Realizar um estudo detalhado e propor uma estratégia multinível de detecção de comunidades considerando redes com estrutura sobrepostas, nas quais um vértice pertence a uma ou mais comunidades.

- Considerando o estudo de caso, pesquisar e propor metodologias mais sofisticadas a fim de melhorar a qualidade da solução. 


\section{Referências Bibliográficas}

Albert, R. e Barabási, A.-L. (2002). Statistical mechanics of complex networks. Rev. Mod. Phys., 74:47-97. (Citado na página 10)

Almeida, L. J. (2009). Deteção de comunidades em redes complexas utilizando estratégia multinível. Master's thesis, Instituto de Matemática e Estatística, Universidade de São Paulo, São Paulo. (Citado na página 46, 46, 46)

Almeida, L. J. e Lopes, A. A. (2009). An ultra-fast modularity-based graph clustering algorithm. Proceedings 14th Portuguese Conference on Artificial Intelligence (EPIA) Web and Network Intelligence Track, pp. 1-9. (Citado na página 3, 29, 51, 52)

Amancio, D. R., Oliveira Jr., O. N., e Costa, L. d. F. (2013). Topological-collaborative approach for disambiguating authors' names in collaborative networks. CoRR, abs/1311.1266. (Citado na página 59)

Barabási, A.-L., Albert, R., e Jeong, H. (2000). Scale-free characteristics of random networks: the topology of the world-wide web. Physica A: Statistical Mechanics and its Applications, 281(1-4):69-77. (Citado na página 18, 18)

Batagelj, V. e Mrvar, A. (2006). Pajek datasets. visited on 2014-02-30. (Citado na página 49)

Bichot, C.-E. (2013). Graph Partitioning, Cap. A Partitioning Requiring Rapidity and Quality: The Multilevel Method and Partitions Refinement Algorithms, pp. 27-63. ISTE - Wiley. (Citado na página 2, 3, 29, 33)

Blondel, V. D., Guillaume, J.-L., Lambiotte, R., e Lefebvre, E. (2008). Fast unfolding of communities in large networks. Journal of Statistical Mechanics: Theory and Experiment, 10:8. (Citado na página 38, 44)

Brandes, U., Delling, D., Gaertler, M., Gorke, R., Hoefer, M., Nikoloski, Z., e Wagner, D. (2008). On modularity clustering. Knowledge and Data Engineering, IEEE Transactions on, 20(2):172-188. (Citado na página 23)

Chen, J. e Yuan, B. (2006). Detecting functional modules in the yeast protein-protein interaction network. Bioinformatics, 22(18):2283-2290. (Citado na página 2) 
Chen, P. e Redner, S. (2010). Community structure of the physical review citation network. Journal of Informetrics, 4(3):278-290. (Citado na página 2)

Clauset, A., Newman, M. E. J., e Moore, C. (2004). Finding community structure in very large networks. Physical Review E, 70:066111. (Citado na página 23, 25, 25, 26, 52)

Costa, L., Rodrigues, F., Travieso, G., e Villas Boas, P. (2007). Characterization of complex networks: A survey of measurements. Advances in Physics, 56:167-242. (Citado na página 1,12$)$

Demšar, J. (2006). Statistical comparisons of classifiers over multiple data sets. J. Mach. Learn. Res., 7:1-30. (Citado na página 6, 7, 53, 62, 63)

Diestel, R. (2010). Graph Theory (Graduate Texts in Mathematics), v. 173. Springer, 4 ed. (Citado na página 9)

Dorogovtsev, S. N. e Mendes, J. F. F. (2002). Evolution of networks. Advances in Physics, 51:1079-1187. (Citado na página 1)

Dourisboure, Y., Geraci, F., e Pellegrini, M. (2007). Extraction and classification of dense communities in the web. In Proceedings of the 16th International Conference on World Wide Web, WWW '07, pp. 461-470, New York, NY, USA. ACM. (Citado na página 2)

Drury, B., Valejo, A., Cardoso, P. F., Valverde-Rebaza, J. C., Pereira, F., e Lopes, A. (2014). An open source tool for crowd-sourcing the manual annotation of texts. In PROPOR, Lecture Notes in Computer Science. Springer.

Erdös, P. e Rényi, A. (1960). On the evolution of random graphs. Publ. Math. Inst. Hungary. Acad. Sci., 5:17-61. (Citado na página 16, 16)

Fan, N. e Pardalos, P. (2012). Multi-way clustering and biclustering by the ratio cut and normalized cut in graphs. Journal of Combinatorial Optimization, 23(2):224-251. (Citado na página 22)

Fiduccia, C. M. e Mattheyses, R. M. (1982). A linear-time heuristic for improving network partitions. In Proceedings of the 19th Design Automation Conference, DAC '82, pp. 175-181, Piscataway, NJ, USA. (Citado na página 4, 34, 36, 36)

Fiedler, M. (1973). Algebraic connectivity of graphs. Czechoslovak Mathematical Journal, 23(2):298-305. (Citado na página 28)

Fortunato, S. (2010). Community detection in graphs. Physics Reports, 486(3-5):75-174. (Citado na página 2, 19, 23, 24, 27)

Garey, M. R., Johnson, D. S., e Stockmeyer, L. J. (1976). Some simplified np-complete graph problems. Theor. Comput. Sci., 1(3):237-267. (Citado na página 2) 
Girvan, M. e Newman, M. E. J. (2002). Community structure in social and biological networks. Proceedings of the National Academy of Sciences, 99(12):7821-7826. (Citado na página $19,20,25)$

Hagen, L. e Kahng, A. (1992). New spectral methods for ratio cut partitioning and clustering. IEEE Transactions on Computer-Aided Design of Integrated Circuits and Systems, 11(9):1074-1085. (Citado na página 22)

Han, H., Giles, L., Zha, H., Li, C., e Tsioutsiouliklis, K. (2004). Two supervised learning approaches for name disambiguation in author citations. In Proceedings of the 4 th ACM/IEEE-CS Joint Conference on Digital Libraries, JCDL '04, pp. 296-305, New York, NY, USA. (Citado na página 50, 59, 60)

Hendrickson, B. e Leland, R. (1995). A multilevel algorithm for partitioning graphs. In Proceedings of the 1995 ACM/IEEE Conference on Supercomputing, Supercomputing '95, New York, NY, USA. (Citado na página 4, 39, 51)

Junior, B., Motta, R., e Lopes, A. A. (2011). Detecção de autores duplicados utilizando estrutura de comunidades em redes de cooperação científica. VIII Encontro Nacional de Inteligência Artificial - ENIA, pp. 335-345. (Citado na página 59, 60, 61, 61)

Karypis, G. e Kumar, V. (1995). Analysis of multilevel graph partitioning. In Proceedings of the 1995 ACM/IEEE Conference on Supercomputing (CDROM), Supercomputing '95, New York, NY, USA. (Citado na página 3, 29, 31, 32)

Karypis, G. e Kumar, V. (1995). Multilevel graph partitioning schemes. In ICPP (3), pp. 113-122. (Citado na página 33, 51)

Karypis, G. e Kumar, V. (1996). Parallel multilevel k-way partitioning scheme for irregular graphs. In Proceedings of the 1996 ACM/IEEE Conference on Supercomputing, Supercomputing '96. IEEE Computer Society. (Citado na página 51)

Karypis, G. e Kumar, V. (1998). A fast and high quality multilevel scheme for partitioning irregular graphs. SIAM J. Sci. Comput., 20(1):359-392. (Citado na página 34, 51)

Karypis, G. e Kumar, V. (1998). Multilevel k-way partitioning scheme for irregular graphs. Journal of Parallel and Distributed Computing, 48:96-129. (Citado na página 4, 29, $34,39,39,39,52)$

Kernighan, B. W. e Lin, S. (1970). An efficient heuristic procedure for partitioning graphs. Bell System Technical Journal, 49(2):291-307. (Citado na página 4, 34, 34, 35, 36)

Krishnamurthy, B. e Wang, J. (2000). On network-aware clustering of web clients. In Proceedings of the Conference on Applications, Technologies, Architectures, and Protocols for Computer Communication, SIGCOMM '00, pp. 97-110, New York, NY, USA. (Citado na página 20) 
LaSalle, D. e Karypis, G. (2013). Multi-threaded graph partitioning. In Parallel Distributed Processing (IPDPS), 2013 IEEE 27th International Symposium on, pp. 225-236. (Citado na página 3, 4, 29, 39)

Lee, D., On, B.-W., Kang, J., e Park, S. (2005). Effective and scalable solutions for mixed and split citation problems in digital libraries. In Proceedings of the 2nd international workshop on Information quality in information systems, IQIS '05, pp. 69-76, New York, NY, USA. ACM. (Citado na página 59)

Liben-Nowell, D. e Kleinberg, J. (2003). The link prediction problem for social networks. In Proceedings of the Twelfth International Conference on Information and Knowledge Management, CIKM '03, pp. 556-559, New York, NY, USA. (Citado na página 41)

Lichtenwalter, R. N. e Chawla, N. V. (2011). Lpmade: Link prediction made easy. J. Mach. Learn. Res., 12:2489-2492. (Citado na página 52)

Lü, L. e Zhou, T. (2011). Link prediction in complex networks: A survey. Physica A, 390(6):1150-1170. (Citado na página 5, 5, 41, 41)

Mena-Chalco, J. P., Digiampietri, L. A., Lopes, F. M., e Cesar Jr., R. M. (2014). Brazilian bibliometric coauthorship networks. Journal of the Association for Information Science and Technology, 65(7):1424-1445. (Citado na página 2)

Milgram, S. (1967). The small-world problem. Psychology Today, 1(1):61-67. (Citado na página 17)

Mislove, A., Marcon, M., Gummadi, K. P., Druschel, P., e Bhattacharjee, B. (2007). Measurement and analysis of online social networks. In Proceedings of the 7th ACM SIGCOMM Conference on Internet Measurement, IMC '07, pp. 29-42. ACM. (Citado na página 48)

Moody, J. e White, D. R. (2003). Structural cohesion and embeddedness: A hierarchical concept of social groups. American Sociological Review, pp. 103-127. (Citado na página 2)

Nepusz, T., Petróczi, A., Négyessy, L., e Bazsó, F. (2008). Fuzzy communities and the concept of bridgeness in complex networks. Physical Review E, 77(1):016107. (Citado na página 1)

Neville, J., Jensen, D., Friedland, L., e Hay, M. (2003). Learning relational probability trees. In Proceedings of the Ninth ACM SIGKDD International Conference on Knowledge Discovery and Data Mining, KDD '03, pp. 625-630, New York, NY, USA. (Citado na página 50)

Newman, M. (2003). Mixing patterns in networks. Phys. Rev. E, 67(2):026126. (Citado na página $4,5,12)$ 
Newman, M. (2004). Detecting community structure in networks. The European Physical Journal B - Condensed Matter and Complex Systems, 38(2):321-330. (Citado na página 19)

Newman, M. (2010). Networks: An Introduction. Oxford University Press, Inc., New York, NY, USA. (Citado na página 5, 12, 19)

Newman, M. E. J. (2002). Assortative mixing in networks. Phys. Rev. Lett., 89:208701. (Citado na página 4, 5, 12, 15, 15)

Newman, M. E. J. (2003). The structure and function of complex networks. SIAMR, 45(2):167-256. (Citado na página 1, 10, 12, 17)

Newman, M. E. J. (2004). Fast algorithm for detecting community structure in networks. Physical Review E, 69(6). (Citado na página 25, 25)

Newman, M. E. J. (2006). Finding community structure in networks using the eigenvectors of matrices. Physical review E, 74(3):036104. (Citado na página 23, 28)

Newman, M. E. J. (2006). Modularity and community structure in networks. Proceedings of the National Academy of Sciences, 103(23):8577-8582. (Citado na página 3, 4, 37, 37)

Newman, M. E. J. (2013). Available at http://www-personal.umich.edu/ mejn/ netdata/; accessed 2014-30-03. (Citado na página 49, 50)

Newman, M. E. J. e Girvan, M. (2004). Finding and evaluating community structure in networks. Phys. Rev. E, 69(2):026113. (Citado na página 20, 20, 20, 22, 23, 23)

Newman, M. E. J., Strogatz, S. H., e Watts, D. J. (2001). Random graphs with arbitrary degree distributions and their applications. Phys. Rev. E, 64(2):026118. (Citado na página $5,12,15,17)$

Noack, A. e Rotta, R. (2009). Multi-level algorithms for modularity clustering. In Proceedings of the 8th International Symposium on Experimental Algorithms, SEA '09, pp. 257-268, Berlin, Heidelberg. (Citado na página 3, 4, 29)

Pietilänen, A.-K. e Diot, C. (2012). Dissemination in opportunistic social networks: The role of temporal communities. In Proceedings of the Thirteenth ACM International Symposium on Mobile Ad Hoc Networking and Computing, MobiHoc '12, pp. 165-174. ACM. (Citado na página 20)

Pons, P. e Latapy, M. (2005). Computing communities in large networks using random walks. In Proceedings of the 20th International Conference on Computer and Information Sciences, ISCIS'05, pp. 284-293, Berlin, Heidelberg. Springer-Verlag. (Citado na página 23) 
Raghavan, U. N., Albert, R., e Kumara, S. (2007). Near linear time algorithm to detect community structures in large-scale networks. Physical Review E, 76:036106. (Citado na página 23)

Reddy, K. P., Kitsuregawa, M., Sreekanth, P., e Rao, S. S. (2002). A graph based approach to extract a neighborhood customer community for collaborative filtering. In Databases in Networked Information Systems, v. 2544 of Lecture Notes in Computer Science, pp. 188-200. Springer Berlin Heidelberg. (Citado na página 19)

Rotta, R. e Noack, A. (2011). Multilevel local search algorithms for modularity clustering. J. Exp. Algorithmics, 16:2.3:2.1-2.3:2.27. (Citado na página 3, 4, 37, 38, 38, 39, 44, 52)

Sanchis, L. A. (1989). Multiple-way network partitioning. IEEE Trans. Comput., 38(1):62-81. (Citado na página 4, 39)

Sanchis, L. A. (1993). Multiple-way network partitioning with different cost functions. IEEE Trans. Comput., 42(12):1500-1504. (Citado na página 4)

Schaeffer, S. E. (2007). Survey: Graph clustering. Comput. Sci. Rev., 1(1):27-64. (Citado na página 23)

Schuetz, P. e Caflisch, A. (2008). Efficient modularity optimization by multistep greedy algorithm and vertex mover refinement. Phys. Rev. E, 77:046112. (Citado na página $3,4,37,38,52)$

Shi, J. e Malik, J. (2000). Normalized cuts and image segmentation. IEEE Transactions on Pattern Analysis and Machine Intelligence, 22(8):888-905. (Citado na página 22, 28)

Spring, N., Mahajan, R., e Wetherall, D. (2002). Measuring isp topologies with rocketfuel. SIGCOMM Comput. Commun. Rev., 32(4):133-145. (Citado na página 50)

Steenstrup, M. (2001). Ad hoc networking. Cap. Cluster-based Networks, pp. 75-138. Addison-Wesley Longman Publishing Co., Inc. (Citado na página 20)

Traag, V. e Bruggeman, J. (2009). Community detection in networks with positive and negative links. Physical Review E, 80:036115. (Citado na página 23)

Valejo, A., Drury, B., Valverde-Rebaza, J. C., e Lopes, A. (2014). Identification of related brazilian portuguese verb groups using overlapping community detection. In PROPOR, Lecture Notes in Computer Science. Springer.

Valejo, A., Valverde-Rebaza, J., Drury, B., e Lopes, A. d. A. (2014). Multilevel refinement based on neighborhood similarity. In Proceedings of the 18th International Database 
Engineering 8 Applications Symposium, IDEAS '14, pp. 67-76, New York, NY, USA. ACM. (Citado na página 3, 4, 5, 29, 34)

Valejo, A., Valverde-Rebaza, J. C., e Lopes, A. (2014). A multilevel approach for overlapping community detection. In Proceedings of the Brazillian Conference on Intelligent Systems, BRACIS 2014. (Citado na página 3)

Valverde-Rebaza, J. e Lopes, A. A. (2012). Link prediction in complex networks based on cluster information. In Advances in Artificial Intelligence - SBIA 2012, v. 7589, pp. 92-101. Curitiba, PR, Brazil. (Citado na página 5, 41, 42, 43)

Valverde-Rebaza, J. e Lopes, A. A. (2013). Exploiting behaviors of communities of twitter users for link prediction. Social Network Analysis and Mining, 3(4):1063-1074. (Citado na página $5,5,41)$

Walshaw, C. e Cross, M. (2000). Mesh partitioning: A multilevel balancing and refinement algorithm. SIAM J. Sci. Comput., 22(1):63-80. (Citado na página 3, 4, 39)

Wasserman, S. e Faust, K. (1994). Social Network Analysis: Methods and Applications. Structural Analysis in the Social Sciences. Cambridge University Press. (Citado na página 5, 13)

Watts, D. J. e Strogatz, S. (1998). Collective dynamics of 'small-world' networks. Nature, 393(6684):440-442. (Citado na página 5, 17)

Ye, Z., Hu, S., e Yu, J. (2008). Adaptive clustering algorithm for community detection in complex networks. Phys. Rev. E, 78:046115. (Citado na página 3, 4, 37, 38, 52)

Yin, Z., Gupta, M., Weninger, T., e Han, J. (2010). A unified framework for link recommendation using random walks. In Proceedings of the 2010 International Conference on Advances in Social Networks Analysis and Mining, ASONAM '10, pp. 152-159, Washington, DC, USA. (Citado na página 5, 19, 41)

Zachary, W. W. (1977). An information flow model for conflict and fission in small groups. Journal of Anthropological Research, 33:452-473. (Citado na página 20)

Zhou, T., Lü, L., e Zhang, Y.-C. (2009). Predicting missing links via local information. The European Physical Journal B, 71(4):623-630. (Citado na página 41) 